RICARDO AUGUSTO DE CASTRO MARCONDES

ESTUDO DO USO DAS TUBULAÇÕES DE PEAD EM SISTEMAS DE DISTRIBUIÇÃO DE ÁGUA NO BRASIL

SÃO PAULO 
RICARDO AUGUSTO DE CASTRO MARCONDES

\section{ESTUDO DO USO DAS TUBULAÇÕES DE PEAD EM SISTEMAS DE DISTRIBUIÇÃO DE ÁGUA NO BRASIL}

Dissertação apresentada à Escola Politécnica da Universidade de São Paulo para obtenção do título de Mestre em Ciências.

Área de Concentração: Engenharia Hidráulica

Orientador: Prof. Dr. Renato Carlos Zambon

SÃO PAULO

2016 
Este exemplar foi revisado e corrigido em relação à versão original, sob responsabilidade única do autor e com a anuência de seu orientador.

São Paulo, de de

Assinatura do autor:

Assinatura do orientador:

Catalogação-na-publicação

Marcondes, Ricardo Augusto de Castro

ESTUDO DO USO DAS TUBULAÇÕES DE PEAD EM SISTEMAS DE DISTRIBUIÇÃO DE ÁGUA NO BRASIL / R. A. C. Marcondes, R. C. Zambon -versão corr. -- São Paulo, 2016.

$103 \mathrm{p}$.

Dissertação (Mestrado) - Escola Politécnica da Universidade de São Paulo. Departamento de Engenharia de Hidráulica e Ambiental.

1.Abastecimento de Água 2.Tubulações 3.Perdas de Água 4.PEAD

I.Universidade de São Paulo. Escola Politécnica. Departamento de

Engenharia de Hidráulica e Ambiental II.t. III.Zambon, Renato Carlos 


\section{AGRADECIMENTOS}

Ao meu orientador Prof. Dr. Renato Carlos Zambon por aceitar a orientação desde o primeiro momento e contribuir muito com sua experiência, incentivo e revisões.

Ao amigo e Engenheiro da Sabesp Hilton Alexandre de Oliveira, pelas nossas conversas frequentes, seu apoio e informações fornecidas.

Aos Professores Kamel Zahed Filho, José Rodolfo Scarati Martins, Alberto Luiz Francato e Podalyro Amaral de Souza pelas revisões e sugestões durante a qualificação e defesa final do trabalho.

A minha colega Aline Hayashi Suzuki, pela ajuda e companheirismo durante todo o mestrado e graduação que cursamos sempre juntos.

A minha namorada Amanda Farias, pela sua paciência e compreensão em diversos momentos.

A Escola Politécnica, em especial ao Departamento de Hidráulica e Ambiental, responsável por toda minha formação e desenvolvimento acadêmico. 


\section{RESUMO}

O polietileno surgiu em 1898 e logo já começou a ser utilizado como conduíte e isolante. Desde então este material vem ganhando muito espaço no mercado de tubulações, seja no saneamento, mineração, indústrias ou no segmento de petróleo e gás. Seu tipo mais usado é o Polietileno de Alta Densidade (PEAD), que apesar de já ser comumente encontrado em adutoras, emissários e ramais prediais, somente nos últimos anos passou a ser utilizado de maneira mais abrangente nas redes de distribuição de água, se tornando um aliado importante no combate aos altos índices de perdas reais.

No Brasil, somente nos últimos anos que a presença de tubulações de PEAD em redes de distribuição de água potável se tornou mais comum. Contudo, é possível identificar cenários de aplicação do PEAD em sistemas de abastecimento de água já relativamente consolidados, como é o caso do Departamento Municipal de Água e Esgotos (DMAE) de Porto Alegre, que utiliza o material há 25 anos, a Companhia de Saneamento Básico do Estado de São Paulo (Sabesp), onde desde 2009 a Diretoria Metropolitana vem utilizando o PEAD em novas aplicações em redes e a Odebrecht Ambiental da cidade de Limeira, que utiliza tubos deste material desde 2007.

Através de análises de custos de implantação, operação e manutenção, de amostragens da condição de tubulações em operação, da evolução de índice de perdas e de entrevistas com as equipes de operação e planejamento, é possível verificar que realmente as tubulações de PEAD auxiliam no combate às perdas reais e na otimização da operação e eficiência das prestadoras de serviços de distribuição de água potável, no sentido de diminuir o tempo de intervenção de redes, os custos de manutenção e a frequência de arrebentamento e vazamentos nas redes de abastecimento.

Palavras-chave: Abastecimento de Água, Tubulações, Perdas de Água, PEAD. 


\begin{abstract}
Polyethylene appeared in 1898 and soon started been used as conduit and insulating material. Since then, the material has been gaining a lot of space in the pipes market in sanitation, mining, industries and oil \& gas production. The most used type is High Density Polyethylene (HDPE), which despite being commonly found in water mains, emissaries and communication pipes, only in recent years began to be used more widely in water distribution networks, becoming an important ally in the fight against high rates of real water losses.

In Brazil, only in recent years the use of HDPE pipes has become more common in public water distribution networks. However, it is possible to identify HDPE application cases in relatively consolidated water supply distribution networks, such as the Departamento Municipal de Água e Esgotos (DMAE) of Porto Alegre, which have used the material for 25 years; the Companhia de Saneamento Básico do Estado de São Paulo (Sabesp), where since 2009 the Metropolitan Unit has been using HDPE in new applications in network pipes and Odebrecht Ambiental, in Limeira city, which uses this material in water pipelines since 2007.

Through research of implementation, operation and maintenance costs, sampling the condition of pipes in operation, analysis the real losses indicators and interviews with the operations and planning teams, it is possible to conclude HDPE pipes contribute to reduction of real losses and optimization of the operation and efficiency of the providers of drinking water distribution services, decreasing maintenance time and costs.
\end{abstract}

Keywords: Water Supply, Pipes, Water Loss, HDPE. 


\section{LISTA DE FIGURAS}

Figura 1 - Divulgação do Programa de Substituição de Redes de Londres ............................................ 17

Figura 2 - Ramificação dos Diferentes Tipos de Polietilenos ................................................................. 19

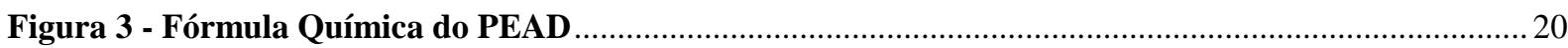

Figura 4 - Análise de Mercado - Oferta e Demanda Mundial de PEAD .............................................22

Figura 5 - Evolução do Mercado de PEAD 2007 - 2012 ........................................................................ 25

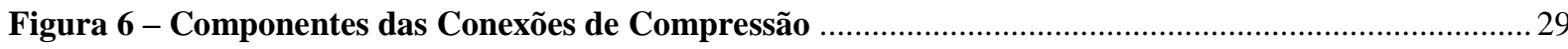

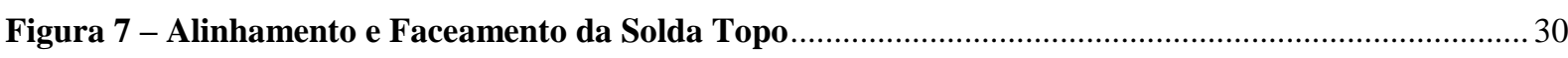

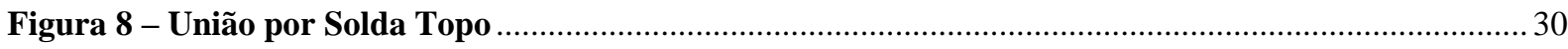

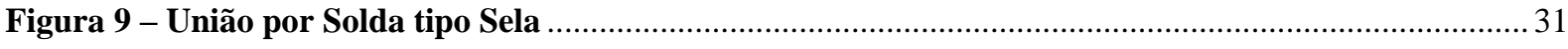

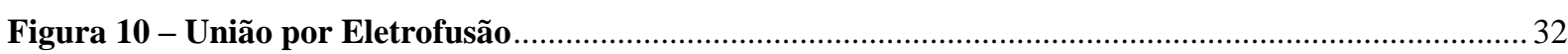

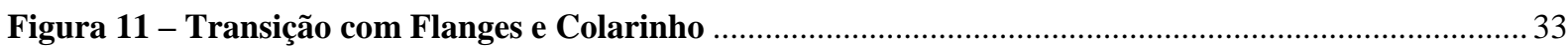

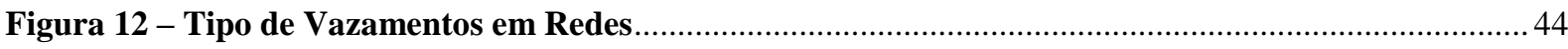

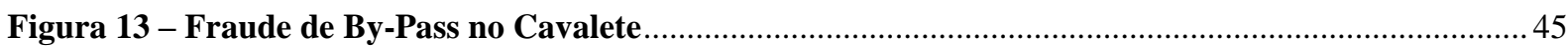

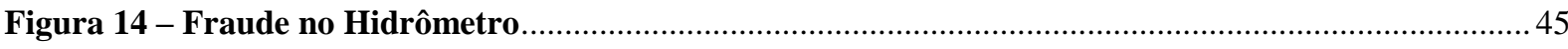

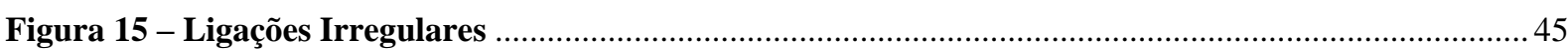

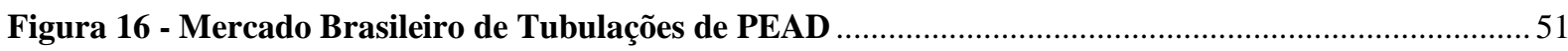

Figura 17 - Tubulações do Sistema de Distribuição de Água - DMAE Porto Alegre ................................ 55

Figura 18 - Dimensões das Tubulações de PEAD do Sistema de Distribuição de Água - DMAE Porto

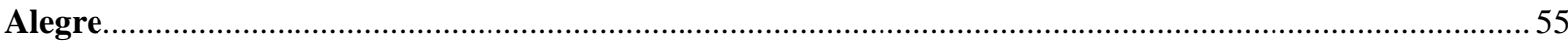

Figura 19 - Extensões de PEAD na Região Metropolitana de São Paulo Estudada.....................................5 57

Figura 20 - Composição da Rede de Distribuição de Água de Limeira - 2007 .......................................59

Figura 21 - Composição da Rede de Distribuição de Água de Limeira - 2014 .........................................59

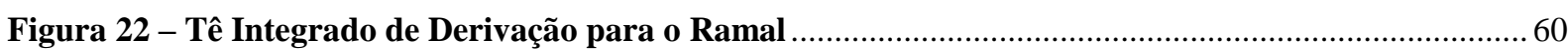

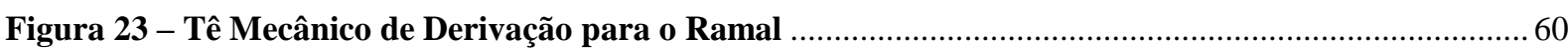

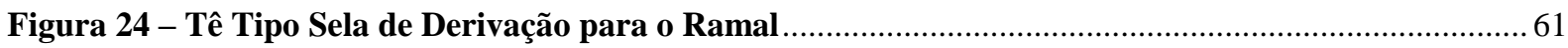

Figura 25 - Conexão Mecânica utilizada em intervenções em rede de PEAD - Tipo 1 .............................662

Figura 26 - Conexão Mecânica utilizada em intervenções em rede de PEAD - Tipo 2 ............................62

Figura 27 - Extensões de Redes de PEAD e Perdas no Sistema de Abastecimento de Água de Porto Alegre.

Figura 28 - Extensões de Redes de PEAD e Perdas no Sistema de Abastecimento de Água de Porto Alegre

Figura 29 - Extensões de Redes de PEAD e Quantidade de Água Produzida em Porto Alegre................. 70

Figura 30 - Índices de Perdas Totais e Recursos Aplicados - Sabesp ................................................. 71

Figura 31 - Substituição de Tubulações de Ferro Fundido por PEAD na Área de Interesse ..................... 72

Figura 32 - Ocorrências de Vazamentos na Área de Interesse - 2007 .......................................... 73 
Figura 33 - Ocorrências de Vazamentos na Área de Interesse - 2008

Figura 34 - Ocorrências de Vazamentos na Área de Interesse - 2009 .................................................... 74

Figura 35 - Ocorrências de Vazamentos na Área de Interesse - 2010 ............................................ 74

Figura 36 - Ocorrências de Vazamentos na Área de Interesse - 2011 ............................................... 75

Figura 37 - Ocorrências de Vazamentos na Área de Interesse - 2012 .................................................. 75

Figura 38 - Ocorrências de Vazamentos na Área de Interesse - 2013 ................................................... 76

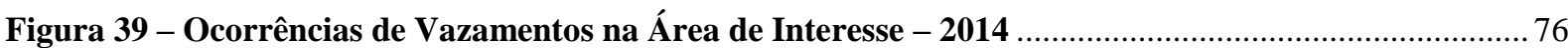

Figura 40 - Número de Ocorrências de Vazamentos na Área de Interesse ........................................... 77

Figura 41 - Evolução do Índice de Perdas Totais do Sistema de Abastecimento da Água de Limeira ....... 78

Figura 42 - Ocorrências de Vazamentos na Área de Interesse - 2014 ................................................. 82

Figura 43 - TIA - Tempo de Intervenção de Água - Limeira/SP ..................................................... 86

Figura 44 - Redes de Água do Reino Unido - Ocorrências de Falhas ........................................................ 87

Figura 45 - Prestadoras de Serviço por Data da Primeira Instalação de Tudo PEAD - Ramal................ 88

Figura 46 - Prestadoras de Serviço por Data da Primeira Instalação de Tudo PEAD - Rede .................. 88

Figura 47 - Comparação da Satisfação com tubos de PE por Geração.................................................. 88

Figura 48 - Percepção Positiva de Satisfação do Cliente ............................................................................. 90

Figura 49 - Número de Ocorrências de Água Turva e Vermelha .......................................................... 90

Figura 50 - Notas dos Clientes em Relação ao Serviço Prestado .......................................................... 91 


\section{LISTA DE TABELAS}

Tabela 1 - Tabela dos SDR's Comercializados - Tubulações de Água ......................................... 21

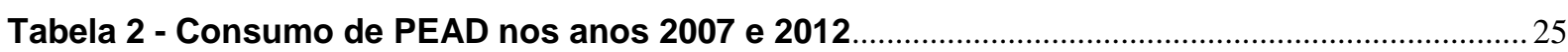

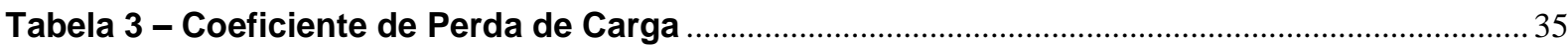

Tabela 4 - Abrasão de Tubos de Diversos Materiais ....................................................................42

Tabela 5 - Caracterização do Sistema de Água - Participantes SNIS 2013 ..................................5 54

Tabela 6 - Rede de Distribuição de Água - Sabesp M ...............................................................5

Tabela 7 - Dados das Tubulações com 20 anos de Operação ..........................................................65

Tabela 8 - Análise Laboratorial das Tubulações com 20 anos de Operação .................................65

Tabela 9 - Dados da Análise Dimensional e Visual das Tubulações com 10 Anos de Operação 67

Tabela 10 - Análise Laboratorial das Tubulações com 10 anos de Operação...............................67

Tabela 11 - Teste Hidrostático das Tubulações com 10 anos de Operação ................................ 67

Tabela 12 - Tempo de Reparo por Tamanho de Tubulação ............................................................ 79

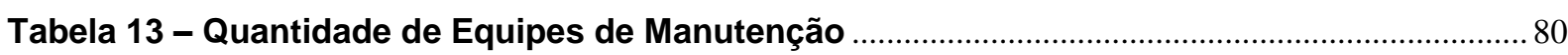

Tabela 14 - Custos de Execução de Redes - DMAE-POA (R\$/metro) (2006) ................................80

Tabela 15 - Custos de Execução de Redes FoFo - Sabesp M (R\$/Metro) ..................................... 84

Tabela 16 - Custos de Execução de Redes PEAD (R\$Metro) ........................................................ 85 


\section{LISTA DE SIGLAS}

ABES Associação Brasileira de Engenharia Sanitária e Ambiental

ABNT Associação Brasileiro de Normas Técnicas

APECS Associação Paulista de Empresas de Consultoria e Serviços em Saneamento e Meio Ambiente

AWWA American Water Works Association

CCDM-SC Centro de Caracterização de Materiais da Universidade Federal de São Carlos

CONVIAS Departamento de Controle de Uso de Vias Públicas

Cosama Companhia de Saneamento do Amazonas

DE Diâmetro Externo

DEFOFO Diâmetro Equivalente de Ferro Fundido

DI Diâmetro Interno

DMAE Departamento Municipal de Água e Esgoto

DMC Distrito de Medição e Controle

DN Diâmetro Nominal

EAC Environment Assisted Cracking

ESC Environment Stress Cracking

ETA Estação de Tratamento de Água

IF Índice de Fluidez

IPT Instituto de Pesquisas Tecnológicas

IWA International Water Association

JICA Japan International Cooperation Agency

LYSA Lyonnaise Des Eaux Services Associés

MCA Metros de Coluna de Água

MND Método Não Destrutivo

NAFTA North American Free Trade Agreement

NF Negro de Fumo

OIT Oxidation Index Time

PE Polietileno

PEAD Polietileno de Alta Densidade

PEBD Polietileno de Baixa Densidade 


$\begin{array}{ll}\text { PEBDL } & \text { Polietileno de Baixa Densidade Linear } \\ \text { PEMB } & \text { Polietileno de Média Densidade } \\ \text { PHI } & \text { Pressão Hidrostática Interna } \\ \text { PIPA } & \text { Plastics Industry Pipe Association of Australia } \\ \text { PN } & \text { Pressão Nominal } \\ \text { POA } & \text { Porto Alegre } \\ \text { PP } & \text { Polipropileno } \\ \text { PRFV } & \text { Polímero Reforçado com Fibra de Vidro } \\ \text { PVC } & \text { Policloreto de Vinila } \\ \text { RMSP } & \text { Região Metropolitana de São Paulo } \\ \text { Sabesp } & \text { Companhia de Saneamento Básico do Estado de São Paulo } \\ \text { SDR } & \text { Standard Dimension Ratio } \\ \text { SIGNOS } & \text { Sistema de Informações Geográficas no Saneamento } \\ \text { SNIS } & \text { Sistema Nacional de Informações sobre Saneamento } \\ \text { TIA } & \text { Tempo de Intervenção das Equipes de Rede de Água } \\ \text { VRP } & \text { Válvula Redutora de Pressão }\end{array}$




\section{SUMÁRIO}

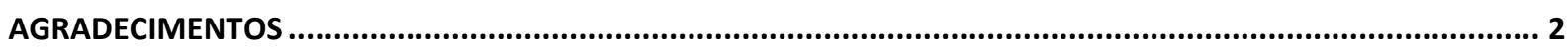

RESUMO

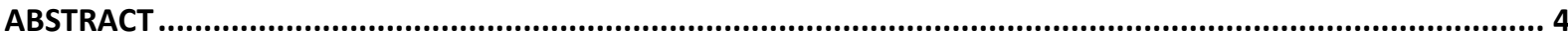

LISTA DE FIGURAS

LISTA DE TABELAS

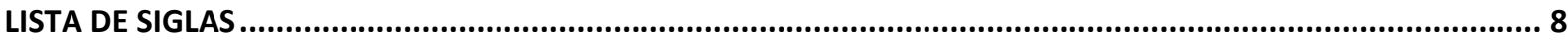

1. INTRODUÇÃO

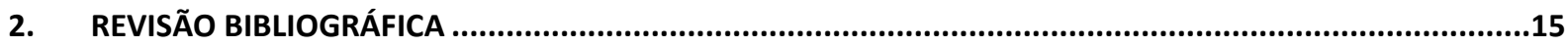

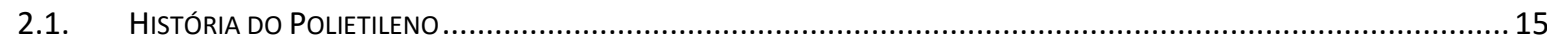

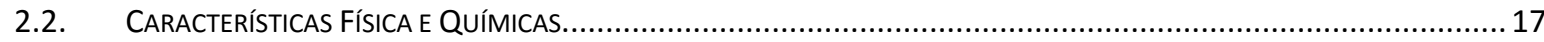

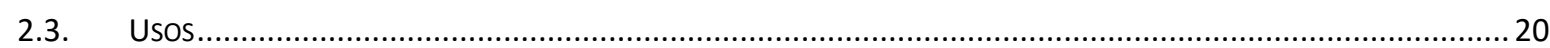

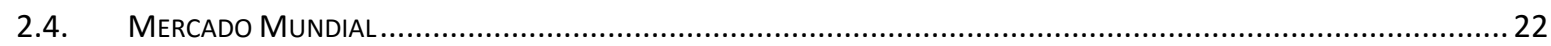

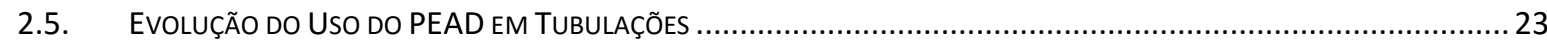

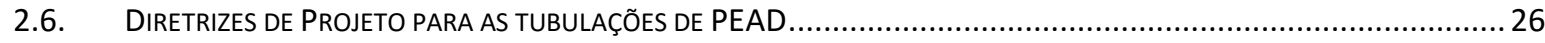

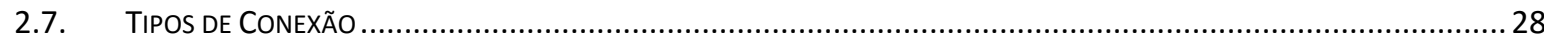

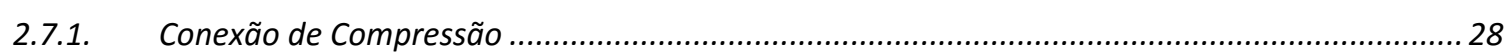

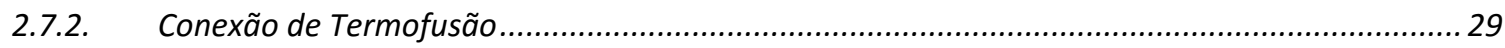

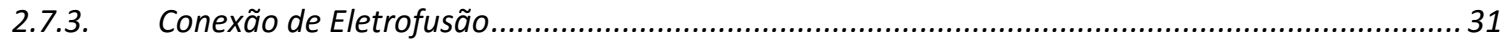

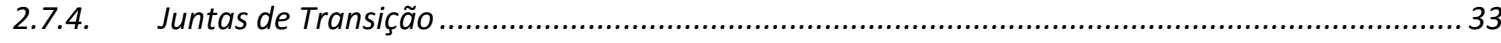

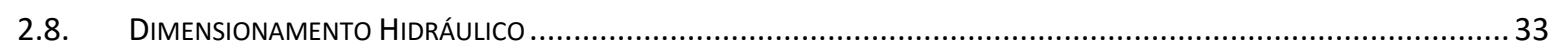

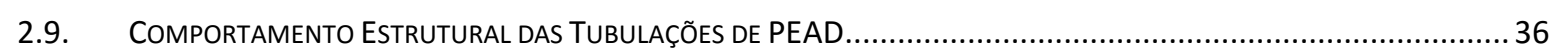

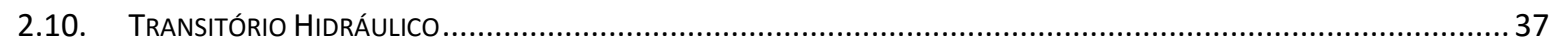

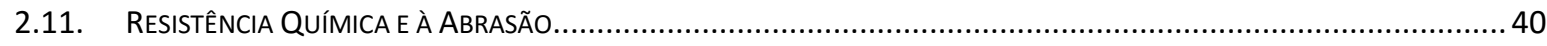

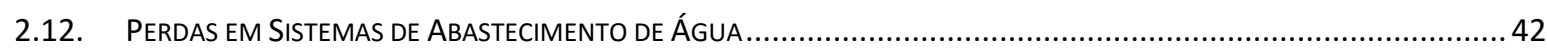

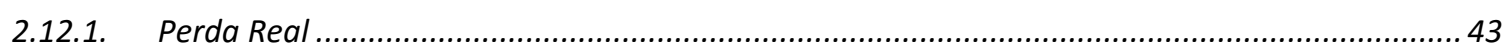

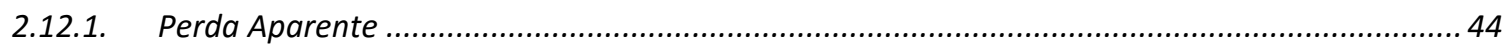

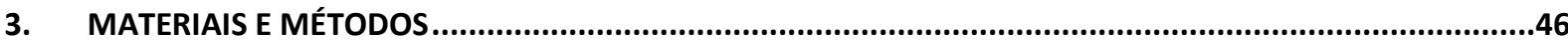

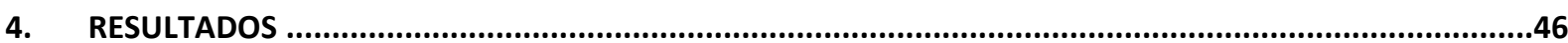

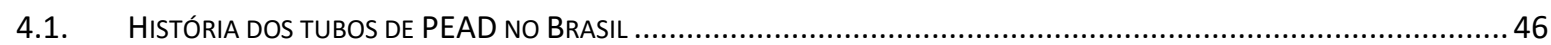

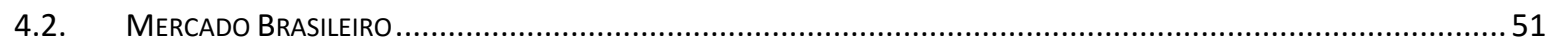

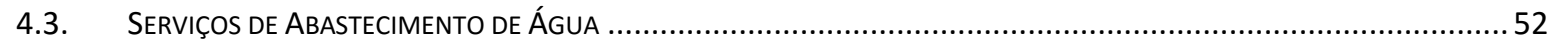

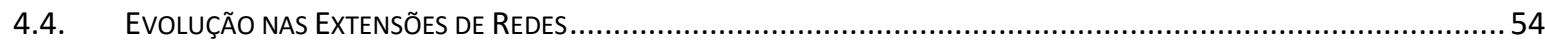

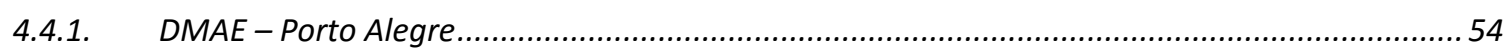




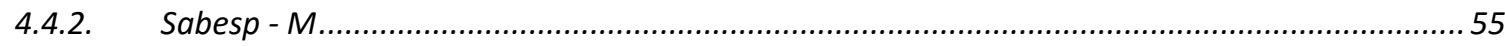

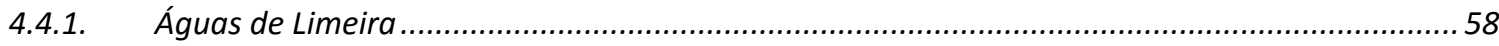

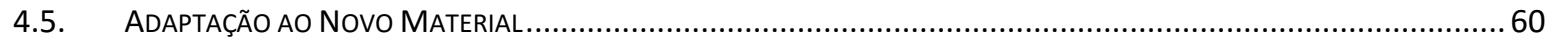

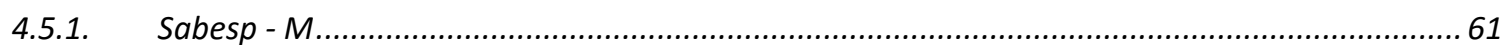

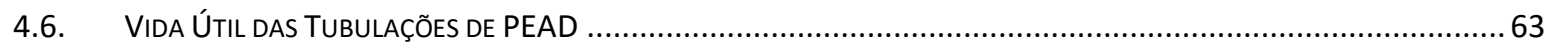

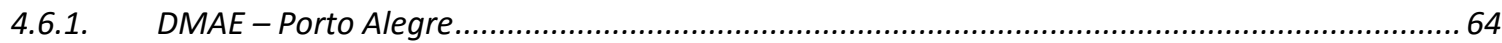

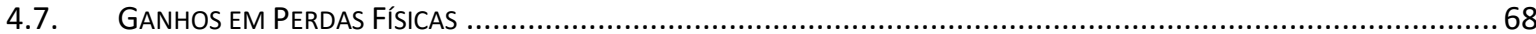

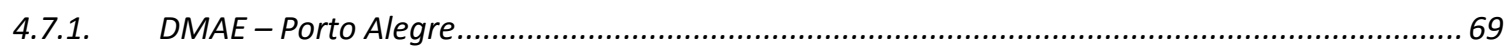

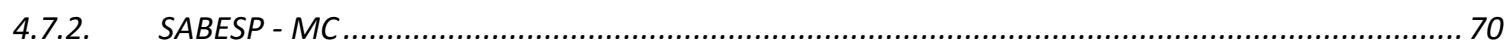

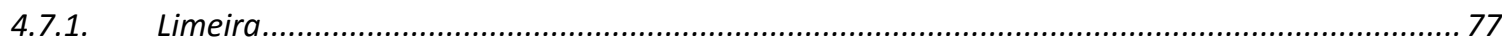

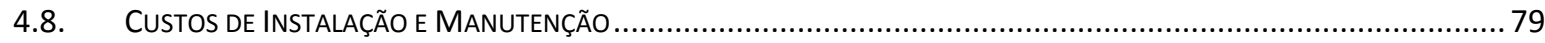

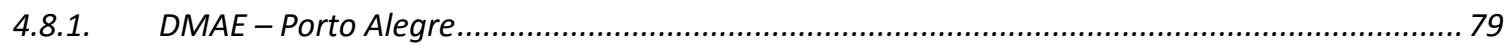

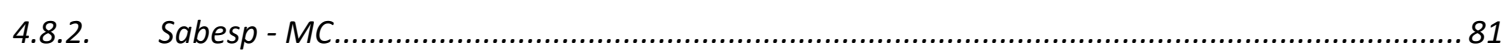

4.8.3. Limeira

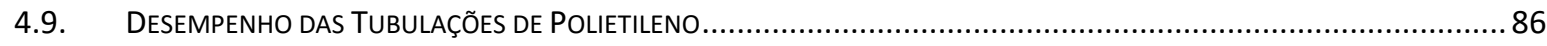

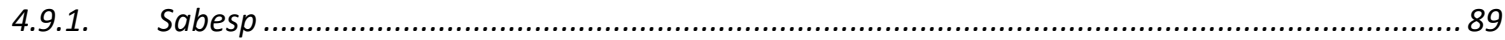

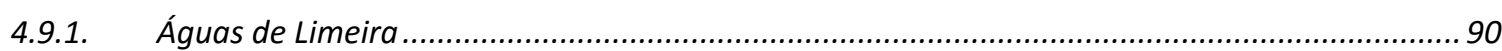

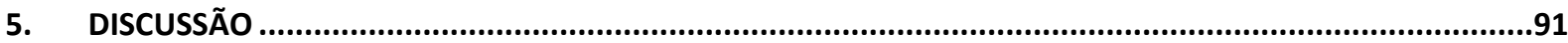

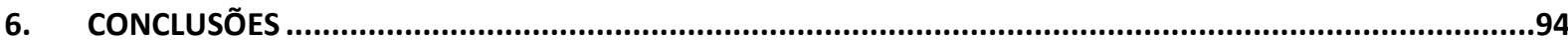

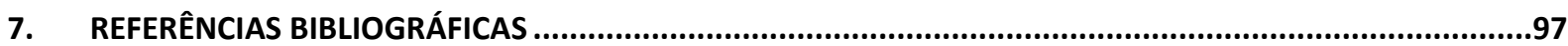

ANEXO - MAPA DO MATERIAL DA REDE DE DISTRIBUIÇÃO DE ÁGUA DA ÁREA ESTUDADA DA REGIÃO METROPOLITANA DE SÃO PAULO 


\section{INTRODUÇÃO}

Vários locais do mundo vêm sofrendo com a escassez de reservas de água potável nos últimos anos. O Brasil não é diferente e a crise hídrica continua muito severa em várias regiões como no nordeste e sudeste, com o seu ápice no ano 2014 principalmente para a cidade de São Paulo. Foi necessária a diminuição da vazão captada nos mananciais, reservatórios e rios destas regiões, para que se recuperasse parte do volume útil e garantisse o atendimento contínuo a demanda. Para isso, governos e prestadores de serviços de tratamento e distribuição de água adotaram uma série de medidas, sendo as principais: a intensificação ao combate às perdas, abastecimento intermitente e incentivos financeiros como bônus e multas nas contas mensais de água.

Em vista desses problemas, o Brasil finalmente começou a seguir uma tendência de consumo mais consciente da água, já iniciada em outros lugares do mundo com escassez de recursos hídricos.

Neste cenário, o combate às perdas reais e aparentes dos sistemas de distribuição da água se torna ainda mais importante, uma vez que o índice médio de perda total na RMSP é de $31,2 \%$, enquanto que em cidades da Alemanha e do Japão, esse índice é por volta de 11\%. (ABES, 2013).

No combate a esse elevado índice, mais precisamente na parcela das perdas reais, as tubulações de Polietileno de Alta Densidade - PEAD vêm sendo utilizadas na substituição das antigas tubulações de ferro fundido, aço e cimento amianto.

Pela possibilidade de ser transportado em bobinas, por apresentar propriedades de resistência à corrosão e por conseguir se conectar através de soldas termoplásticas (eliminando as conexões mecânicas do tipo ponta e bolsa), possibilitou boas garantias contra vazamentos e arrebentamentos, se tornando amplamente utilizado em todo o mundo. Estas propriedades são vantajosas principalmente nas cidades, onde o tráfego de veículos pesados é maior, gerando vibrações no solo, podendo comprometer principalmente as tubulações rígidas com conexões mecânicas.

O aumento da utilização do PEAD nos sistemas de distribuição de água potável também se deve ao fato de ser utilizado como alternativa única ou preferencial nos 
método não destrutivos (MND) de instalação ou substituição de redes subterrâneas, sem aberturas de valas. Cada vez mais estes métodos vem sendo adotados pelas empreiteiras, uma vez que diminui o impacto ambiental, econômico e social na região em relação aos métodos de instalação em vala a céu aberto. As tubulações de polietileno por serem flexíveis, leves e serem fabricadas em bobinas de até 100 metros de extensão (dependendo do diâmetro), se tornam um material muito interessante para este tipo de aplicação.

Contudo, apesar do grande aumento na utilização de tubulações de polietileno nos sistemas públicos de abastecimento de água, muitas dúvidas ainda pairam sobre as concessionárias, empreiteiras e projetistas, são elas:

- A relação custo $x$ benefício das tubulações de PEAD é de fato melhor que as tubulações de ferro fundido?

- Regiões que sofreram intervenção em sua rede de abastecimento de água com tubulações de PEAD apresentaram diminuição em volume de perdas reais?

- Quanto em vazão a perda real pode diminuir com substituição de redes antigas por novas de PEAD?

- Quais os custos de instalação e manutenção das tubulações de PEAD?

- Podemos realmente considerar o coeficiente de rugosidade das tubulações de Hazen-Williams $C=150$ e que não sofre envelhecimento?

- Já existe no Brasil um mercado capaz de atender demanda de grandes projetos, assim como prover assistência técnica e garantias?

- Já existem normas técnicas e padrões brasileiros específicos das tubulações de PEAD?

Tendo em vista todas estas dúvidas e somado com a adoção mais frequente do polietileno nas redes de distribuição de água, além da crise hídrica vivenciada por várias regiões do país nos últimos anos, o presente trabalho visa estudar a evolução do uso das tubulações de PEAD no país, desde a primeira tubulação instalada até os dias de hoje, em que várias prestadoras de serviço de água já o utilizam como principal material para suas novas tubulações, e assim contribuir com o conhecimento sobre as questões apresentadas. 
Foram realizados estudos de caso em sistemas públicos de abastecimento de água potável que possuem tubulações de polietileno em operação, visando estimar as vantagens e desvantagens em relação a operação, combate às perdas de água na distribuição, custos de instalação e manutenção e disponibilidade do material. 


\section{REVISÃO BIBLIOGRÁFICA}

\subsection{História do Polietileno}

O polietileno foi sintetizado pela primeira vez em 1898 pelo químico alemão Hans Von Pechmann, que o preparou acidentalmente ao aquecer o diazometano. $\mathrm{Na}$ época, o pó branco de aspecto ceroso, sem nenhuma serventia ou uso comercial, foi caracterizado como uma longa sequência de $\mathrm{CH}_{2}$ e foi denominado de polimetileno. A primeira síntese que resultou em um produto industrial foi descoberta por pesquisadores do ICl Chemicals em 1939 no Reino Unido, quando se misturou eteno e benzaldeído sob elevada pressão (Suzuki, 2009).

A primeira utilização do polietileno que se tem notícia foi durante a segunda guerra mundial, na fabricação de conduítes e eletrodutos subaquáticos. Também foi utilizado em substituição à borracha em isolamentos elétricos. Na guerra foi usado no revestimento de equipamentos como radares, os tornando mais leves e mais fáceis de serem carregados em aviões. Na fabricação de tubos, começou a ser empregado nos processos industriais e no transporte de água no meio rural, aplicações de baixa pressão. Passou também a ser utilizado na produção de petróleo, onde havia a necessidade de tubulações leves, flexíveis e resistentes para acompanhar o rápido crescimento da indústria de gás e petróleo.

O sucesso no emprego nestas áreas fez logo com que os tubos de polietileno também fossem utilizados na distribuição de gás natural para casas e indústrias. A flexibilidade do PEAD, aliada com sua capacidade de ser fornecida em bobinas de até 100 metros de extensão para diâmetros mais comuns, e a possibilidade de uniões de tubos através de soldas de eletro e termofusão, possibilitaram boas garantias contra vazamentos e arrebentamentos, atribuindo maior confiabilidade da operação também dos sistemas de transporte de água.

Segmentos da indústria, do saneamento e da mineração também passaram a se interessar pelo material, devido principalmente a sua elevada vida útil estimada entre 50 e 100 anos para aplicações de transporte de água, gerando um considerável aumento da demanda da resina nos últimos anos (Plastics Pipe Institute ${ }^{\circledR}$ Handbook of Polyethylene Pipe, 2009). 
Desde que começou a ser utilizado na distribuição de água potável, os tubos de polietileno passaram por várias modificações de sua propriedades físico-químicas, devido a constante evolução das resinas e dos processos produtivos, somando-se isso ao surgimento de novas normas e padrões. Avanços nas propriedades das resinas, aditivos e extrusão dos tubos fizeram com que as tubulações atuais sejam bem diferentes das de décadas passadas.

As primeiras tubulações de polietileno utilizadas em sistemas de abastecimento de água que se tem informação foram instaladas no começo da década de 1960. Desde então há relatos de cidades e empresas que decidiram adotar o PEAD como principal material de suas tubulações.

Em 1985, a cidade de Kobe no Japão foi atingida por um terremoto de grandes proporções, que foi responsável por destruir meio milhão de casas e matar aproximadamente seis mil pessoas. Destruiu também as tubulações de gás feitas em ferro e aço, enquanto que a maioria das tubulações de PEAD permaneceu intacta (PIPA Seminars, 2006). Comprovou-se então na prática a capacidade já esperada das tubulações de polietileno resistirem a deformações e solicitações devido a sua flexibilidade e ao uso de juntas com soldas termoplásticas, tanto que para a reconstrução da cidade só se utilizou tubos de polietileno na distribuição de gás.

A cidade de Londres, por possuir uma rede de distribuição de água muito antiga cerca da metade com mais de 100 anos e um terço com mais de 150 anos e a maioria de ferro fundido - implementou através de sua concessionária Thames Water, um extenso programa de substituição de redes no ano de 2006, abrangendo $1.600 \mathrm{~km}$ de extensão total - dados de 2007 (Borouge PTE, 2007). O material escolhido para substituição foi o polietileno, que inclusive foi usado nas campanhas publicitária de divulgação do programa e conscientização e educação das pessoas, como um símbolo de combate as perdas e tecnologia nas distribuição de água. Um cartaz mostrando uma tubulação de PEAD azul e descrevendo suas principais vantagens foi utilizado como propaganda da prestadora de serviço inglesa, como pode ser visto na figura a seguir: 


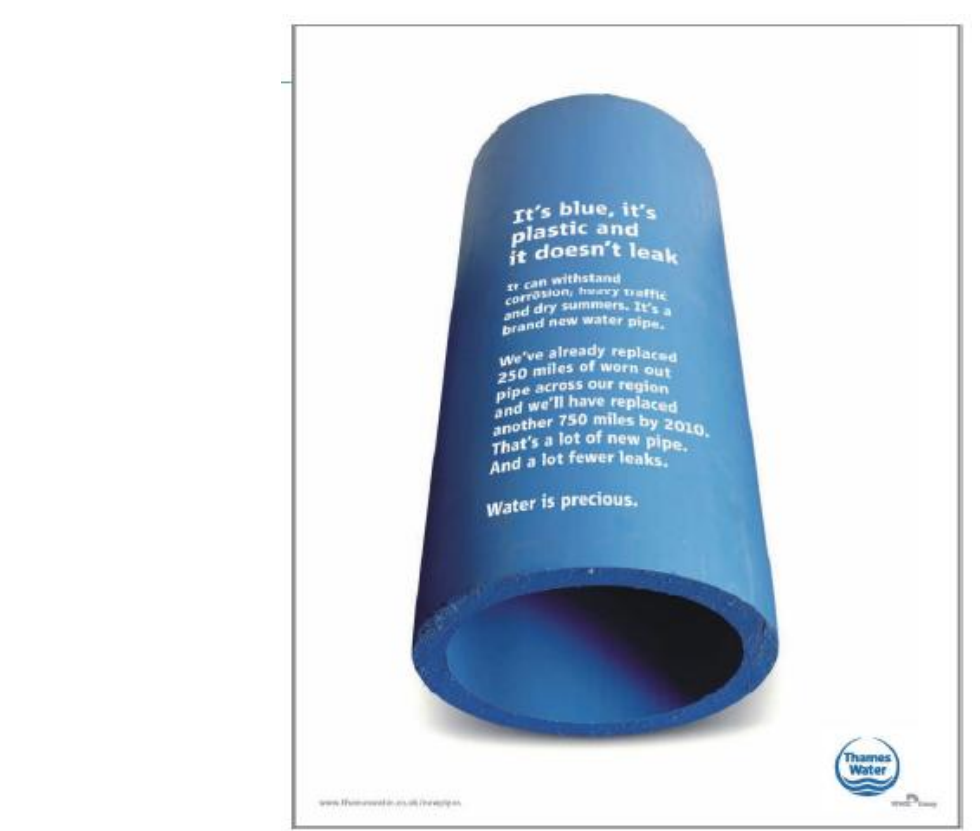

Figura 1 - Divulgação do Programa de Substituição de Redes de Londres

Fonte: PIPA Seminars Australia - 2007

\subsection{Características Física e Químicas}

O PEAD é uma espécie de polietileno, que por sua vez é um tipo de polímero. O polímero é uma macromolécula composta por muitas dezenas ou centenas de milhares de unidades de repetição denominadas meros, ligadas por ligação covalente. Os polímeros são obtidos por meio da reação de polimerização dos monômeros, isto é, uma molécula com uma (mono) unidade de repetição. Do ponto de vista da nomenclatura, para se denominar um polímero usa-se o nome do monômero que foi usado na sua síntese e não o nome químico da unidade repetitiva do mesmo. Assim, por exemplo, utiliza-se o termo polietileno, pois este deriva do etileno $\left(\mathrm{CH}_{2}=\mathrm{CH}_{2}\right)$. (Mesquita, 2010)

O polietileno é um composto plástico produzido por meio de diversos tipos de reações de polimerização do etileno sob a presença de catalisadores. A maior parte do etileno é proveniente do petróleo por meio do cracking da nafta oriunda do petróleo.

O etileno pode ainda ser obtido da desidratação catalítica do álcool etílico. Por advirem de hidrocarbonetos olefínicos, o polietileno é chamado de resina poliolefínicas (possuem apenas hidrogênio e oxigênio em sua molécula). 
A obtenção do polietileno basicamente se resume da polimerização do etileno em reator na presença de solventes, catalisadores, hidrogênio e comonomêros quando foi caso. O catalisador entra no processo para desencadear a reação e propiciar a estereoespecificidade, ou seja, fazer com que as unidades básicas se interliguem na conformação desejada (daí o terno catalisador estereoespecífico), enquanto o hidrogênio $(\mathrm{H})$ entra como elemento finalizador ou limitador de comprimento das macromoléculas.

O produto em forma de pó branco, ou em forma de flocos, precipita-se no reator e a seguir é lavado e secado para eliminação do solvente e de resíduos catalíticos. Depois então, é conduzido a uma unidade para mistura de aditivos específicos e pigmentos, conforme a aplicação do produto, passando daí a unidade de granulação (extrusora) e embalagem (Danieletto, 2014).

A extrusão é um processo mecânico onde o material é forçado através de uma matriz adquirindo assim a configuração pré-determinada pela forma da matriz projetada para a peça.

Segundo MESQUITA (2010), os tipos de polietileno mais comum são: PEAD, PEMD (Polietileno de Média Densidade) e PEBD (Polietileno de Baixa Densidade). Segundo a norma ASTM D-4976, esta classificação deve seguir a seguinte escala de densidade:

- Classe $1(0,910$ a 0,925) = Polietileno de Baixa Densidade;

- Classe $2(>0,925$ a 0,940) = Polietileno de Média Densidade;

- Classe $3(>0,940$ a 0,960) = Polietileno de Alta Densidade;

- Classe $4(>0,960)=$ Polietileno de Alta Densidade.

O PEBD ainda pode ser subdivido em PEBD normal (Polietileno de Baixa Densidade) e PEBDL (Polietileno de Baixa Densidade Linear), de acordo com a configuração de suas cadeias. Abaixo estão descritos usos para cada tipo de polietileno citado, segundo MESQUITA (2010):

- PEBD (Polietileno de Baixa Densidade): devido a sua flexibilidade, facilmente processável, elevada resistência química e boas propriedades isolantes, este polietileno é muito usado para extrusão de filmes, fios e cabos, além de sua utilização para moldagem de sopro e moldagem de injeção; 
- PEBDL (Polietileno de Baixa Densidade Linear): é um termoplástico com elevada resistência de solda a quente, sendo utilizado principalmente na produção de filmes para embalagens, sacaria industrial e filme esticável (stretch);

- PEMD (Polietileno de Média Densidade): possui rigidez intermediária, sendo utilizado principalmente na produção de embalagens e na obtenção de filmes gofrados para a produção de fraldas descartáveis e absorventes higiênicos e, no processo de rotomoldagem, para a produção de caixas d'água, brinquedos, reservatórios e tanques para produtos químicos e componentes para máquinas agrícolas.

- PEAD (Polietileno de Alta Densidade): linear, com baixo teor de ramificações e altamente cristalino. A linearidade das cadeias do PEAD torna a orientação, o alinhamento e o empacotamento das cadeias mais eficiente, fazendo com que as forças intermoleculares (do tipo Van der Waals) possam agir mais intensamente. Possui elevada rigidez, resistência à fluência, à abrasão, ao impacto e ao tenso fissuramento sob tensão ambiental e química.

A seguir temos o esquema de ramificação dos três principais tipos de polietileno:

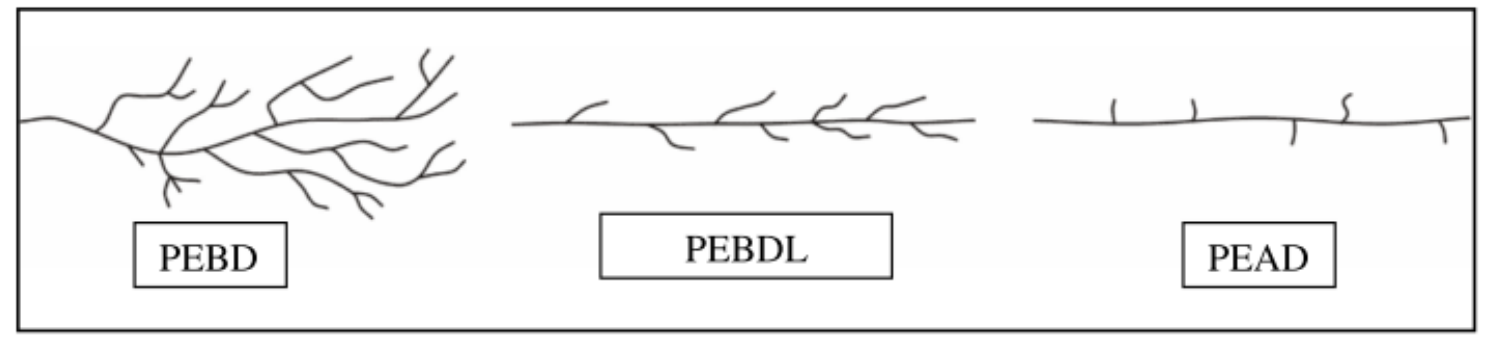

Figura 2 - Ramificação dos Diferentes Tipos de Polietilenos

Fonte: Adaptado de MESQUITA (2010), pag. 20

Assim como ou outros polietilenos, a fórmula molecular do PEAD é composta por carbonos e hidrogênios, como na Figura 1 a seguir e sua cadeia de moléculas pode variar de 500.000 a 1.000 .000 de moléculas. 


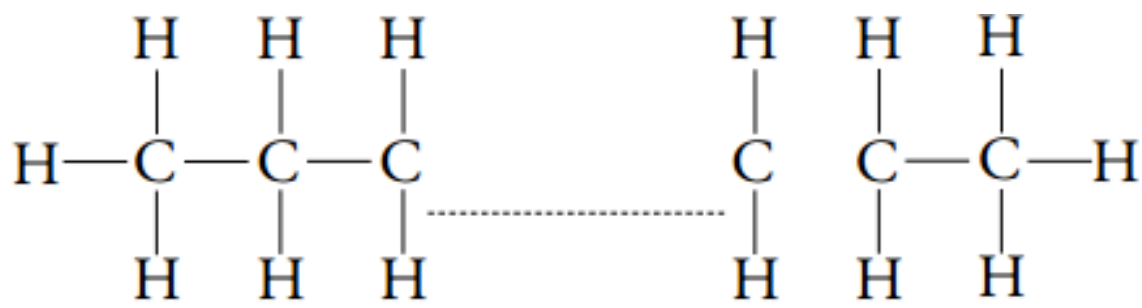

Figura 3 - Fórmula Química do PEAD

De acordo com a associação internacional PlasticPipe (https://plasticpipe.org/pdf/high density polyethylene pipe systems.pdf, consultado em novembro de 2014), as tubulações de PEAD apresentam característica de elevada resistência química contra corrosão, ferrugem, apodrecimento e crescimento de comunidades biológicas. São flexíveis, podendo fazer curvas de raio maior que trinta vezes o diâmetro externo e com alta resistência a fadiga. De acordo com a norma são fabricados para ter uma vida útil superior a 50 anos.

Os tubos de polietileno são obtidos por meio de extrusão de resinas na forma de pó ou grânulos e as taxas de controle de velocidade de resfriamento interferem, entre outros aspectos importantes, a orientação molecular e o grau de cristalinidade. (Peres, 2005).

Segundo HORLACHER (1998), o PEAD, assim como o PVC, apresenta um comportamento viscoelástico no qual sua deformação depende da temperatura, tempo e gradiente de pressão. Significa que a mudanças de vazão e pressão que ocorrem nas tubulações viscoelásticas durante os fenômenos transitórios não são diretamente proporcionais como nos materiais elásticos, ou seja, a velocidade de propagação da onda de pressão não é mais constante. A pressão de cada ponto da tubulação dependerá da deformação da seção no instante anterior e da real variação de pressão.

\subsection{Usos}

O polietileno pode ser produzido por vários processos, resultando produtos para diversas aplicações como tubos, fios, cabos, filmes, chapas, brinquedos, pallets, tampas, potes, isolamentos e outros artigos soprados, injetados ou rotomoldados. 
Dentre os polietilenos, o PEAD é o de maior produção mundial e pode ser produzido através dos processos de extrusão, moldagem por sopro e moldagem por injeção. Por extrusão, o PEAD é utilizado principalmente em isolamentos de fios telefônicos, geomembrana, sacos de lixo, sacolas de supermercados, revestimentos de tubulações metálicas e tubos para redes de saneamento e de distribuição de gás. Pelo processo de sopro, destaca-se a transformação em frascos para sucos e bebidas lácteas, tanques de combustíveis, bombonas e tambores para produtos químicos, agroquímicos, de higiene e limpeza e óleos lubrificantes. No processo de injeção, o PEAD é usado para a fabricação de baldes, brinquedos, potes, tampas para garrafas, entre outros (MESQUITA, 2010)

No ramo do saneamento e infraestrutura, o PEAD é utilizado como material para várias tubulações e condutos como: ramais, redes, adutoras, captação de água, emissários e travessias subaquáticas, redes coletoras de esgoto, redes antiincêndio, redes de gás combustível, águas pluviais e drenagem, mineração, dragagem, irrigação, produtos químicos, dutos elétricos, telefônicos, fibra-ótica, furo direcional e pipe-bursting.

Pela capacidade do tubos polietilenos serem produzidos com espessuras de parede e resinas distintas, para a comercialização das tubulações de água se utiliza um parâmetro chamado SDR (Standard Dimension Ratio), que nada mais é que a razão entre o diâmetro e a espessura da tubulação. A seguir temos a fórmula do SDR e a tabela dos tipos demais comercializados em relação as resinas PE 80 e 100:

$$
S D R=\frac{D E}{e}
$$

Sendo:

$\mathrm{DE}=$ Diâmetro externo $(\mathrm{mm})$

$\mathrm{e}=$ espessura da parede $(\mathrm{mm})$

Tabela 1 - Tabela dos SDR's Comercializados - Tubulações de Água

\begin{tabular}{|c|c|c|c|c|c|c|c|c|}
\hline $\begin{array}{c}\text { PN/ } \\
\text { RESINA }\end{array}$ & $\begin{array}{c}\text { PN4 } \\
\text { SDR }\end{array}$ & $\begin{array}{c}\text { PN 5 } \\
\text { SDR }\end{array}$ & $\begin{array}{c}\text { PN 6 } \\
\text { SDR }\end{array}$ & $\begin{array}{c}\text { PN 8 } \\
\text { SDR }\end{array}$ & $\begin{array}{c}\text { PN 10 } \\
\text { SDR }\end{array}$ & $\begin{array}{c}\text { PN 12.5 } \\
\text { SDR }\end{array}$ & $\begin{array}{c}\text { PN 16 } \\
\text { SDR }\end{array}$ & $\begin{array}{c}\text { PN 20 } \\
\text { SDR }\end{array}$ \\
\hline PE80 & 32,25 & 26 & 21 & 17 & 13,6 & 11 & 9 & 7,25 \\
\hline PE100 & - & 32,25 & 26 & 21 & 17 & 13,6 & 11 & 9 \\
\hline
\end{tabular}




\subsection{Mercado Mundial}

O mercado de polietileno cresceu muito nos últimos anos, se tornando o termoplástico mais usado e reconhecido em todo mundo. Segundo relatório da IHS Inc., Polyethylene Global View (2012).., a demanda mundial de polímeros para o ano de 2012 foi de 232,6 milhões de toneladas. Desta, o PEAD corresponde cerca de $17 \%$, perdendo apenas para o PP-Polietileno-PP (25\%) e o PVC (18\%). No gráfico abaixo pode ser observado as expectativa para o crescimento do mercado de PEAD:

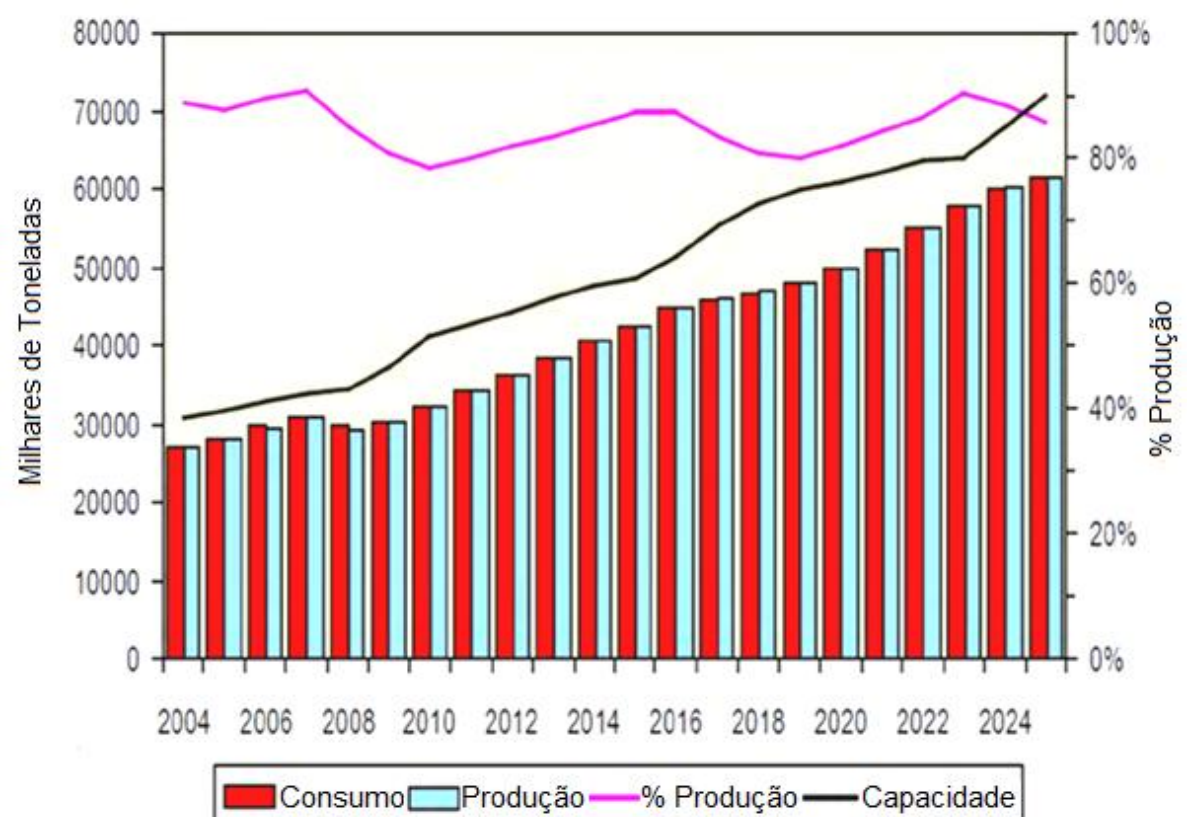

Figura 4 - Análise de Mercado - Oferta e Demanda Mundial de PEAD

Fonte: IHS Inc., 2012

Vários relatórios apontam elevada tendência de crescimento deste mercado para os próximos anos, principalmente nos países em desenvolvimento e no mercado asiático. O PEAD está incluso nesta perspectiva, com um crescimento estimado em 5\% até 2016 (IHS Inc., 2012).

Dentre os polietilenos, o PEAD é o de maior produção mundial (MESQUITA, 2010), alcançando em 2012 o volume aproximado de 35 milhões de toneladas consumidas.

Praticamente $100 \%$ das novas redes de distribuição de gás são feitas com tubos de Polietileno nos centros urbanos de todo o mundo (ABPE, 2012). Contribui para esse cenário a substituição de tubos antigos por métodos nãos destrutivos (MND), que instalam tubulações de PEAD sem a necessidade de abertura de valas, viabilizando de forma econômica, rápida e segura a recuperação das antigas redes. 
A participação de tubos de PEAD nas redes, ramais e adutoras de água, bem como em esgotos pressurizados cresce em taxa considerável, em especial na Europa, substituindo os tubos tradicionais. Nos novos ramais e redes de água de diâmetro até $110 \mathrm{~mm}$ na Europa, a participação dos tubos de polietileno é de quase $100 \%$ e vem aumentando paulatinamente nos diâmetros maiores.

Nas adutoras e captação de água com diâmetros externos chegando a $2.000 \mathrm{~mm}$, os tubos de PEAD vêm ganhando espaço no mercado antes dominado pelas tubulações de Ferro e Aço, em especial nas aplicações de baixas pressões, onde o custo desse material, comparado aos dos materiais tradicionais, já representa vantagens imediatas.

\subsection{Evolução do Uso do PEAD em Tubulações}

A história das tubulações de polietileno pode ser dividida em três gerações. A primeira se deu início por volta de 1950, com a fabricação de tubos pela empresa alemã Hoechst AG, pelo processo Ziegler de baixa pressão. Esta geração é composta por diferentes tipos de resinas chamadas, como PE 32, 40 e 50, sendo que a maioria era de baixa densidade. Estes tubos eram usados nas aplicações de transporte de fluidos em baixa/média pressões, principalmente para fins de irrigação. Nesta época também passou a ser utilizados como conduíte e eletroduto no Reino Unido. Na década de 1960, passou a ser utilizado como tubulações de drenagem pluvial de cidades e rodovias. Na década seguinte a British Gás já passou a utilizar tubulações amarela de PEAD para o transporte de gás.

Na década de 1980, com o aumento dos comonômeros e consequente aumento do peso molecular das resinas de polietileno, houve uma melhora no balanço geral das propriedades e surgiram assim o PE 63 e 80, a segunda geração das tubulações de polietileno. Eram produzidos tanto pelo método Ziegler quanto pelo Philips e em alta e média densidade. Nessa geração os tubos já começaram a ser regularizados com o surgimento de normas e padrões mais rígidos, e passaram a serem utilizados em aplicações de baixa pressão para gás e altas pressões para líquido (até 1,6 MPa). Nesta época a Inglaterra já passou utilizar tubulações de Polietileno de Alta e Média Densidade, de pigmentação azul para transporte de água potável. 
Finalmente, no começo da década de 1990, com a melhoria do processo através introdução seletiva de comonômeros nas cadeias moleculares mais longas, surge o PE 100, e com ele a terceira geração dos polietilenos. Este novo material tornou os tubos mais resistentes e permitiu sua utilização para transporte de gás sob alta pressão. (Danieletto, 2014)

O polietileno tem sido muito empregado na condução de água potável, particularmente em ramais prediais. Este polímero apresenta vantagens em relação a seus concorrentes, como flexibilidade, baixo preço, facilidade de instalação e resistência à corrosão. Apesar de sua utilização vir se tornando cada vez mais popular nos ramais prediais, os tubos de polietileno instalados podem apresentar falhas inesperadas em serviço, prematuras em relação à sua vida útil prevista, através de um mecanismo conhecido como "slow crack growth" ou crescimento lento de trincas (Peres, 2005).

O potencial do comércio de tubulações de PEAD pode ser percebido através do crescimento nos últimos anos deste mercado nas diversas regiões do mundo. Entre 2007 e 2012 houve um crescimento em todo mundo de aproximadamente $6 \%$, enquanto que em regiões como a Europa Central e Oriental esse crescimento chegou a mais de $10 \%$. Esses dados podem ser observados na tabela a seguir, retirado da pesquisa realizada pela empresa Lyondellbasell, em 2012. 
Tabela 2 - Consumo de PEAD nos anos 2007 e 2012

\begin{tabular}{|c|c|c|c|}
\hline Região & $\begin{array}{c}2007 \\
\text { (1.000 ton) }\end{array}$ & $\begin{array}{c}2012 \\
\text { (1.000 ton) }\end{array}$ & Crescimento (\%) \\
\hline Europa Ocidental & 927 & 1110 & 3 \\
\hline Europa Central e Oriental & 580 & 930 & 10 \\
\hline África & 140 & 214 & 9 \\
\hline Oriente Médio & 202 & 257 & 5 \\
\hline Japão & 88 & 92 & 1 \\
\hline Ásia & 1067 & 1597 & 8 \\
\hline NAFTA & 750 & 860 & 3 \\
\hline América do Sul & 120 & 177 & 8 \\
\hline TOTAL & 3873 & 5227 & 6 \\
\hline
\end{tabular}

Esse crescimento também pode ser observado no mercado mais amplo de polietileno, sem se restringir à resina de alta densidade e a aplicações em tubos. Entre os anos de 2007 e 2012 houve um crescimento de aproximadamente $35 \%$ no mercado europeu de polietileno, como demonstrado no gráfico a seguir:

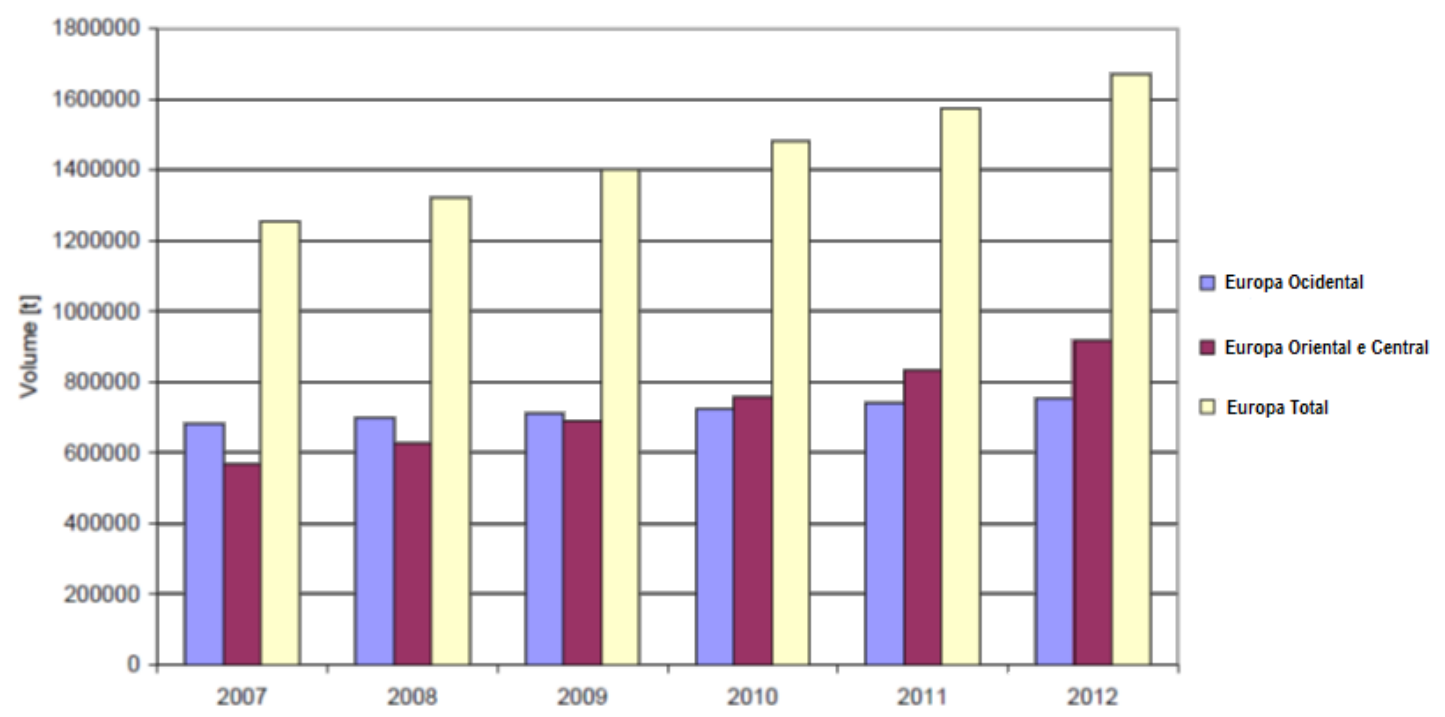

Figura 5 - Evolução do Mercado de PEAD 2007 - 2012

Fonte: Apresentação APECS (2012), apud SABIC Market Study

$\mathrm{Na}$ indústria de gás natural dos Estados Unidos, o PEAD é o material amplamente mais utilizado nas aplicações, correspondendo cerca de $95 \%$ do mercado das novas tubulações. Com relação ao mercado de distribuição de água, os tubos de polietileno dominam cerca de $65 \%$ do mercado, enquanto que mais especificamente no Reino Unido, chegam a dominar cerca de $85 \%$ do mercado de novas tubulações. Nos EUA, sua representatividade ainda é pequena, apesar do crescimento apresentado nos últimos anos (Vibien, 2009). 


\subsection{Diretrizes de Projeto para as tubulações de PEAD}

Existem diversas normas da Associação Brasileira de Normas Técnicas (ABNT) com diretrizes para uso de tubulações de PEAD na distribuição de água. São elas:

- NBR 14299:1999, Sistemas de ramais prediais de água - Tubos, conexões e composto de polietileno PE - Determinação da estabilidade dimensional;

- NBR 14300:1999, Sistemas de ramais prediais de água - Tubos, conexões e composto de polietileno PE - Determinação do tempo de oxidação induzida;

- NBR 14301:1999, Sistemas de ramais prediais de água - Tubos de polietileno PE - Determinação das dimensões;

- NBR 14302:1999, Sistemas de ramais prediais de água - Tubos de polietileno PE - Determinação da retração circunferencial;

- NBR 14303:1999, Sistemas de ramais prediais de água - Tubos de polietileno PE - Determinação da resistência ao esmagamento;

- NBR 14470:2000, Conexões de polietileno PE 80 e PE 100 - Verificação da resistência ao impacto em tês de serviço;

- NBR 14472:2000, Tubos e conexões de polietileno PE 80 e PE 100 Qualificação do soldador;

- NBR 18553:2005, Método para avaliação do grau de dispersão de pigmentos ou negro de fumo em tubos, conexões e compostos poliolefínicos;

- NBR 15593:2008, Sistemas enterrados para distribuição e adução de água e transporte de esgoto sob pressão - Requisitos para conexões soldáveis de polietileno de PE 80 e PE 100;

- NBR 8415:2007, Tubos e conexões de polietileno - Verificação da resistência à pressão hidrostática interna;

- NBR 15561:2007, Sistemas para distribuição e adução de água e transporte de esgoto sanitário sob pressão - Requisitos para tubos de polietileno PE 80 e PE 100;

- NBR 15802:2010, Sistemas enterrados para distribuição e adução de água e transporte de esgoto sob pressão - Requisitos para projetos em tubulação de polietileno PE 80 e PE 100 de diâmetro externo nominal entre 63 mm e 1600 $\mathrm{mm}$; 
- NBR 15803:2010, Sistemas enterrados para distribuição e adução de água e transporte de esgoto sob pressão - Requisitos para conexões de compressão para junta mecânica, tê de serviço e tê de ligação para tubulação de polietileno de diâmetro externo nominal entre 20 mm e 160 mm;

- NBR 9056:2015, Tubo de polietileno PE5 para ligações prediais de água Verificação da estanqueidade de juntas mecânicas com tubos curvados a frio;

- NBR 9057:2015, Tubo de polietileno PE5 para ligações prediais de água Verificação da resistência de junta mecânica a esforço axial.

Como pode ser observado na lista anterior, as primeiras normas brasileiras sobre polietileno se tratavam exclusivamente de ramais prediais, sendo somente em 2007 que surgem as normas para tubulações de polietileno para redes e adutoras de água.

Dentre as normas listadas acima, podemos destacar algumas que tratam mais especificamente dos projetos e obras com tubulações de PEAD.

A norma ABNT NBR 15802, que trata de requisitos para projetos em tubulações de PEAD, enumera diversas especificações e recomendações para projetos e obras em adutoras e redes de distribuição de água com este tipo de material, de diâmetros externos nominais entre $63 \mathrm{~mm}$ e $1.600 \mathrm{~mm}$. Traz informações sobre o dimensionamento de tubos PE 80 e 100, contendo considerações sobre a máxima pressão de operação, dimensionamento hidráulico, sobrepressões, subpressões e transientes hidráulicos. Também traz informações sobre as alturas de aterro, métodos de uniões e conexões, transição de materiais e curvas e mudanças de direções.

Já a norma ABNT NBR 15803 versa mais especificamente das conexões de junta mecânica, tê de serviço e tê de ligação, de diâmetro entre $20 \mathrm{~mm}$ e $160 \mathrm{~mm}$. Traça diretrizes sobre os tipos de conexão, resistência à pressão hidrostática e esforço axial, estanqueidade em tubo curvado a frio, resistência ao impacto, aspectos visuais, entre outros. Além disso, traz informações sobre controle do processo de fabricação e marcação e embalagem.

A norma ABNT NBR 15593 trata das conexões soldáveis de PE 80 e PE 100. Traz informações sobre classificação das conexões, dimensões e tolerâncias, conexões 
segmentadas e do tipo ponta, conexões de eletrofusão do tipo bolsa e sela, juntas de transição, entre outros. A norma apresenta também informações sobre controle do processo de fabricação, inspeção de recebimento, requisitos do material e marcação, rotulagem e embalagem.

\subsection{Tipos de Conexão}

Além das conexões mecânicas por compressão, os termoplásticos permitiram o desenvolvimento de técnicas de soldagem denominadas por termofusão e eletrofusão, devido a suas propriedades características de se fundirem sob determinadas temperaturas e pressões, podendo ser moldados e resfriados na forma desejada e serem remoldados a novos ciclos de temperatura e pressão. (Danieletto, 2014)

\subsubsection{Conexão de Compressão}

Constituída por bolsa, anel de vedação, uma garra (normalmente de metal) e uma porca. Este tipo de conexão "morde" o tubo, sendo capaz de resistir de tração.

É utilizado em tubulações de pequenos diâmetros, sendo encontrada geralmente de diâmetros entre DE 12 a 110 mm, mas pode ser encontrado também em DE 160 $\mathrm{mm}$. É empregado principalmente para fins de irrigação e ramais prediais, mas também pode ser utilizado em redes de distribuição de água até PN 16.

São de fácil instalação e uma boa alternativa para reparos, em especial quando não se consegue estancar totalmente a tubulação para executar a solda. Não exigem pessoal de alta qualificação, nem ferramentas e equipamentos caros e elétricos. Por serem autotravados, não necessitam ancoragem, adequando-se a terrenos inconsistentes e linhas aéreas. (Danieletto, 2014).

A figura a seguir mostra o esquema de uma conexão típica por compressão e seus componentes. Vale ressaltar que existe uma infinidade de outros moldes de conexão por compressão no mercado, como cotovelos, redução, tê, adaptador macho e adaptador fêmea, todos com configurações diferentes porém com os mesmo componentes para a união. 


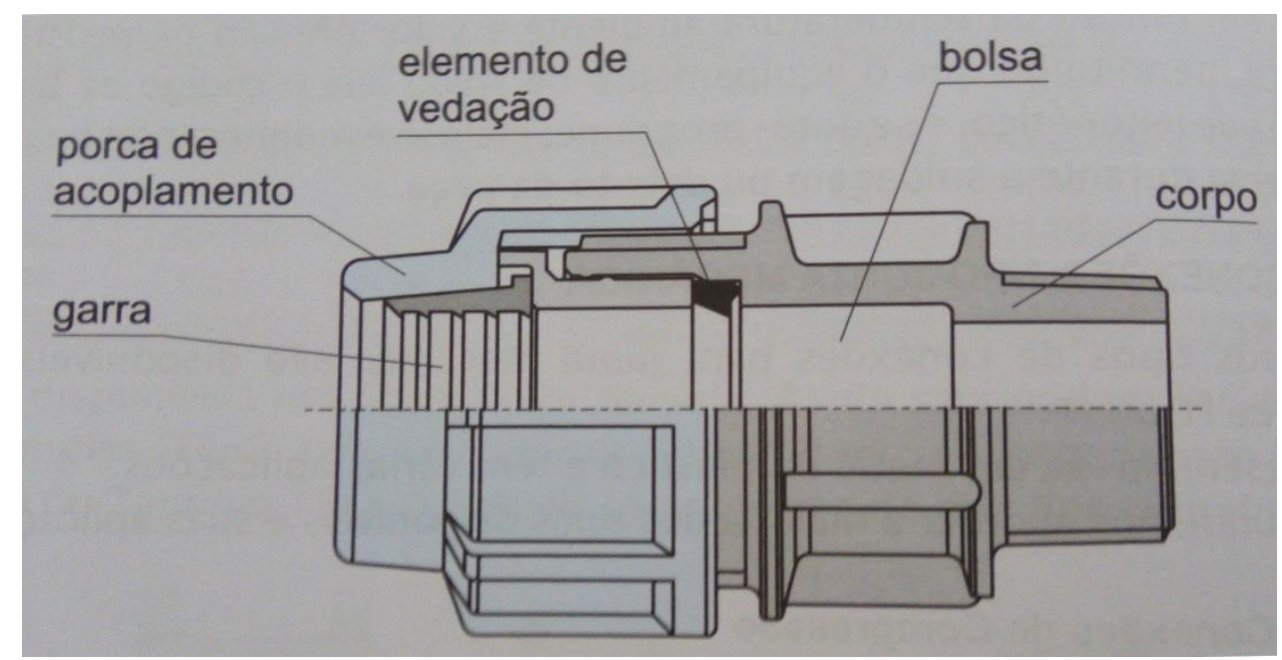

Figura 6 - Componentes das Conexões de Compressão

Fonte: Danieletto (2014)

\subsection{2. $\underline{\text { Conexão de Termofusão }}$}

É o tipo de união mais utilizado nas redes e adutoras de água em PEAD. Também conhecido com "solda topo", por soldar face a face as tubulações, é aplicada mais comumente em tubulações de diâmetros maiores ou iguais a DE 63. Este tipo de conexão permite a união de resinas diferentes, como PE 80 com PE 100, porém é necessário que seja da mesma espessura (ou SDR).

$\mathrm{Na}$ solda de termofusão são necessários equipamentos para a correta elaboração da união, tais como: abraçadeiras, unidade de força, faceador, placa de solda e transformador de tensão.

A termofusão pode ser divida em quatro etapas:

- A preparação, que compreende:

$\checkmark$ Alinhamento dos tubos e/ou conexões;

$\checkmark$ Limpeza das superfícies de solda;

$\checkmark$ Faceamento das extremidades de solda, assegurando $o$ perfeito paralelismo das partes e a remoção de possível camada oxidada;

$\checkmark$ Determinação da pressão de arraste.

- $O$ aquecimento que objetiva que o material atinja a temperatura de fusão apropriada; 
- A solda que consiste na compressão das tubulações e/ou conexões. A pressão de solda deve ser mantida até que a temperatura caia abaixo da temperatura de fusão do material.

- O resfriamento, que ocorre ainda com pressão elevada e depois zerando a pressão, mas mantendo o conjunto imóvel.

A seguir temos a Figura 7, representando a preparação para a solda topo, com as tubulações, abraçadeiras e o faceador, enquanto que Na Figura 8 temos uma representação de uma união por solda topo realizada com sucesso.

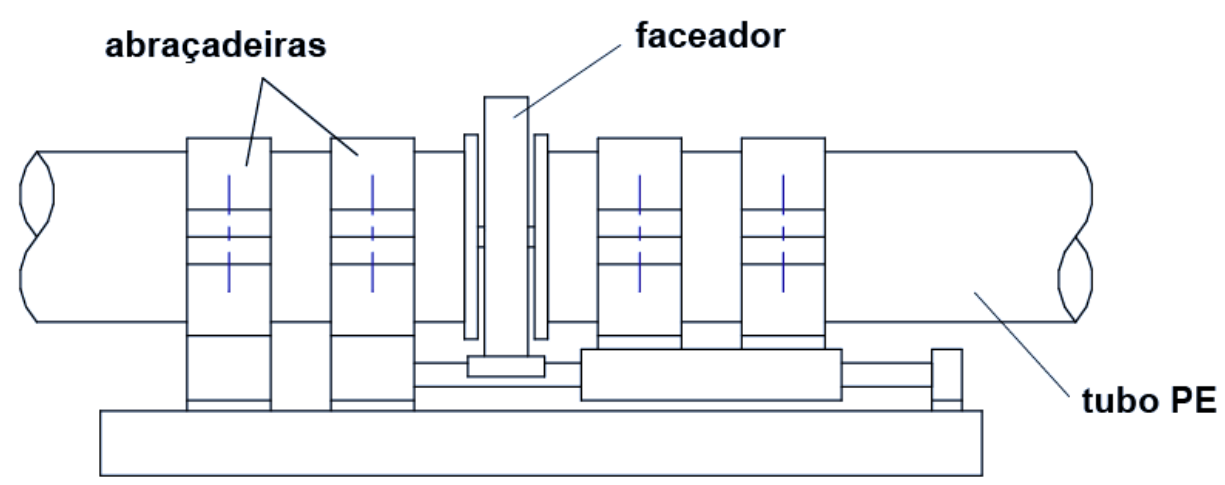

Figura 7 - Alinhamento e Faceamento da Solda Topo

Fonte: Apresentação ABPE (2012)

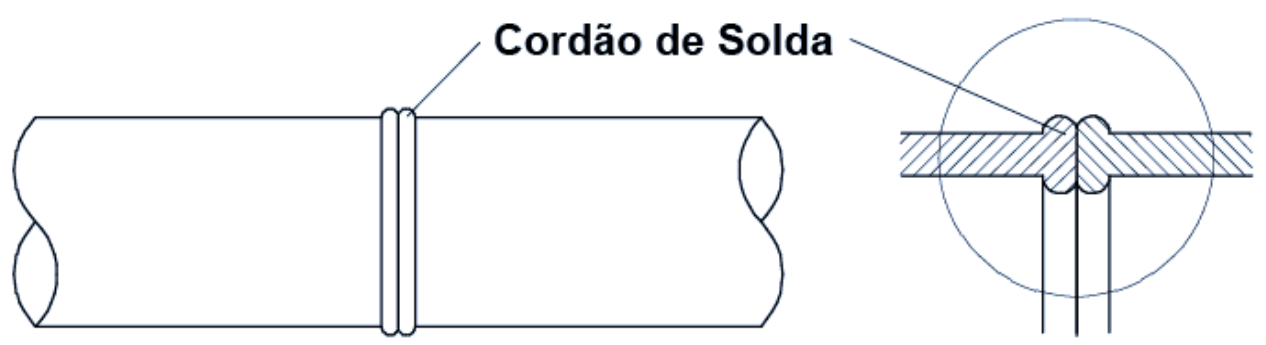

Figura 8 - União por Solda Topo

Fonte: Apresentação ABPE (2012)

Também existe o subtipo de conexão por termo fusão do tipo sela, que se trata de uma conexão injetada ou usinada, que possui uma base em forma de sela, que se assenta sobre o tubo. Por meio de um dispositivo térmico de aquecimento, funde-se o material da base da conexão e o da superfície externa do tubo, a seguir comprimese a peça contra o tubo, provendo-se a interação das massas fundidas até que resfriem. 


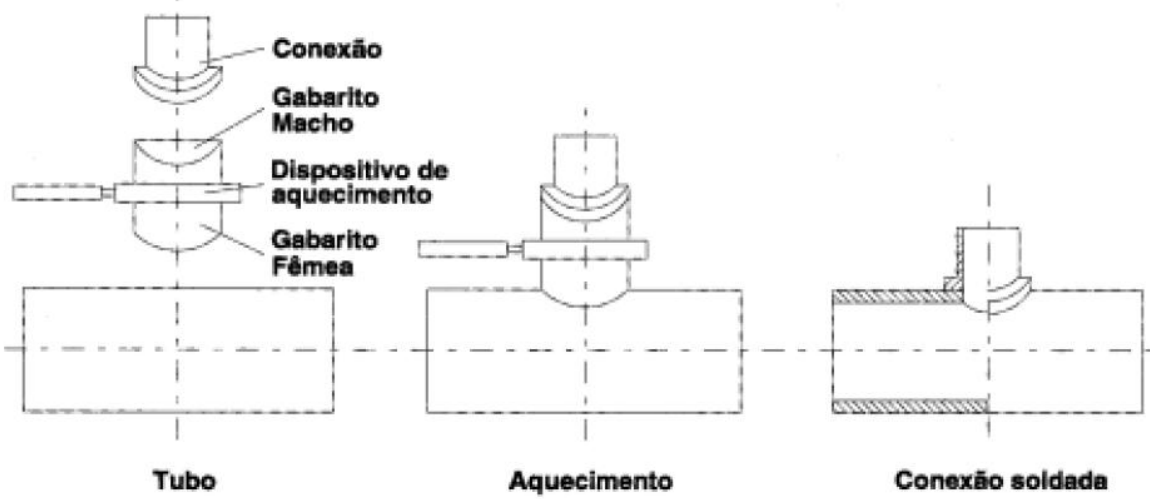

Figura 9 - União por Solda tipo Sela

Fonte: Manual Técnico do Polietileno - Brastubo

Devido a sua grande dependência do soldador e criticidade, foi abandonada para redes de água e gás, em quase todo mundo, estando praticamente restrita às fabricações de peças especiais, como alguns tês de redução, onde não houver outras opções.

\subsubsection{Conexão de Eletrofusão}

Surgida na década de 70, começou a ganhar impulso na segunda metade do da década de 80 e vem crescendo muito no mercado de gás e água, devido sua praticidade e custos. Em termos gerais, em comparação com a termofusão, essa aplicação é mais fácil, com menor margem de erro de execução, porém é mais cara. Apresenta grande segurança, facilidade de execução e rastreabilidade com as máquinas automáticas, através de códigos de barras nas tubulações e conexões, capazes de serem lidas e cadastradas instantaneamente por sistemas automatizados

Os custos deste tipo de conexão vêm diminuindo nos últimos anos. Nos menores diâmetros, já se torna mais viável em determinadas situações que a solda de termo fusão. É disponível em diâmetro DE 20 a 1.000 mm, entretanto é mais comum nos diâmetros menores ou iguais a DE 160 devido aos custos e disponibilidade de peças e tubulações.

Emprega conexão provida de bolsa (ou sela) com resistência elétrica espiralada incorporada, cujas extremidades são conectadas a terminais que se localizam na parte externa da peça que, quando submetidas à corrente elétrica e tempo, geram 
calor a fim de possibilitar a solda da peça ao tubo com a superfície externa da tubulação.

Este método exige um transformador de tensão e um timer, além da peça própria de eletrofusão. O controle é maior neste tipo de união, visto que em cada peça existe um código de barra que comunica com o equipamento de solda o tempo, temperatura e tensão.

A tensão aplicada na peça gera uma corrente elétrica na resistência inserida dentro da peça que funde a superfície interna da peça com a superfície externa da tubulação.

Neste método também é necessário realizar o faceamento e verificar a ovulação das tubulações. A Figura 10 mostra esquematicamente o processor de uma união por eletrofusão.

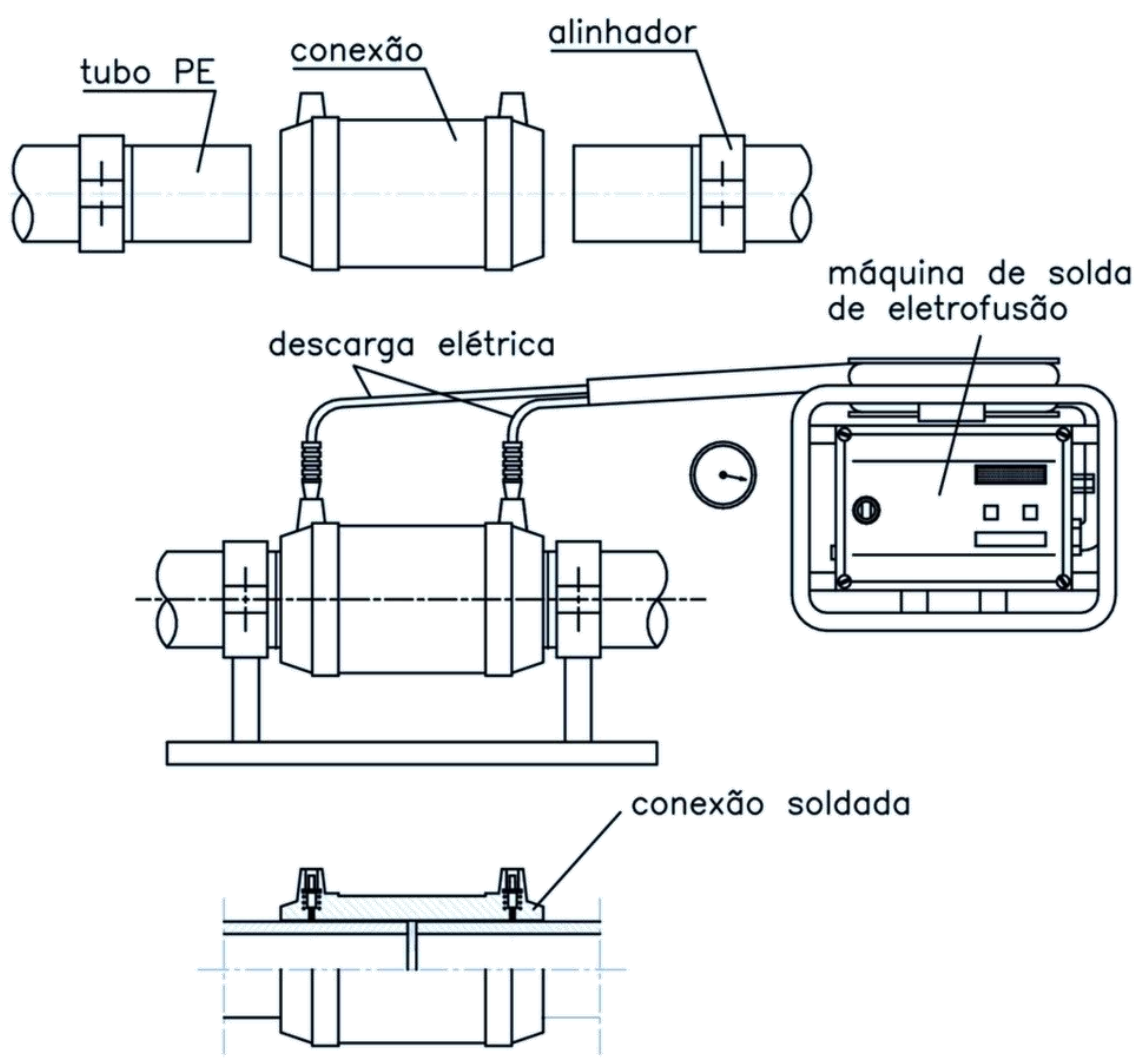

Figura 10 - União por Eletrofusão

Fonte: Apresentação ABPE (2012) 


\subsubsection{Juntas de Transição}

A forma mais comum encontrada de transição entre tubulações de polietileno para ferro fundido ou aço é a transição por flange. Neste tipo, se usa uma tubulação de polietileno de colarinho longo, que é comprimida entre dois flanges de ferro fundido ou aço, realizando assim a transição.

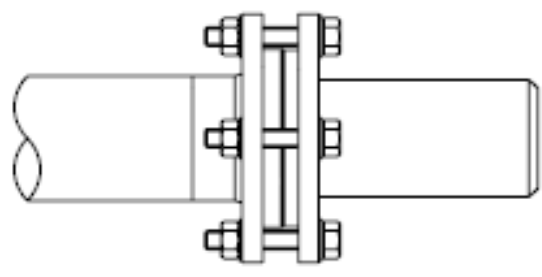

tubo PE e PP $\times$ tubo aço / FoF / PVC / PRFV / etc.

Figura 11 - Transição com Flanges e Colarinho

Fonte: Catálogo Polyeasy

É também possível realizar a transição através de peças adaptadoras como as Ultralink e Ultraquick, capazes de se travar mecanicamente em pontas de tubos de vários materiais.

Existem outras formas de transição como peças especiais de juntas de transição PE X AÇO e PE X LATÃO, contudo são mais utilizadas nas linhas de gás.

\subsection{Dimensionamento Hidráulico}

Nos cálculos e modelagem hidráulica de redes deve-se adotar o diâmetro interno da tubulação de PEAD, ou seja, subtrair do diâmetro nominal externo duas vezes a espessura da parede do tubo.

$$
D I=D E-2 e
$$

Onde:

$\mathrm{DI}$ = Diâmetro interno da tubulação $(\mathrm{mm})$;

$\mathrm{DE}=$ Diâmetro externo e nominal da tubulação $(\mathrm{mm})$;

$\mathrm{e}=$ espessura da parede da tubulação $(\mathrm{mm})$. 
Sobre o cálculo de perda de carga distribuída nas tubulações, a norma ABNT NBR 15802 indica o uso da fórmula Universal ou a de Hazen-Williams, tanto para PE 80 como para PE 100, descritas da forma a seguir para a água, no escoamento turbulento rugoso:

Fórmula da Hazen-Wiliams:

$$
\Delta H=10,643 \cdot Q^{1,85} \cdot C^{-1,85} \cdot d^{-4,87} \cdot L
$$

Onde:

$\Delta \mathrm{H}=$ Perda de carga $(\mathrm{m})$

$\mathrm{Q}=\operatorname{Vazão}\left(\mathrm{m}^{3} / \mathrm{s}\right)$

$\mathrm{C}=$ Coeficiente de Hazen-Wiliams

$\mathrm{d}=$ Diâmetro interno $(\mathrm{m})$

$\mathrm{L}=$ Comprimento do tubo $(\mathrm{m})$

Fórmula Universal:

$$
\Delta H=\frac{f \cdot v^{2} \cdot L}{d .2 g}
$$

Onde:

$\Delta \mathrm{H}=$ Perda de carga $(\mathrm{m})$

$f=$ Fator de atrito

$\mathrm{v}=$ Velocidade média $(\mathrm{m} / \mathrm{s})$

$\mathrm{L}=$ Comprimento do tubo $(\mathrm{m})$

$\mathrm{d}=$ Diâmetro interno $(\mathrm{mm})$

$\mathrm{g}=$ aceleração da gravidade $\left(\mathrm{m} / \mathrm{s}^{2}\right)$

Ainda segundo a norma ABNT NBR 15802, deve-se adotar para a fórmula de Hazen-Wiliams o coeficiente $C=150$. Já para a fórmula Universal, é necessário um cálculo de $f$ através de fórmulas e do coeficiente de rugosidade $(k)$. Para o regime 
turbulento onde o número de Reynolds (Re) é maior que 2000, caso encontrado na grande maioria das adutoras e redes de água em operação, tem-se para o cálculo de f, no escoamento turbulento rugoso, de acordo com Souza (1986):

$$
\frac{1}{\sqrt{f}}=-2,0 \cdot \log \left(\frac{2,51}{R e \cdot \sqrt{f}}+\frac{k}{3,71 \cdot d}\right)
$$

Ou da forma simplificada, sem necessidade de interações, e com valores bem próximos de resultados empíricos:

$$
f=\left[\frac{1}{-2,0 \cdot \log \left(\frac{k}{3,71 . d}+\frac{5,62}{R e^{0,9}}\right)}\right]^{2}
$$

Onde:

$\mathrm{k}=$ Coeficiente de rugosidade $(\mathrm{m})$

$\mathrm{d}=$ Diâmetro interno $(\mathrm{m})$

$R e=$ Número de Reynolds

Para o cálculo, a norma ABNT NBR 15802 sugere a adoção de $k=10 \times 10^{-6} \mathrm{~m}$, quando do diâmetro externo for menor ou igual a $200 \mathrm{~mm}$, e $\mathrm{k}=25 \times 10^{-6} \mathrm{~m}$ quando o diâmetro externo for maior que $200 \mathrm{~mm}$.

A tabela seguir mostra os valores de coeficientes hidráulicos sugeridos na norma:

Tabela 3 - Coeficiente de Perda de Carga

\begin{tabular}{|c|c|c|}
\hline Método & \multicolumn{2}{|c|}{ Valores } \\
\hline Hazen-Wiliams & \multicolumn{2}{|c|}{$\mathrm{C}=150$} \\
\hline \multirow{2}{*}{$\begin{array}{c}\text { Fórmula } \\
\text { Universal }\end{array}$} & $\mathrm{DE} \leq 200 \mathrm{~mm}$ & $\mathrm{k}=10 \times 10^{-6} \mathrm{~m}$ \\
\cline { 2 - 3 } & $\mathrm{DE}>200 \mathrm{~mm}$ & $\mathrm{k}=25 \times 10^{-6} \mathrm{~m}$ \\
\hline
\end{tabular}

A norma diz ainda que não há qualquer diferenciação entre os métodos de dimensionamento para os tipos PE 80 e PE 100 e que não é necessário considerar a redução da capacidade hidráulica devido ao envelhecimento e esclerosamentos por incrustações, abrasão, corrosão etc. 


\subsection{Comportamento Estrutural das Tubulações de PEAD}

As propriedades mecânicas do PEAD são muito influenciadas por fatores estruturais como massa molecular, distribuição de massas moleculares, quantidade e extensão das ramificações, densidade das moléculas de união, cristanilidade, estrutura morfológica e orientação (BOENIG, 1973); (OGORKIEWICZ, 1974); (BILLMEYER, 1975); (MORTON-JONES, 1989); (BROWN et al, 1991); (HERTZBERG, 1995); (KINLOCH \& YOUNG, 1995); (MEYERS \& CHAWLA, 1999); (CALLISTER, 2000); (COUTINHO et al, 2003); (PERES, 2005).

O estudo das propriedades físicas e das características de processamento de qualquer tipo de polietileno requer o entendimento da influência e importância desses fatores. Brown et al (1991) apresentaram uma revisão de trabalhos realizados, nos quais foram estabelecidas relações quantitativas entre variáveis externas (tensão, temperatura), parâmetros de mecânica da fratura (fator de intensidade de tensão, $\mathrm{K}$, Integral J), variáveis morfológicas (densidade, tamanho de cristal), variáveis moleculares e estruturais (massa molecular, densidade e distribuição de ramificações), taxa de crescimento de falhas e tempo de falha através do mecanismo de crescimento lento de trincas (BROWN et al, 1991); (PERES, 2005).

A maioria dos materiais de construção convencionais tem um comportamento elástico ou quase elástico do ponto de vista de resistência, ou seja, aplica-se a lei de Hook para sua análise estrutural. Isso significa que a relação entre tensão e deformação é linear até um determinado nível de tensão e também é independente do tempo de duração e da temperatura a níveis práticos. Retirando a força ou a carga aplicada, o material volta à sua forma original.

Para plásticos, porém, as condições são diferentes. A deformação não é proporcional à tensão, nem independente da sua duração. Sob ação de uma carga, ocorre o escoramento do material (creep), o qual também é influenciado pela temperatura, e cuja consequência final é a ruptura do material após um determinado tempo. Esse tempo, entretanto, é inversamente proporcional à magnitude da carga, e portanto a tensão admissível de dimensionamento dependerá da vida útil esperada para um aplicação específica. 
A consequência do creep é que, independente da magnitude da tensão, o material entrará em colapso depois de certo tempo. Este tempo, entretanto, varia inversamente com o valor da tensão e é precisamente isto que permite a utilização do plástico como material de construção. A tensão de projeto de materiais plásticos de construção depende, portanto, da vida útil desejada na aplicação. Para tubos de água sob pressão, as Normas ISO recomendam vida útil de 50 anos (vida útil de projeto), em função de fatores econômicos envolvidos na prestação envolvidos da prestação de serviços públicos (2\% de depreciação/ano). (DANIELETTO, 2014)

As condições de fabricação do tubo são muito importantes. A taxa de extrusão e a velocidade de resfriamento controlam, entre outros aspectos importantes, a orientação molecular e o grau de cristalinidade. Se o resfriamento foi lento, por exemplo, haverá tempo suficiente para que um maior número de cadeias possam ser ordenadas nos cristalitos. Consequentemente, o grau de cristalinidade e a densidade serão maiores, com significativos reflexos sobre as propriedades que dependem desses fatores, como resistência a tração, dureza, rigidez, contração, etc (WIEBECK \& HARADA, 2002); (LU et al, 1994); (PERES, 2005).

\subsection{Transitório Hidráulico}

Em grande parte dos projetos de sistemas de distribuição de água, principalmente nos de pequena extensão e diâmetro, o regime transitório é muitas vezes negligenciado. Entretanto a busca pela máxima eficiência na prestação de serviços por parte destes sistemas tem motivado o tratamento mais cuidadoso deste fenômeno na fase de projeto e posteriormente na operação de tais sistemas, para que seja possível prevenir danos nos diversos componentes advindos de condições operacionais inadequadas.

O transitório hidráulico, também chamado de golpe de aríete, é o fenômeno que ocorre durante a mudança entre diferentes regimes permanentes de escoamento. SANTOS (2000) define transitório como qualquer alteração no movimento ou paralisação eventual de um elemento do sistema. Após a ocorrência da perturbação, como o desligamento de uma bomba, o regime permanente presente antes da perturbação é alterado, dando origem a um regime não permanente que posteriormente passará a um novo estado estacionário. 
Nele, a vazão e pressão em certo ponto se alteram muito rapidamente com o tempo, o que o torna uma matéria de difícil análise e modelagem, e também por isso, é muitas vezes negligenciado em diversos trabalhos e estudos hidráulicos. Simplificadamente, a sobrepressão máxima para um fechamento brusco de válvula ou parada de bomba para água e comportamento elástico, pode ser expressa por:

$$
\Delta P=\frac{\text { a. } \Delta \mathrm{v}}{g}
$$

Onde: $\Delta \mathrm{P}=$ Sobrepressão máxima devido ao golpe $(\mathrm{m})$

$\Delta \mathrm{V}=$ Variação da velocidade média do fluido $(\mathrm{m} / \mathrm{s})$

$\mathrm{g}$ = Aceleração da gravidade $\left(\mathrm{m}^{2} / \mathrm{s}\right)$

$\mathrm{a}=$ Velocidade de propagação da onde de pressão (celeridade) $(\mathrm{m} / \mathrm{s})$

Para Martins (2013), a onda de pressão, característica do Golpe de Aríete, é uma onda do tipo elástica, com celeridade de propagação expressa em termos das propriedades físicas citadas, do diâmetro interno do tubo e da espessura da parede, cuja expressão analítica é:

$$
a=\frac{\sqrt{\frac{K}{\rho}}}{\sqrt{1+\frac{K}{A} \cdot \frac{\Delta A}{\Delta p}}}
$$

Onde: $\mathrm{a}=$ Velocidade de propagação da onde de pressão (celeridade) (m/s)

$\mathrm{K}=$ Módulo de elasticidade volumétrico do fluido $(\mathrm{Pa})$

$\rho=$ Massa específica do fluido $\left(\mathrm{kg} / \mathrm{m}^{3}\right)$

$A=$ Área da seção transversal da tubulação $\left(\mathrm{m}^{2}\right)$

$\Delta \mathrm{A}=$ Variação da área da seção transversal da tubulação $\left(\mathrm{m}^{2}\right)$

$\Delta \mathrm{p}=$ Variação da pressão $(\mathrm{Pa})$

O numerador da equação acima representa fisicamente a celeridade de onda elástica (velocidade do som) no meio fluido considerado infinito, isto é, sem fronteiras. 
Para LIMA (2006) é importante lembrar que apesar de ser uma expressão que envolve as propriedades físicas do tubo e do fluido, e os parâmetros geométricos do tubo, a celeridade de onda elástica é, em si, uma propriedade física, não dependendo, portanto, das condições do escoamento, ou melhor, das variáveis pressão e velocidade e das variáveis independentes posição e tempo.

Segundo SILVA (2006), observa-se que a variação de carga é diretamente proporcional à celeridade de onda "a", o que permite considerar que uma diminuição no valor da característica "a" provocará redução imediata no valor da variação de carga " $\Delta H$ ", como pode ser observado pela fórmula 2.6. Essa conclusão tem sido objeto de pesquisas na busca de uma solução prática, utilizando materiais que proporcionem modificações nas características do meio fluido, tal que resulte na diminuição do valor de celeridade da onda (atenuador de celeridade) que, associada a um meio de controle, possa ser aplicada nos projetos hidráulicos como dispositivo de proteção contra o golpe de aríete.

O golpe de aríete é um tanto maior em magnitude quanto maior a velocidade média do fluido e maior a distância entre o golpe e a fonte do mesmo. O golpe de aríete é em si mesmo um assunto bastante complexo. Nos casos de tubos plásticos, essa complexidade aumenta porque as equações utilizadas para os tubos rígidos devem ser adaptadas, devido à grande flexibilidade das paredes dos tubos plásticos, o que permite desprezar a compressibilidade da água, e também devido à variação do módulo de elasticidade com o tempo. De uma forma geral, os tubos plásticos absorvem (diminuem) melhor o efeito do golpe de aríete em virtude de sua flexibilidade (DANIELETTO, 2014).

Contudo, de acordo com SHIROMOTO (2005), as tubulações de PEAD merecem cuidados especiais pois são susceptíveis à redução de resistência por efeitos térmicos e dinâmicos (fadigas). É necessário avaliar se, em tais condições, com a intermitência operacional, o tubo de PEAD poderá romper por fadiga, após um curto período de operação. Os tubos plásticos tem limitada resistência às solicitações cíclicas, e por esta razão devem operar com cargas controladas. 


\subsection{Resistência Química e à Abrasão}

A temperatura ambiente, os polietilenos são considerados como praticamente inertes à maioria dos produtos químicos comuns, mas quando expostos à solventes em temperaturas mais elevadas pode ocorrer inchamento, dissolução parcial ou degradação do material. Apesar de altamente resistente à água e algumas soluções aquosas, inclusive a altas temperaturas, o polietileno é atacado lentamente por agentes oxidantes. (OGORKIEWICZ, 1974) (COUTINHO et al, 2003); (PERES, 2005). Em especial, é importante considerar a presença de cloro na água, o qual é usado como agente desinfetante e mantido em níveis residuais e baixas concentrações e lembrar que normalmente o sistema é pressurizado (há tensões atuando no material). Bodycote Polymer $\mathrm{AB}$, um laboratório de teste de tubos plásticos independente, localizado em Nyköping, Suécia, tem desenvolvido estudos sobre o efeito da água clorada na vida útil dos tubos plásticos, tendo verificado que pequenas quantidade de cloro provoca forte efeito oxidante sobre tubos fabricado com poliolefinas (o polietileno é um tipo de poliolefina), com significativa redução da vida útil esperada (BODYCOTE, 2003); (PERES, 2005).

Os tubos metálicos são sensíveis não só a ataques químicos como à corrosão eletrolítica. Quanto à corrosão química, esses tubos sofrem até mesmo o ataque de efluentes comuns encontrados na engenharia sanitária. Já os tubos de PE não sofrem corrosão eletrolítica ou galvânica.

Para os usos mais comuns, ou mesmo para a maioria dos produtos considerados perigosos para outros tubos, o PE pode ser considerado material praticamente imune ao ataque químico. Somente materiais não voláteis ou pouco voláteis podem causar danos permanentes, uma vez que as propriedades originais reaparecem após a evaporação do agente inchante.

Nas tubulações que transportam sólidos abrasivos, o desgaste por abrasão é um fator de maior importância. Isto ocorre nos tubos de dragagem, nos minerodutos, cinzodutos e em todos os casos de transporte hidráulicos de sólidos em tubulações. Em engenharia sanitária, embora em menor escala, a abrasão também ocorre, especialmente em tubos de esgoto. 
No tocante à abrasão, testes conduzidos por diferentes pesquisadores indicaram para os tubos de PEAD uma resistência bastante elevada, muito superior à de materiais convencionais (DANIELETTO, 2014).

O Prof. Lars-Erik Janson do Instituto Real de Tecnologia de Estocolmo, no seu livro "Plastic Pipe in Sanitary Engineering", tem reunido os resultados de várias pesquisas relacionadas com abrasão em tubulações, e converteu o desgaste em um aumento equivalente de tensões na parede do tubo, para os seguintes tipos de materiais: 


Tabela 4 - Abrasão de Tubos de Diversos Materiais
\begin{tabular}{|c|c|}
\hline Material & $\begin{array}{c}\text { Aumento Relativo } \\
\text { da Tensão, em \% }\end{array}$ \\
\hline Cimento Amianto & 13 \\
\hline Aço & 7 \\
\hline PVC & 3 \\
\hline PEAD & 0,3 \\
\hline
\end{tabular}

Observa-se em testes para a avaliação de falhas prematuras de tubos de polietileno que, sob certas condições de temperatura, o tempo para ocorrência de falhas é sensível a meio hostis (agente químico polares e/ou oxidantes, álcoois, detergentes, halogêneos e aromáticos), mesmo estando o material submetido a tensões relativamente baixas, mas por longo períodos de tempo, sugerindo suscetibilidade dos tubos de polietileno ao environment-assisted cracking (EAC) ou environment stress cracking (ESC). Trata-se de mecanismo de crescimento subcrítico de trincas, que descreve a falha acelerada de um material devido a ação cooperativa ou combinada de exposição ao meio e à tensão (HERTZBERG, 1995); (PERES, 2005).

\subsection{Perdas em Sistemas de Abastecimento de Água}

O entendimento elementar do conceito de "perdas de água" é a diferença do volume de água tratada que foi produzida e o volume de água dos consumos autorizados, usualmente medidos nos hidrômetros dos consumidores finais. Essa noção aborda a perda como algo físico, contudo, a água tratada se refere a um produto industrializado, com mais valores agregados e custos intrínsecos de produção.

Elevadas perdas produzem impactos negativos de diversas naturezas, tais como: no meio ambiente (maior demanda de água, esgotamento de mananciais); nos custos (maior necessidade de investimentos em novas instalações de produção e de distribuição de água, maiores custos operacionais no tratamento); nas receitas (redução do faturamento) (REVISTA BRASILEIRA DE SANEAMENTO AMBIENTAL E MEIO AMBIENTE, 2003); (PERES, 2005).

As perdas de um sistema de abastecimento são fatores importantes para os consumidores nas tarifas pagas às prestadoras de serviço de distribuição de água potável, pois geralmente seus custos são incorporados na composição do preço das contas de água. 
Segundo Tsutiya (2006), Perda Física correspondente ao volume de água produzido que não chega ao consumidor final, devido à ocorrência de vazamentos nas adutoras, redes de distribuição e reservatórios, bem como de extravasamentos em reservatórios setoriais. De acordo com a nova nomenclatura definida pela International Water Association - IWA, esse tipo de perda denomina-se Perda Real.

Perda Não-Física, corresponde ao volume de água consumido, mas não contabilizado pela companhia de saneamento, decorrente de erros de medição nos hidrômetros e demais tipos de medidores, fraudes, ligações clandestinas e falhas no cadastro comercial. Nesse caso, então, a água é efetivamente consumida, mas não é faturada. De acordo com a International Water Association (IWA), esse tipo de perda denomina-se Perda Aparente.

\subsubsection{Perda Real}

Com relação à Perda Real, pode-se dizer que os volumes perdidos nos vazamentos carregam consigo os custos de produção e transporte da água tratada, tais como os custos de energia elétrica, produtos químicos, mão de obra, etc. Vale ressaltar dois pontos de extrema importância em relação a este tipo de perda:

- O primeiro relacionado à conservação de recursos naturais, pois quanto menos volume se perde no sistema, menor é a necessidade de explorar ou ampliar as captações de água, acarretando menor impacto ambiental. Podese argumentar que as Perdas Reais recarregam o lençol freático, o que é fato, mas isso não parece uma forma adequada de gestão de recursos hídricos, na medida em que para atender à crescente demanda de água tratada, é requerida a execução de obras com elevado custo e com forte impacto ambiental, representadas por barragens, represas, importação de águas de outras bacias, etc.

- O segundo ponto diz respeito à saúde pública, em decorrência da existência de vazamentos na rede de distribuição de água, onde qualquer despressurização do sistema (manutenção ou intermitência no abastecimento, por exemplo) pode levar à contaminação da água pela entrada de agentes nocivos na tubulação. Este risco não é meramente potencial, há diversos casos relatados, inclusive em países do Primeiro Mundo, de mortes ou doenças ocasionadas por contaminação de redes 
através de pontos de vazamento após despressurização (Martins, 2001); (Tsutiya, 2006).

Mais especificamente a respeito dos vazamentos em ramais e redes, a Sabesp adota a seguinte classificação:

- Vazamentos Inerentes: são vazamentos não-visíveis e não-detectáveis por equipamentos de detecção acústica. Ações contra este tipo de vazamento são: redução de pressão, qualidade dos materiais e da execução da obra e redução do número de juntas;

- Vazamentos Não-Visíveis: são vazamentos que não afloram à superfície, detectáveis por métodos acústicos de pesquisa. Ações contra este tipo de vazamento são: redução de pressão e pesquisa de vazamentos não-visíveis;

- Vazamentos Visíveis: são vazamentos que afloram à superfície, comunicados pela população e/ou detectados. Ações contra este tipo de vazamento são: redução de pressão e redução do tempo de reparo.

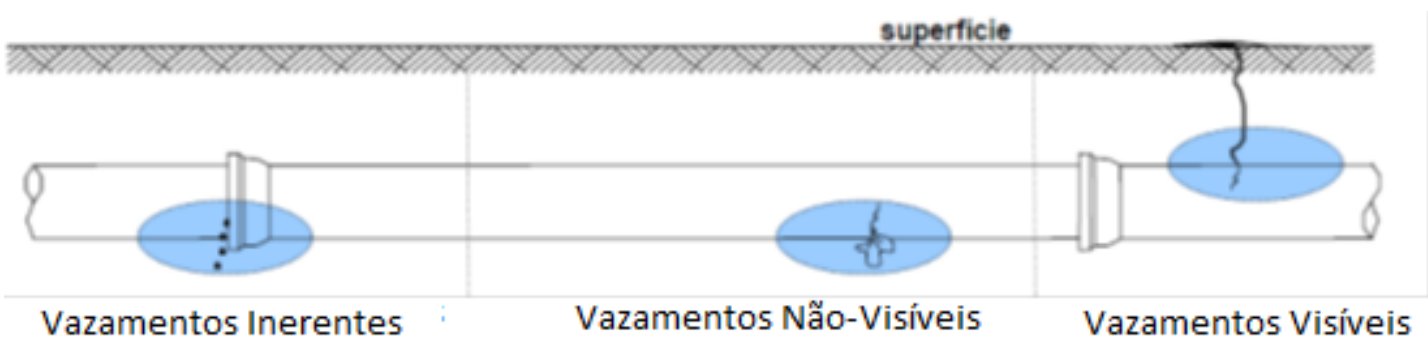

Figura 12 - Tipo de Vazamentos em Redes

Fonte: Sabesp, 2006

\subsubsection{Perda Aparente}

Nas Perdas Aparentes a volume de água é consumido, porém seu valor não é faturado pela prestadora de serviços. São perdas não-físicas, decorrentes de submedição nos hidrômetros, fraudes e falhas do cadastro comercial. Grande parte desta parcela de perda acontece nas ligações irregulares de favelas e áreas invadidas.

Os custos envolvidos neste tipo de perda são relativos ao preço de venda da água no varejo, ou seja, correspondem ao valor pago pelo consumidor de acordo com a política tarifária de cada companhia. 
A seguir temos fotografias que ilustram alguns dos tipos de fraudes mais comuns. A Figura 13 é foto de um by-pass realizado no cavalete, a Figura 14 é uma adulteração com prego no hidrômetro e a Figura 15 mostra várias ligações irregulares em favelas.

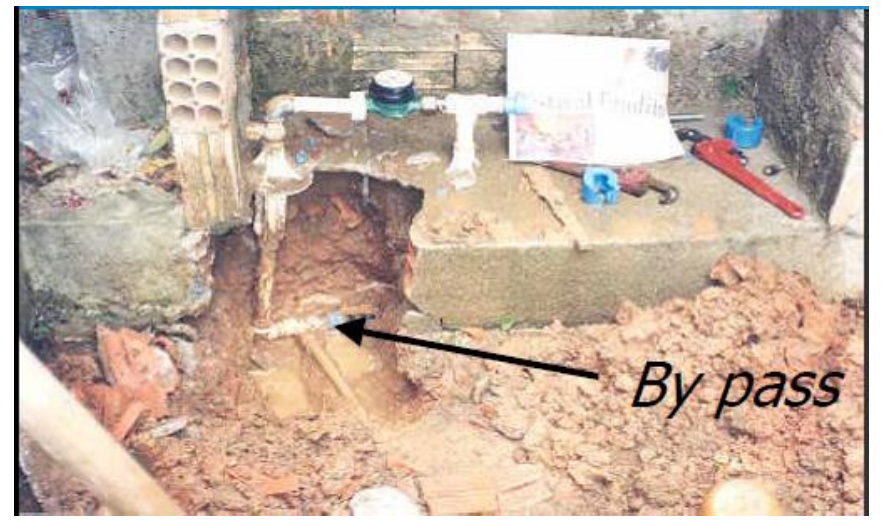

Figura 13 - Fraude de By-Pass no Cavalete

Fonte: SABESP (2006)

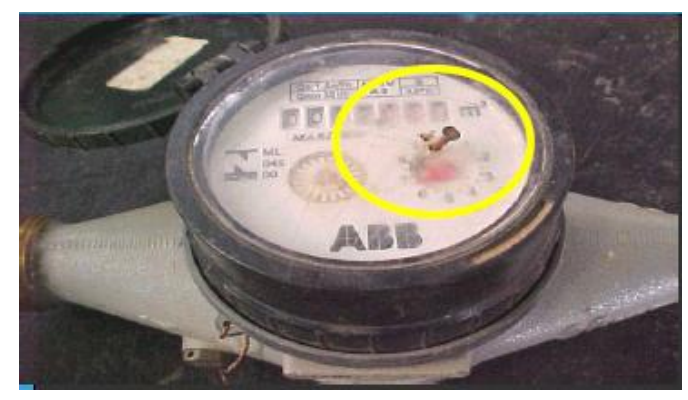

Figura 14 - Fraude no Hidrômetro

Fonte: SABESP (2006)

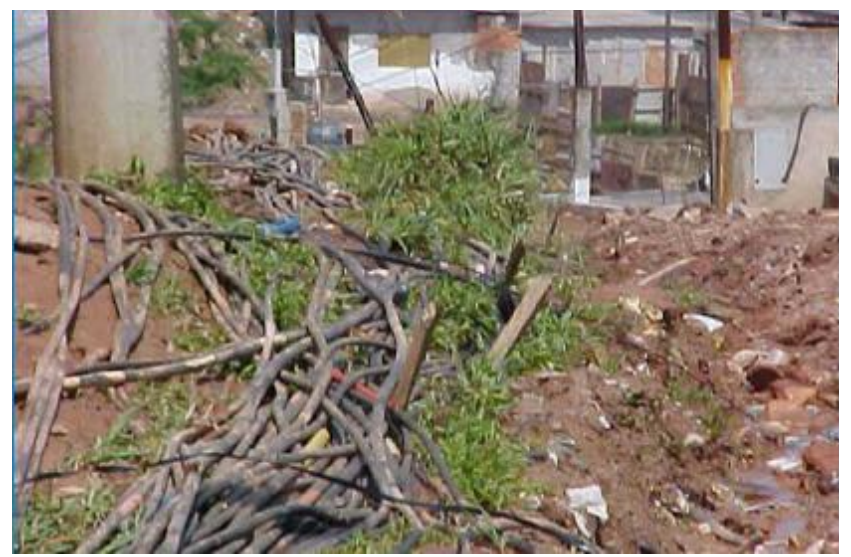

Figura 15 - Ligações Irregulares

Fonte: SABESP (2006)

Para o combate às perdas aparentes, são necessárias medidas como inspeções periódicas a ligações inativas e irregulares, substituição de hidrômetros de pequena 
e grande capacidade, adequação/calibração de macromedidores, melhoria na análise de dados, redução do consumo não autorizado e melhoria na medição e transmissão de dados.

\section{MATERIAIS E MÉTODOS}

O projeto foi desenvolvido através da pesquisa em trabalhos acadêmicos, bibliografias da área e entrevistas com fabricantes de tubos e conexões de polietileno e profissionais da área, visando encontrar dados melhores e mais atualizados sobre o uso das tubulações de PEAD no país. Também foram consultadas empresas públicas e privadas prestadoras de serviço de abastecimento de água potável nas cidades brasileiras, em busca da evolução deste mercado, assim como problemas e vantagens na implantação e operação de sistemas com PEAD. Ao mesmo tempo, se procurou estimar os ganhos com relação às perdas reais e custos de manutenção, instalação e operação dos sistemas, em comparação com o uso das tradicionais tubulações de ferro, aço e PVC.

\section{RESULTADOS}

\subsection{História dos tubos de PEAD no Brasil}

As tubulações PEAD chegaram ao Brasil por volta do ano de 1974, através de uma parceria de empresas brasileiras com a indústria química alemã Hoechst AG. O projeto em questão era uma adutora de água para a Companhia de Saneamento do Amazonas - Cosama e consistia em uma tubulação de 900 mm de diâmetro e 3.600 metros de comprimento, apoiada a até 60 metros de profundidade no leito do Rio Negro. Dois anos mais tarde, chegaria ao país a primeira extrusora de polietileno, de fabricação norueguesa e marca Grainger, adquirida pela empresa TranspaviCodrasa S/A.

No ano de 1978, a empresa Aracruz Celulose contratou a Transpavi-Codrasa S/A para a fabricação de tubulações de Polipropileno - PP, com capacidade de suportar elevadas temperaturas para o descarte do efluente de sua planta industrial, 
localizada no Espírito Santo. Foram construídas duas tubulações lançadas em mar aberto, com $1.000 \mathrm{~mm}$ de diâmetro e 7.030 metros de comprimento total, incluindo os trechos terrestres. Apesar de terem sido projetadas para uma vida útil de 15 anos, estas tubulações estão em funcionamento até os dias de hoje.

Em 1980 surge a primeira fábrica de tubos e conexões de tubulações de PEAD de grandes diâmetros do Brasil, chamada Dutoflex, próxima ao rio Branco em São Vicente-SP, que seria de grande importância na fabricação e transporte das tubulações de grande comprimento pela água. A fabricação passou a seguir a norma alemã DIN 8074/75 na extrusão de tubos da antiga classificação PE 5, na época chamado de PEAD tipo 2. Nesse mesmo ano mais um emissário de efluentes foi fabricado para a empresa TIBRAS - Titânio Brasil, com $400 \mathrm{~mm}$ de diâmetro e aproximadamente 6.000 metros de extensão em mar aberto. Devido ao sucesso destes trabalhos, o material passou a ser consagrado nas aplicações para emissários submarinos, sendo utilizado em Guarujá-SP, Boa Vista - RR, São Sebastião - SP, Praia Grande - SP e Guanabara da Tijuca - RJ (Rodrigues, 2012). O emissário de Guarujá de 900 mm de diâmetro e construído em 1982, operou por alguns anos, antes de apresentar problemas de operação e flutuar no oceano, sendo desativado. Algumas hipóteses surgiram para a causa deste problema, como falha na instalação dos lastros e falta de pesquisa na resistência das tubulações ao cisalhamento subaquático, porém nunca se chegou a uma conclusão.

Nesta época, o polietileno e o polipropileno começaram a ser adotados também nas indústrias de cana de açúcar e extração mineral. Nas usinas de álcool, devido à alta resistência térmica, as tubulações de PEAD passaram a ser usadas no transporte do vinhoto quente na fabricação de fertilizantes. Nas mineradoras como AngloGold e Paranapanema, passaram a ser utilizadas nas mais diversas aplicações de transporte: dragagem, brita, polpa, minério e efluentes ácidos.

No início da década de 80 , havia dois grandes produtores de resinas no Brasil, a Hoescht AG com a fábrica em Triunfo-RS e a Polialden Petroquímica S/A com fábrica em Camaçari-BA. Antes disto, toda resina utilizada era importada da Europa. Durante anos a Dutoflex foi a única fabricante de tubos e conexões de PEAD no Brasil, com diâmetros variando entre 20 e 1.000 mm, até que durante a década de 80, surgiram outras grandes produtoras de tubulações: Tigre S/A, Polierg LTDA e 
Vulcan S/A. O mercado do polietileno continuava a crescer e começou a atrair novos fabricantes. No final desta década já havia aproximadamente 120 produtores de tubulações de PEAD no país, muitos sem experiência e padrões de qualidade.

Em 1985, foi construída para a CEG - Companhia Estadual de Gás do Rio de Janeiro a rede de distribuição urbana de gás da llha do Governador toda em PEAD. Neste período a Companhia de Energia Elétrica Eletropaulo também passou a aceitar PEAD para revestimento de suas tubulações subterrâneas. A Companhia de Gás de São Paulo - Comgás passou a adotar as tubulações de PEAD em 1989, porém somente em testes e aplicações especiais como travessias. Somente em 1998, a COMGAS começou a se utilizar consideravelmente dos tubos de polietileno, e hoje $100 \%$ das tubulações novas em São Paulo são de PEAD e instaladas por método não destrutivo.

Em meados da década de 90, o uso do PEAD no sistema de distribuição de água começou a se tornar mais comum, como em Porto Alegre, onde o Departamento Municipal de Água e Esgoto (DMAE) passou a utilizar o material em ramais e redes, e na Companhia de Saneamento Básico do Estado de São Paulo (Sabesp), na utilização em ramais prediais e aplicações especiais, como travessias terrestres e sub fluviais. Segundo Peres (2005), a Sabesp começou as aplicações de polietileno em ramais de água em 1976, contudo o material e instalação não seguiam normas e padrões. Aliado a pouca experiência das concessionárias e fabricantes e até pela "má fé" de fornecedores, vários lotes fornecidos eram de baixa qualidade, sendo alguns fabricados de material reciclado sem origem garantida, gerando muitos problemas de vazamentos e arrebentamentos nos tubos instalados.

Segundo Rocha (2001), o relatório intitulado "Programa de redução de águas não faturadas" elaborado pela Sabesp no ano de 1994, apontou que 95\% dos vazamentos que ocorriam na rede de distribuição de água eram devido à falhas nos ramais prediais, e, desse total, $80 \%$ eram vazamentos verificados nos novos ramais prediais de PEAD. Em visita a 270 ramais com ocorrência de vazamento, Rocha classifica as principais tipologias de vazamentos como: furo no trecho central do tubo $(48,9 \%)$, trinca no adaptador (18,9\%), vazamento na junta mecânica $(10,7 \%)$, vazamento em junta rosqueada $(6,7 \%)$ e trinca no registro de boca $(5,2 \%)$, e atribui como principais causas a má qualidade o material e peça implantados e falha na 
execução da obra. No mesmo trabalho, Rocha propõe um novo desenho para os cavaletes das ligações prediais, que posteriormente seria adotado pela Sabesp para diminuir a ocorrência desses problemas.

Devido a todos esses problemas, ainda no ano de 1994, empresas e concessionárias como a Sabesp, através dos problemas levantados alteraram as normas vigentes e passaram a adotar os tubos de cor azul, apenas e tão somente, para diferenciar os tubos novos fabricados pelas novas normas dos antigos. Outro motivo foi para que seus funcionários aceitassem melhor o material, já que atribuíam aos tubos pretos como ruins. Além da coloração das tubulações, as novas normas brasileiras se tornaram mais claras no sentido de proibir o uso de material regranulado ou reciclado em condutos de água potável e adotando certificações/inspeções das fabricantes pelas concessionárias. O polietileno de alta densidade também passou a ser usado em tubos lisos de diâmetros maiores para adutoras de água, como em Caraguatatuba, Ilha Bela, Cotia e Suzano. Atualmente, o Brasil tem capacidade de fabricar tubulações com até 3.500 mm de diâmetro.

Em 1986, a resina PE 80 começou a ser produzida em território nacional pela Ipiranga Petroquímica S.A., que havia adquirido a fábrica da Hoechst, e também foi a primeira a produzir a resina PE 100 no ano de 2006. Um ano mais tarde, a Ipiranga Petroquímica S/A. foi adquirida pela Braskem S/A. Com o início da fabricação do PE 80, o PE 63 ficou restrito a aplicações de conduítes elétricos e de fibra ótica, ou seja, foram abandonados para tubos de pressão, por não haver mais justificativa técnica e econômica no seu emprego. Anos mais tarde, em 2005, o PE 63 também passou a ser utilizado na fabricação de tubos corrugados de grandes diâmetros, para aplicação em redes de esgoto e de águas pluviais de baixa pressão.

Já na década de 90 começam a aparecer no país alguns poucos tubos PE 100, capazes de admitir uma tensão circunferencial maior que o PE 80, com a mesma espessura de parede. Portanto, para uma mesma aplicação, a espessura da parede de uma tubulação de PE 100 será menor que a do PE, economizando matéria prima, transporte e tempo de soldagem nas obras. Por outro lado, as tubulações de PE 100 são mais rígidas, podendo dificultar a instalação principalmente nos usos em ramais de água, onde muitas vezes são necessárias curvas de raios menores. Outro motivo que esse tipo de resina ainda não é difundida no país é que somente nos últimos 
anos as fabricantes de tubulações ampliaram sua capacidade produtiva, podendo somente agora atender a demanda de grandes projetos. A partir de 2010 o uso de PE 100 foi intensificado e hoje é o mais utilizado no país.

Em setembro de 1994 surge a Associação Brasileira de Tubos Poliolefínicos e Sistemas - ABPE com a finalidade de divulgar, intensificar e ordenar normativamente o uso de tubos e conexões de polietileno e polipropileno. É composta por diversos atores da cadeia produtiva dos tubos destes materiais: fabricantes de matéria-prima, fabricantes de tubos e conexões, projetistas, instaladores, prestadores de serviços, laboratórios de testes e usuários.

Em janeiro de 2003, a ABPE firmou contrato com o CCDM-SC (Centro de Caracterização de Materiais da Universidade Federal de São Carlos) onde amostras de tubos e conexões de sistemas de PEAD que apresentem problemas de desempenho são encaminhadas para na análise visando avaliar sua conformidade com os padrões normativos e a garantia de uma vida útil de 50 anos do material. Atualmente, a associação vem colaborando na elaboração/revisão de normas técnicas brasileiras no recém-criado Comitê Brasileiro do Saneamento Básico da ABNT - Associação Brasileira de Normas.

A ABPE lançou também quatro métodos e padrões visando à qualidade das tubulações e instalação, sendo elas: ABPE/E006 - Equipamentos e ferramentas de soldagem e instalação; ABPE/M011 - Determinação da tensão residual de resfriamento - Método de ensaio; ABPE/P011, ABPE/P016 - Execução de ensaio de estanqueidade pneumática - Procedimento, que complementam as normal listadas no capítulo 2.6 das Diretrizes de Projeto para as tubulações de PEAD.

Em 2010 a Braskem S.A. inaugurou uma planta de produção da resina chamada Polietileno Verde, com a capacidade de fabricar anualmente 200 mil toneladas do produto. Na fabricação desta resina, ao invés de se utilizar matérias primas de fonte fóssil, como petróleo ou gás natural, é utilizado o etanol derivado da cana de açúcar, mantendo-se as mesmas propriedades e desempenho de aplicações dos polietilenos de origem fóssil. 


\subsection{Mercado Brasileiro}

A produção de tubos de polietileno vem seguindo uma tendência de crescimento nos últimos anos, chegando ao ano 2008 com uma produção maior que 21.000 toneladas de tubos lisos, como pode ser observado no gráfico a seguir:

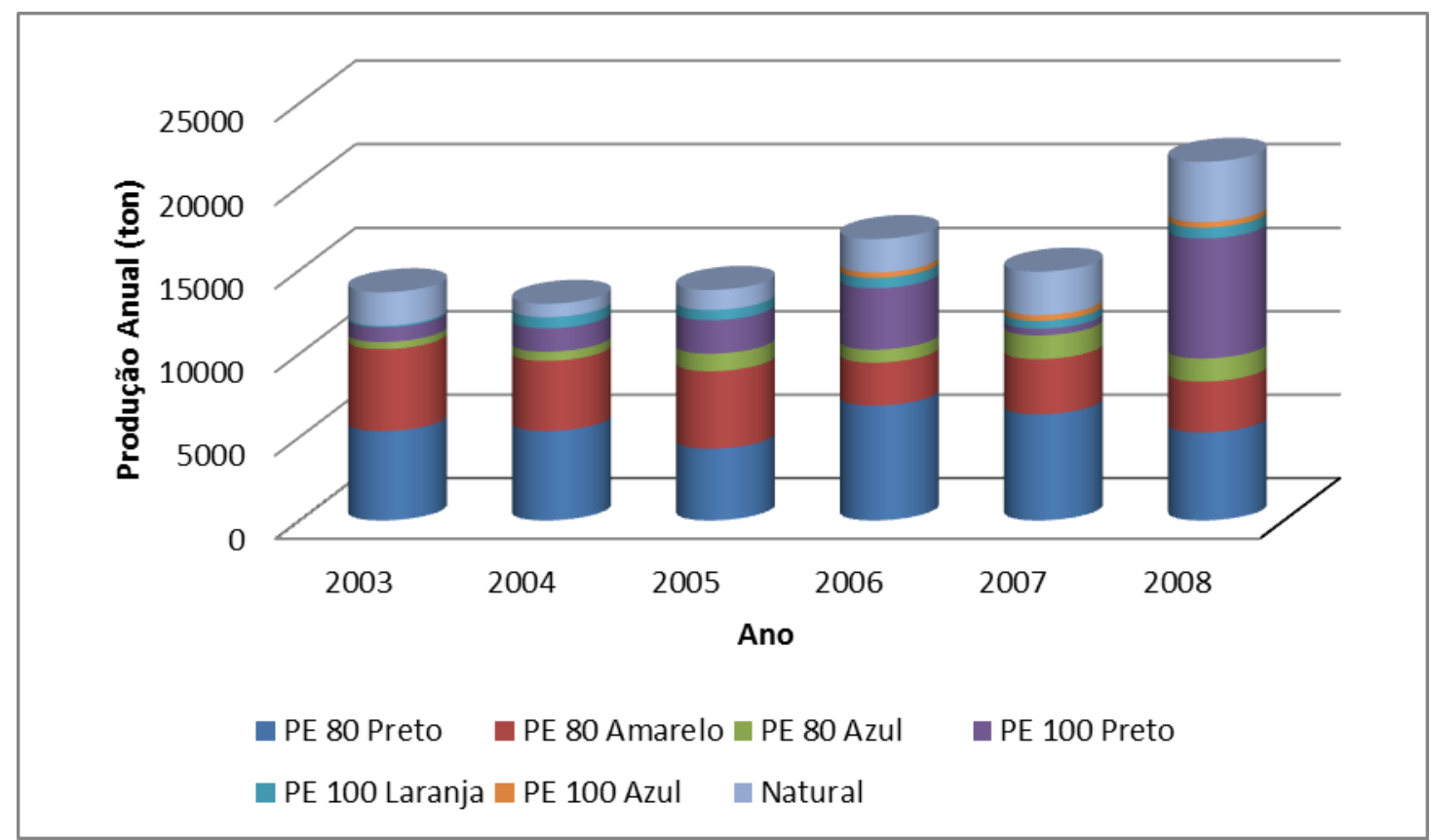

Figura 16 - Mercado Brasileiro de Tubulações de PEAD

Fonte: Apresentação ABPE - 2012

Recentes medidas governamentais de incremento da participação do gás natural na matriz energética, tais como o gasoduto Brasil-Bolívia, encontram nos tubos de PE a solução técnica para a construção das novas redes de distribuição e na substituição e recuperação das redes de Ferro Fundido através da técnica de inserção no próprio caminhamento (pipebursting).

Nas rodovias brasileiras recentemente sob regime de concessão estão sendo instalados sistemas de comunicação com telefones de socorro a cada quilômetro e sinalização de tráfico interativa que implica na instalação de uma infovia com milhares de quilômetros de tubulações de polietileno, através de valetadeiras contínuas e bobinas de tubos com grandes lances.

Na mineração, as tubulações de PE também vêm ganhando espaço no país, sendo utilizado em diversas aplicações dragagem, e transporte de brita, polpa, minério. Além das aplicações como tubos, é utilizado como membrana em lagoas e tanques. Contudo, apesar desta grande evolução do mercado de PEAD junto às mineradoras, 
ainda há um enorme potencial para ser explorado. Por exemplo, somente o uso de tubulações de PE nas minerações do Chile já supera o volume total do mercado desses tubos no Brasil, em 2009.

As tubulações de polietileno já podem ser encontradas facilmente em termoelétricas, cervejarias, plantas petroquímicas e fábricas multinacionais que estão se instalando no país e já trazem seus projetos especificações para este material, devido às suas propriedades de resistência química. Os tubos de PEAD também são utilizados frequentemente nas aplicações industriais a baixas temperaturas (menores que $\left.50^{\circ} \mathrm{C}\right)$. Os tubos de PE destacam-se também nas usinas de açúcar e destilarias de álcool no transporte de vinhoto ou vinhaça, efluente com elevada acidez.

No Brasil, vem se destacando no segmento do saneamento como substituto natural do ferro dúctil como matéria prima para condutos. Cabe ressaltar que somente em 2014, estima-se uma demanda de aproximadamente 70.000 toneladas de tubos lisos de PEAD, com uma capacidade de produção instalada da ordem de 120.000 toneladas (ABPE, 2014). Vale destacar também a contribuição do Brasil no desenvolvimento de material de fontes renováveis, usando o etanol para a produção da matéria prima, dispensando o petróleo sem perda de qualidade e resistência (Mesquita, 2010).

\subsection{Serviços de Abastecimento de Água}

O Diagnóstico de Serviços de Água e Esgotos do Sistema Nacional de Informações sobre Saneamento (SNIS) de 2013, publicado em dezembro de 2014 pela Secretaria Nacional de Saneamento Ambiental, integrante do Ministério das Cidades, é um compilado de informações fornecidas pelos prestadores de serviços de saneamento, com indicadores calculados com base nessas informações.

Em 2013, o SNIS apurou informações sobre abastecimento de água em 5.035 municípios, com população urbana de 165,7 milhões de habitantes, assegurando uma representatividade de 90,4\% em relação ao total de municípios e de 97,6\% em relação à população urbana do Brasil, assegurando assim uma base confiável para a elaboração dos indicadores. 
Segundo o relatório, os municípios brasileiros, cujos dados estão presentes no SNIS em 2013, possuem 571,4 mil quilômetros de redes de água, às quais estão conectados 49,6 milhões de ramais prediais. Verifica-se um bom crescimento dos sistemas brasileiros na comparação com o ano de 2012, sendo detectados novos 1,4 milhão de ramais na rede de água, crescimentos relevantes quando se trata de ampliação de sistemas de abastecimento de água nas cidades brasileiras, que correspondem a aumento de 3,0\%.

Com relação à população urbana atendida por redes de água, o diagnóstico aponta 154 milhões de habitantes, o que representa um incremento de novos 4,6 milhões de habitantes atendidos, crescimento de 3,1\%, na comparação com 2012. Na média do país, para os índices de atendimento total e urbano com rede de abastecimento de água em 2013 tem-se uma ligeira queda de 0,2 ponto percentual, quando comparado ao ano de 2012, quando esses índices foram de 82,7 e 93,2\%, respectivamente

O consumo médio de água no país apontado é de 166,3 litros por habitante ao dia, uma pequena queda de $0,7 \%$ em relação a 2012, e espera-se uma diminuição ainda maior para os próximos anos, devido aos programas de redução de perdas implementados por vários prestadores de serviços no enfretamento à crise hídrica a partir de 2014. Quanto aos volumes, verifica-se aumento de 255,4 milhões de metros cúbicos na produção de água $(1,6 \%)$ e 264,9 milhões de metros cúbicos no volume de água consumido $(2,7 \%)$

Sobre os índices de perdas totais na distribuição, para 2013 o índice foi 37,0\%, número praticamente igual ao de 2012, quando o valor foi de 36,9\%. Também se espera a diminuição desses valores devido aos programas de redução de perdas implementados.

O porte dos serviços de água e esgotos na economia pode ser medido pela movimentação financeira de $R \$ 91,6$ bilhões em 2013 , referente aos investimentos que totalizaram $R \$ 10,5$ bilhões, mais receitas operacionais de $R \$ 42,6$ bilhões e despesas de $R \$ 38,5$ bilhões. 
Tabela 5 - Caracterização do Sistema de Água - Participantes SNIS 2013

\begin{tabular}{|l|c|c|}
\hline \multicolumn{1}{|c|}{ Informação } & Unidade & Valor \\
\hline População total atendida com abastecimento de água & hab & 159.964 .320 \\
\hline Quantidade de ligações de água & unid. & 49.635 .400 \\
\hline Quant. de economias residenciais ativa & unid. & 51.857 .023 \\
\hline Extensão da rede de água & $\mathrm{km}$ & 571.433 \\
\hline Volume de água produzido & $\mathrm{mil} \mathrm{m}^{3}$ & 16.117 .584 \\
\hline Volume de água consumido & $\mathrm{mil} \mathrm{m}^{3}$ & 10.144 .946 \\
\hline
\end{tabular}

\subsection{Evolução nas Extensões de Redes}

\subsubsection{DMAE - Porto Alegre}

O Departamento Municipal de Água e Esgotos de Porto Alegre (DMAE-POA) é o órgão responsável pela captação, tratamento e distribuição de água, assim como pela coleta e tratamento do esgoto sanitário da cidade de Porto Alegre. Possui seis Estações de Tratamento de Água (ETA), 99 reservatórios com capacidade de armazenamento de $200.509 \mathrm{~m}^{3}$ e a vazão de água tratada é igual 198.069.074 m³/ano, enquanto que a vazão de água faturada é de $105.420 .687 \mathrm{~m}^{3} / \mathrm{ano}$. Possui um total de 308.692 ligações e uma extensão de rede de $4.052 \mathrm{~km}$. O índice de perdas é de 24,63\%. (DMAE-POA - 2015)

O Sistema de Abastecimento de Água de Porto Alegre seguiu o plano de substituição de redes implantado em 1990, que estabeleceu a troca dos tubos de PVC e Ferro Fundido Cinzento que apresentavam maiores índices de vazamento e arrebentamentos, por tubulações de PEAD, em uma taxa de $100 \mathrm{~km}$ de rede ao ano. Desta forma, em 2009 já eram aproximadamente $1.700 \mathrm{~km}$ de redes de distribuição e adução e $100 \mathrm{~km}$ de redes coletoras de esgoto sanitário em operação na cidade de Porto Alegre em PEAD.

Nos gráficos a seguir podemos ver a evolução da extensão das tubulações de PEAD ao longo dos anos. 


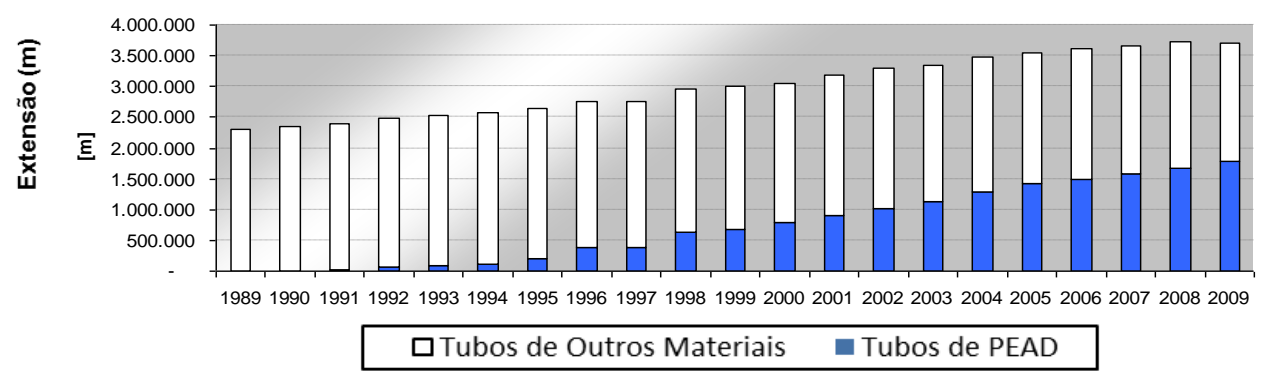

Figura 17 - Tubulações do Sistema de Distribuição de Água - DMAE Porto Alegre

FONTE: DMAE-POA (2010)

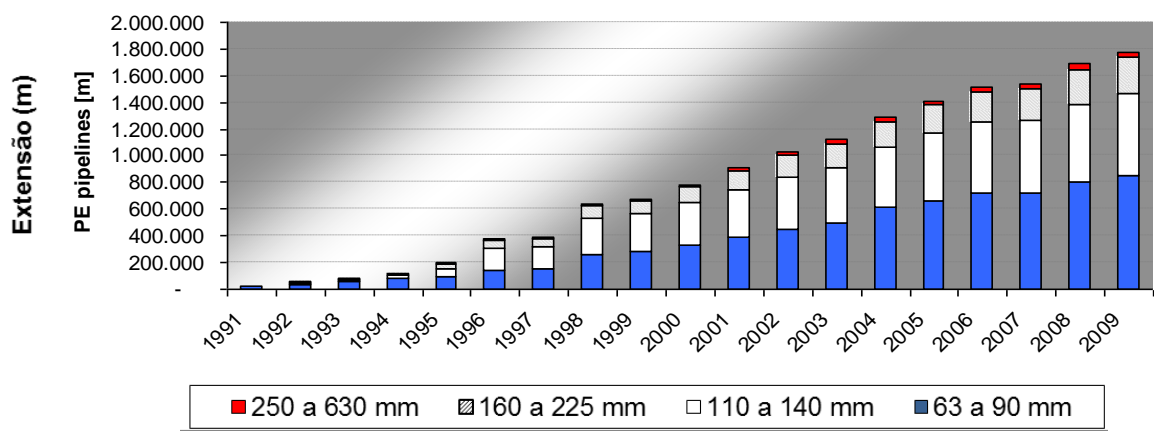

Figura 18 - Dimensões das Tubulações de PEAD do Sistema de Distribuição de Água - DMAE Porto Alegre

FONTE: DMAE-POA (2010)

\subsubsection{Sabesp - M}

A Diretoria Metropolitana da Companhia de Saneamento Básico do Estado de São Paulo - SABESP M - opera 37 municípios, incluindo a cidade de São Paulo. Atende 15,8 milhões de habitantes, através de 3,8 milhões de ligações e 5,7 milhões de economias.

Para o estudo das redes de PEAD, foram pesquisadas as redes das unidades de negócio Metropolitana Centro (MC) e Metropolitana Oeste (MO), abrangendo os municípios de São Paulo, Itapevi, Santana do Parnaíba, Vargem Grande Paulista, Barueri, Carapicuíba, Taboão da Serra e Cotia. No total 27.187 km de tubulações levantadas no cadastro, não contabilizando ramais nem cavaletes.

Deste total, $18.947 \mathrm{~km}$ são de ferro fundido, representando quase $70 \%$ do total de extensão de rede, enquanto que pouco mais de $1.000 \mathrm{Km}$ são de PEAD, representando aproximadamente 3,7\% da extensão total de rede. As tubulações de PVC também representam uma parcela considerável das extensões, com mais de 
$6.000 \mathrm{~km}$ (somando-se PVC e PVC-DEFOFO), correspondendo a mais de $22 \%$ do total.

A seguir temos a Tabela 6 que indica as extensões de redes da Sabesp M e sua respectiva porcentagem, de acordo com cadastro SIGNOS extraído no mês de novembro de 2015.

Tabela 6 - Rede de Distribuição de Água - Sabesp M

\begin{tabular}{c|c|c}
\hline MATERIAL & Ext. $(\mathbf{m})$ & $\%$ \\
\hline FERRO FUNDIDO & 18.947 .433 & $69,69 \%$ \\
\hline PVC & 5.989 .174 & $22,03 \%$ \\
\hline PEAD & 1.006 .103 & $3,70 \%$ \\
\hline CIMENTO AMIANTO & 743.217 & $2,73 \%$ \\
\hline AÇO & 381.665 & $1,40 \%$ \\
\hline CONCRETO & 22.759 & $0,08 \%$ \\
\hline PVC-DEFOFO & 19.874 & $0,07 \%$ \\
\hline PRFV & 381 & $0,00 \%$ \\
\hline DESCONHECIDO & 76.797 & $0,28 \%$ \\
\hline TOTAL & $\mathbf{2 7 . 1 8 7 . 4 0 8}$ & $\mathbf{1 0 0 , 0 0 \%}$ \\
\hline
\end{tabular}

No Anexo 1 deste trabalho, temos o mapa da área estudada da região metropolitana de São Paulo, sendo identificadas as redes de distribuição de água e seus respectivos materiais. Podemos ver a grande predominância das tubulações de ferro fundido, em azul, principalmente no Município de São Paulo. Temos "manchas" de tamanho considerável de tubulações de PVC (verdes) dispersas por toda a região metropolitana, contudo com maior predominância na área a oeste do mapa. Sobre o PEAD, temos pequenas manchas pulverizadas por toda região, porém nenhuma com um tamanho considerável. Podemos perceber que as áreas com tubos de PEAD aparecem tanto nas regiões com predominância de tubulações de Ferro Fundido, como em áreas com predominância de tubos de PVC.

Segundo Peres (2005), a Companhia de Saneamento Básico do Estado de São Paulo - SABESP, principal empresa de saneamento básico do Brasil, utiliza desde 1976 nos ramais de água o polietileno de alta densidade. Em 1998, 73,3\% dos ramais prediais da Região Metropolitana de São Paulo - RMSP eram de PEAD, 26\% de aço galvanizado e 0,7\% de PVC. 
Somente por volta de 2009 a Sabesp resolveu utilizar amplamente as tubulações de PEAD nas redes do sistema de distribuição de água de São Paulo. Do total de 853,3 $\mathrm{km}$ de redes de PEAD cadastrada no SIGNOS (Sistema de Informações Geográficas no Saneamento), 844,9 km possuem a data de instalação. Através destes dados é possível elaborar uma curva do crescimento do uso das tubulações de PEAD na cidade de São Paulo. Apesar de sua extensão ainda não representar uma proporção significativa da extensão total da rede, pode ser observado um crescimento vertiginoso nos últimos anos. Do começo de 2009 até final de 2015, a extensão de redes em PEAD aumentou $147 \%$ na área estudada.

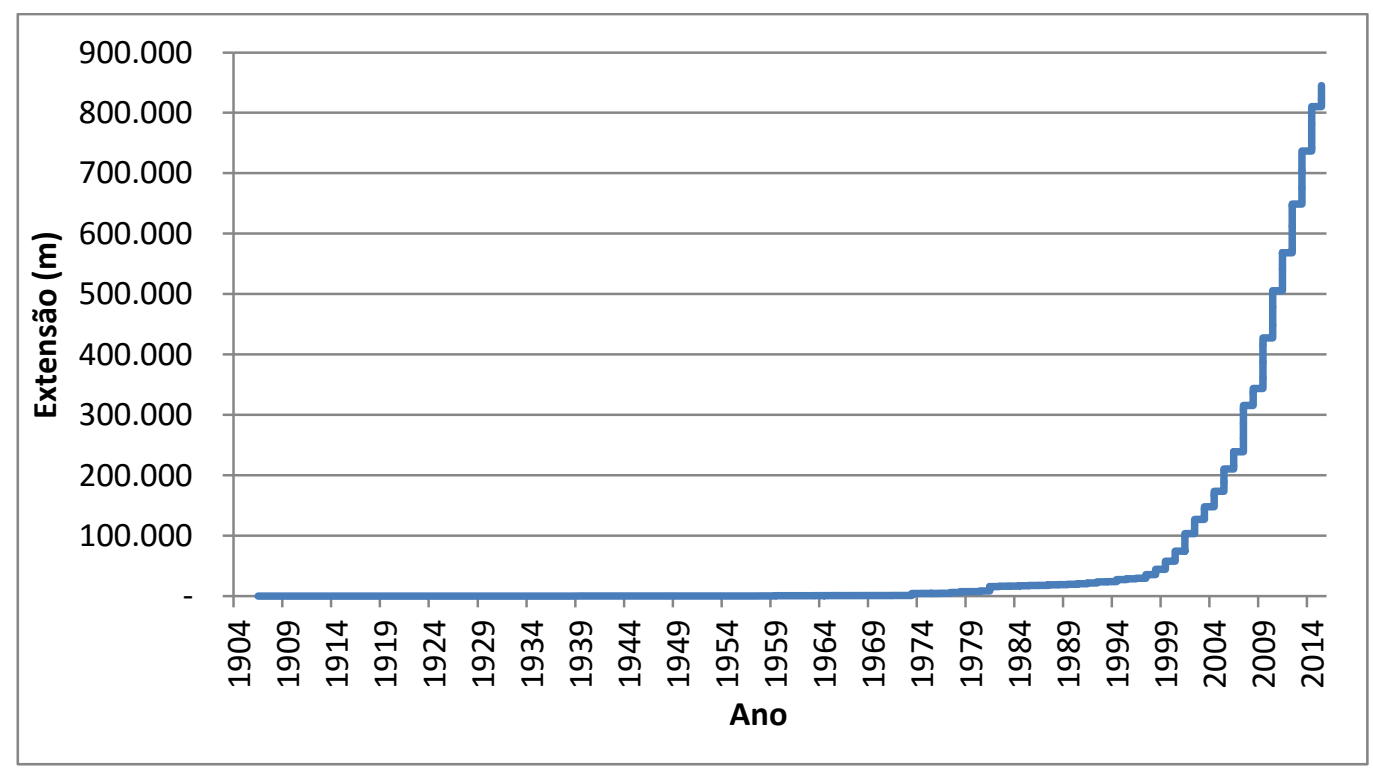

Figura 19 - Extensões de PEAD na Região Metropolitana de São Paulo Estudada

FONTE: SIGNOS (2015)

Este considerável aumento do uso do PEAD em redes nos últimos anos se deve ao fato destas tubulações serem viscoelásticas e apresentarem juntas de eletro e termofusão, se tornando assim uma ótima alternativa em substituição as redes de rígidas e com conexões mecânicas de ponta e bolsa, que têm apresentado elevadas ocorrências de vazamentos e arrebentamentos principalmente em regiões de tráfego intenso de veículos, onde há elevada vibração no solo devido à movimentação de caminhões, ônibus e outros veículos pesados.

Outro motivo que pode ser atribuído ao crescimento do uso do PEAD na cidade de São Paulo é o aumento da utilização do método não destrutivo nas trocas de tubulações e reforço de rede, como o "pipebursting" e o furo direcional. Nestes tipos de intervenção o PEAD se tornou o material ideal principalmente por sua leveza e 
flexibilidade. Em várias regiões da cidade de São Paulo, o Departamento de Controle de Uso de Vias Públicas - CONVIAS não autoriza mais obras de intervenção com o método da vala a céu aberto, somente autorizando obras pelo MND (método não destrutivo).

Aliado a isso, o crescimento do uso de PEAD também se deve a implementação do Programa Corporativo de Redução de Perdas de Água, cuja primeira etapa, financiada pela Japan International Cooperation Agency (JICA), está ocorrendo entre os anos 2013 e 2017 e consiste entre outras ações, a substituição de 915 mil ramais antigos e $670 \mathrm{~km}$ de redes. Dentre as diretrizes sugeridas para estes projetos está a diretriz que todas os novos ramais fossem de PEAD, e que todas as redes com diâmetro menor igual ou igual a $315 \mathrm{~mm}$ também fossem de polietileno. E mesmo para diâmetros maiores, se as condições de obras exigissem a realização em método não destrutivo, estas deveriam também ser projetadas com material de PEAD.

\subsection{1. Águas de Limeira}

A empresa Odebrecht Ambiental é a concessionária que opera e administra o Sistema de Abastecimento de Águas de Limeira. Iniciou o uso das tubulações de PEAD em 1996, com a instalação de redes em novos loteamentos, e posteriormente passou a utilizar em substituições e reforços. No começo, o tipo de solda utilizado era de termofusão e compreensão, mas hoje também já se utiliza a união por eletrofusão. Os diâmetros utilizados estão variam entre DE 20 e 160 mm.

A seguir temos dois gráficos da composição de material das redes de água de Limeira para dois anos distintos, 2007 e 2014. Comparando ambos os gráficos é possível perceber uma considerável evolução nas extensões do polietileno durante esse anos, passando em porcentagem de extensão de redes de 12,9 \% em 2007 para 18,5 \% em 2014. Vale ressaltar a diminuição da porcentagem de redes em PVC, mostrando que o PEAD vem substituindo grande parte de material. 


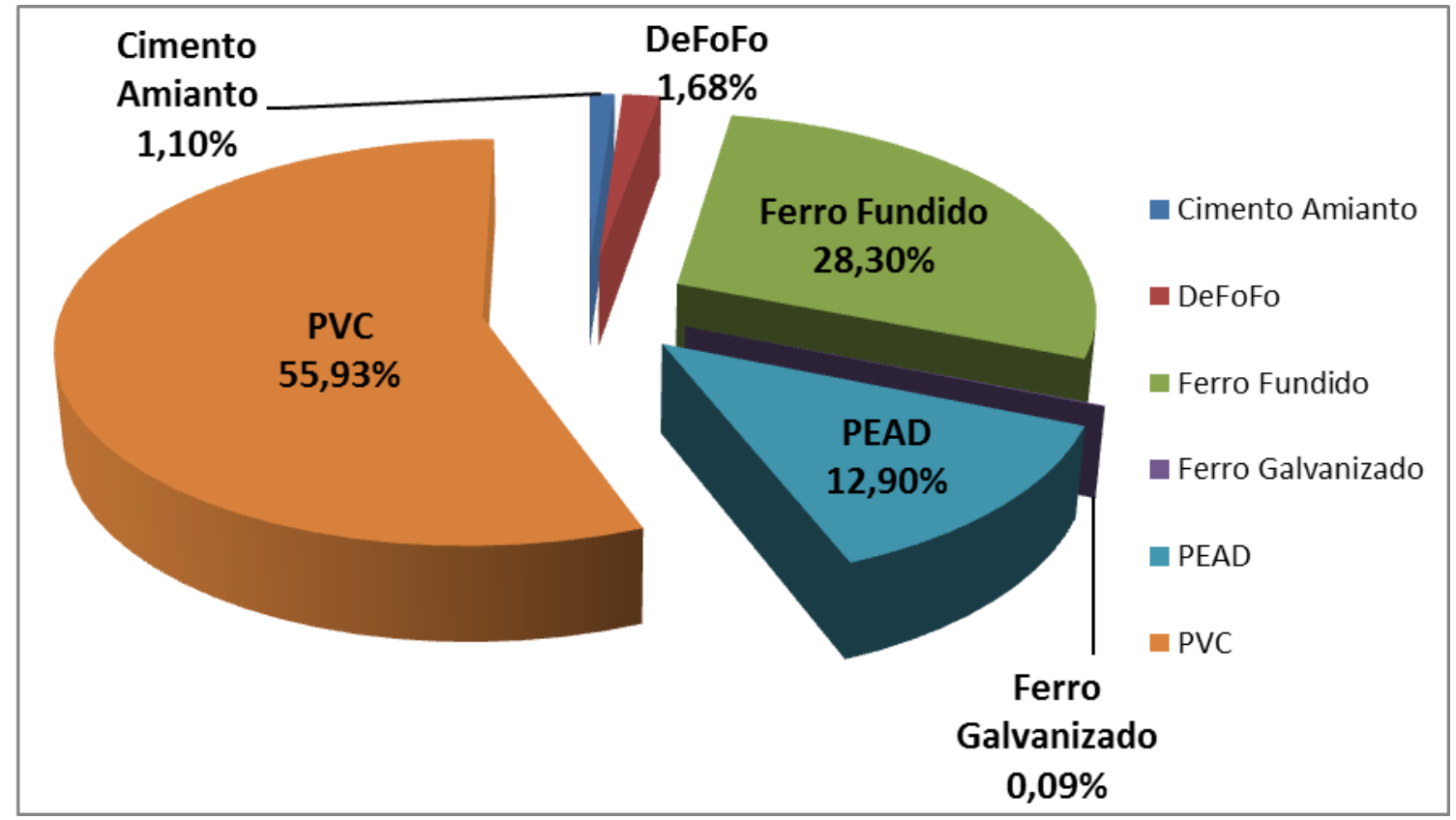

Figura 20 - Composição da Rede de Distribuição de Água de Limeira - 2007 (\% em extensão de rede)

Obs: Total de $1.108 \mathrm{~km}$ de redes.

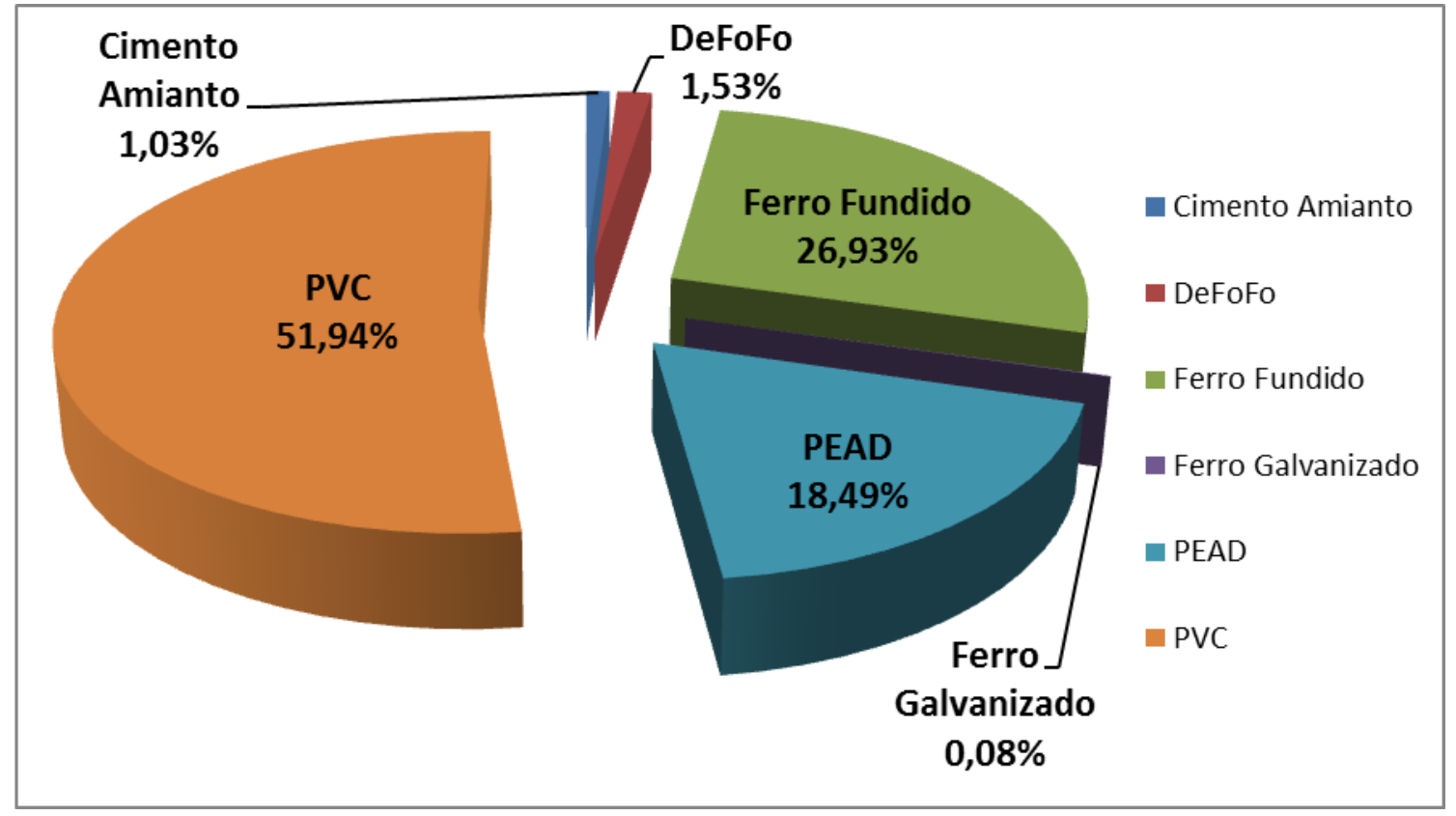

Figura 21 - Composição da Rede de Distribuição de Água de Limeira - 2014 (\% em extensão de rede)

Obs: Total de $1.028 \mathrm{~km}$ de redes. 


\subsection{Adaptação ao Novo Material}

Como as tubulações de PEAD são muito diferentes das tubulações clássicas de PVC e Ferro Fundido, principalmente no que se refere à união das tubulações através de soldas termoplásticas, diferente das pontas e bolsas presentes nas juntas elásticas tradicionais, houve alguns problemas no início da utilização dos tubos de Polietileno.

Todas três concessionárias estudadas: Águas de Limeira, Sabesp-M e DMAE-POA realizaram treinamento da equipe, adquiriam equipamentos e peças de termo e eletrofusão e trabalharam sempre com fornecedores certificados, e acompanhados pela ABPE.

No tocante aos ramais, as empresas já trabalhavam há mais tempo com esse material e o mercado já está mais desenvolvido, portanto não foram relatados grandes problemas. O que se verificou foi o uso nas derivações das redes de tês mecânicos e integrados para diâmetros menores ou iguais a $110 \mathrm{~mm}$ e tês tipo sela para diâmetros maiores até $315 \mathrm{~mm}$, como pede ser observado nas figuras a seguir:

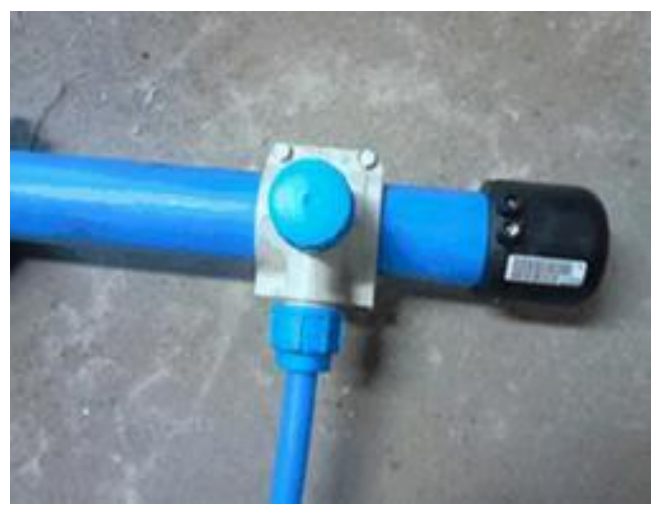

Figura 22 - Tê Integrado de Derivação para o Ramal

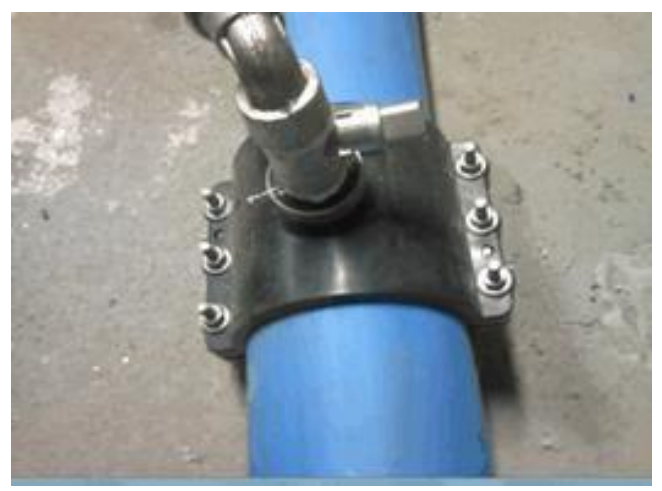

Figura 23 - Tê Mecânico de Derivação para o Ramal 


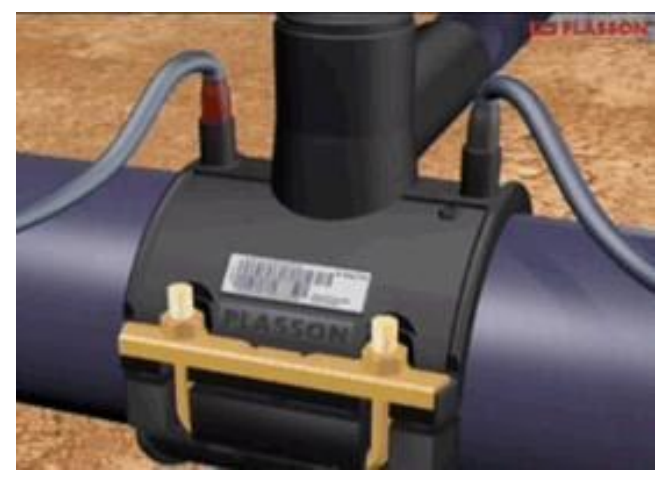

Figura 24 - Tê Tipo Sela de Derivação para o Ramal

A respeito das redes de polietileno, em conversa com a gerência e com as equipes de manobra e manutenção das concessionárias, foram relatados alguns problemas, uns já solucionados enquanto outros não, principalmente a respeito em intervenção em redes existentes.

\subsubsection{Sabesp - M}

Segundo polos de operação entrevistadas, a Sabesp-M conta com máquinas e equipamentos para solda de termofusão e eletrofusão, tais como faceadores, niveladores, abraçadeiras e máquina de solda, além de peças como colarinho longo, adaptadores de transição, curvas e tês em seu almoxarifado. Além disto, foi realizado treinamento com líderes de equipes de manobra, e estes repassaram os conhecimentos adquiridos para os demais manobristas.

Contudo, foi relatado falta de prática pelas as equipes de manutenção e manobra. Primeiramente porque, como visto no capítulo 4.4.2, a extensão de redes de PEAD na região metropolitana de São Paulo operada pela Sabesp-M na região de estudo ainda é muito pequena, cerca de $3,70 \%$ do total de rede. E em geral são redes novas e raramente apresentam vazamentos e arrebentamentos. O segundo motivo é que as redes novas de PEAD geralmente são instaladas por empresas terceiras, empreiteiras ganhadoras de licitação.

Por esses motivos, as equipes de manobra e manutenção da Sabesp-M, apesar do treinamento recebido, ficam sem prática no manuseio deste novo material no dia a dia e quando há a necessidade de reparo encontram dificuldades no procedimento com o novo material: identificar peças necessárias, máquina de solda está descarregada, procedimento da solda termoplástica entre outros problemas mencionados. 
O maior problema relatado pelas equipes de operação da Sabesp é quanto à intervenção em redes em operação de PEAD. Segundo eles, quando é necessária a parada de uma rede de PEAD, com o fechamento de registros, para uma intervenção qualquer, como conserto de vazamento, nova interligação e instalação de uma válvula, a tubulação normalmente não fica completamente estanque, uma vez que os registros de ferro fundido utilizados, principalmente os tipo gaveta, muito raramente conseguem bloquear totalmente a vazão da água. Devido a isso, se for necessário cortar a rede e reconecta-la depois, será muito difícil realizar a solda, visto que para a união de termo e eletrofusão é necessário o completo estancamento do material. Este problema tem sido relatado frequentemente pelas empresas que trabalham com PEAD e é claramente o motivo de maior reclamação.

A equipe de manobra do polo de São Mateus, da Sabesp - M tem adotado para esses casos peças mecânicas de ferro e aço, adaptadas por eles mesmos para a união destas tubulações de PEAD. Abaixo podemos ver duas destas peças que têm sido usadas. A primeira, semelhante a uma junta de desmontagem de ferro fundido, e a segunda uma adaptação de uma luva de eletrofusão, só que conectada mecanicamente.

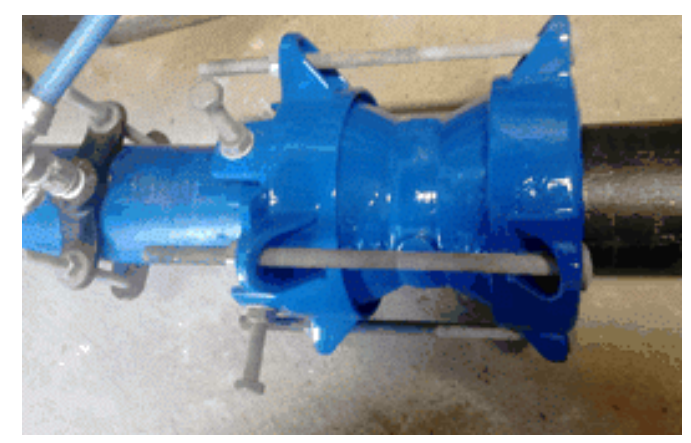

Figura 25 - Conexão Mecânica utilizada em intervenções em rede de PEAD - Tipo 1

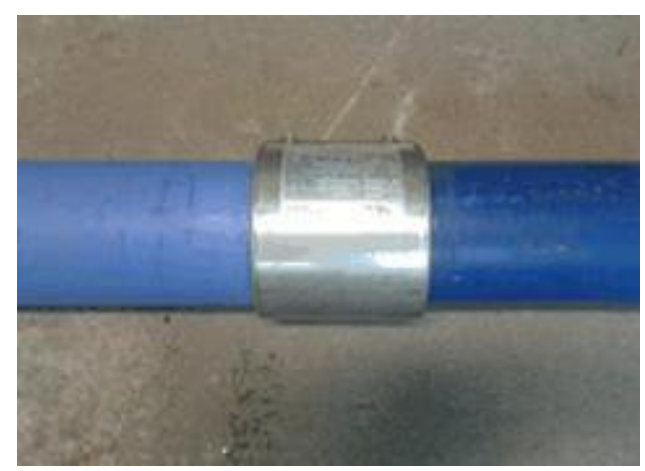

Figura 26 - Conexão Mecânica utilizada em intervenções em rede de PEAD - Tipo 2 
Apesar de serem peças adaptadas, até o momento não foram relatados problemas quanto à operação das redes. Além disso, a equipe de operação do polo São Mateus tem realizados estudos sobre essas conexões, fazendo ensaios em laboratório de acordo com a norma NBR 8415:2007. Contudo, os testes em bancada ainda estão em andamento e o estudo ainda não foi finalizado.

\subsection{Vida Útil das Tubulações de PEAD}

A norma ABNT NBR 15802 as tubulações de PEAD PE 80 e PE 100 são projetadas para terem um vida útil de 50 anos. Isso quer dizer, em poucas palavras, que toda a deformação sofrida pela tubulação por pressão aplicada (se limitando a classe de pressão), se recuperará gradativamente quando retirado do esforço. Após 50 anos, pode ocorrer o chamado "creep", quando a tubulação não consegue mais se recuperar mesmo quando o esforço cessa, se tornando uma deformação permanente. Contudo, vários fabricantes afirmam que este tempo será facilmente superado.

Como ainda não há tubulações de PEAD em operação por 50 anos ou mais fabricadas em conformidade com normas no Brasil, não é possível verificar a vida útil média dos tubos, contudo é aceitável realizar amostragem e ensaios para estima-la.

Para assegurar a qualidade da água transportada pelos tubos de polietileno no passar dos anos, vários experimentos foram realizados com o objetivo de simular o funcionamento de tubulações em longo prazo, de 50 anos da vida útil da tubulação até mais de 100 anos de uso. Estes experimentos aceleram as condições de funcionamento observadas em laboratório, inclusive a exposição continua de vazão de água clorada, e através dele é possível prever o comportamento da tubulação até o final da vida útil, antes mesmo de enterra-la (Oliphant; Conrad; Chung, 2011).

Contudo, o mercado das tubulações de PEAD é muito dinâmico, surgindo novos materiais e procedimentos em intervalos curtos de tempo. Segundo Oliphant, Conrad, e Chung, (2011), em 2007 se deu início a uma grande pesquisa nos Estados Unidos da América para se analisar o desempenho da nova geração das tubulações de PEAD. Com mais de 200 laboratórios e 300 amostras sujeitas a condições aceleradas de operação no laboratório, foram realizados testes com 
análises de indicadores físicos e químicos de desempenho das tubulações. Além disso, foram retiradas amostras de tubulações em operação instaladas entre 2003 e 2005, e os resultados foram consistentes que a vida útil restante das tubulações superará 100 anos.

\subsubsection{DMAE - Porto Alegre}

Visando verificar as condições das tubulações em funcionamento e constatar os ganhos obtidos e a qualidade das tubulações de PEAD instaladas, foi realizado em 2008 um experimento pelo Departamento Municipal de Água e Esgoto de Porto Alegre (Dmae-POA), analisando amostras de tubulações de polietileno em operação.

Segundo Flores (2009), a DMAE-POA é a empresa pública de saneamento básico com a maior experiência brasileira no uso do polietileno em redes de distribuição para abastecimento de água e de coleta de esgotos no país, portanto seria o cenário mais propício para a análise das condições das tubulações após anos de operação.

As primeiras experiências realizadas nas redes de distribuição de água de Porto Alegre com este material foram em 1986 e visavam encontrar um material menos suscetível a vazamentos, principalmente em suas juntas. Em 1990 já se iniciou um plano de substituição das redes de PVC e Ferro Fundido Cinzento, que apresentavam maiores índices de vazamento e arrebentamentos, por tubulações de PEAD, em uma taxa de $100 \mathrm{~km}$ de rede ao ano.

Devido a este histórico de uso do material, viu-se no Sistema de Abastecimento de Água de Porto Alegre o cenário mais propício para a realização do experimento de verificação da vida útil das tubulações de polietileno. Em parceria com a ABPE, o DMAE-POA realizou uma pesquisa que consistia em coletar amostras de tubulações de polietileno de dois grupos diferentes, de acordo com a data de instalação: o primeiro grupo composto por tubos instalados e em operação há 20 anos e 0 segundo grupo por tubulações com 10 anos de instalação e operação. As amostras de ambos os grupos foram encaminhadas para o laboratório para gerar indicadores de qualidade do material, analisando principalmente o grau de degradação e projeção de sua vida útil - curva deformação por tensão aplicada. 
As tubulações analisadas do primeiro grupo foram instaladas e colocadas em operação em 1988, sem vazamentos, arrebentamentos ou qualquer outra intervenção registrada. Todas foram fabricadas pela empresa Dutoflex, instaladas pela empresa Transpavi- Codrasa S/A e eram tubos com diâmetro externo (DE) 90 mm, tipo PE-5A, de cor preta, produzidos de acordo com a norma alemã DIN 8075. Foram implantados na época com uma extensão de 500 metros no bairro Vila São José, de população de baixa renda sem abastecimento de água e coleta de esgoto até então, e operavam em uma pressão diurna de 15 metros de coluna d'água (MCA) e noturna de 53 mca.

Para a pesquisa foi retirada uma amostra de 10 metros de extensão da tubulação, na época com 20 anos de operação (2008) e enviada para laboratório para análises. Em complemento, foi realizada uma análise dimensional e visual da tubulação in loco, obtendo os seguintes resultados:

Tabela 7 - Dados das Tubulações com 20 anos de Operação

\begin{tabular}{c|c}
\hline Indicador Analisado & Resultados \\
\hline Cor & Preto \\
\hline Diâmetro Externo Nominal & DE $90 \mathrm{~mm}$ \\
\hline SDR & 32 \\
\hline Deformação Diametral & Imperceptível \\
\hline Fissuras/Trincas & Imperceptível \\
\hline Deposição/Incrustações & Não \\
\hline
\end{tabular}

Tabela 8 - Análise Laboratorial das Tubulações com 20 anos de Operação

\begin{tabular}{c|c|c|c|c}
\hline Indicador & Requisitos & Resultados & Unidade & Norma \\
\hline IF 190ㄷㄷk & $<1,3$ & 0,63 & $\mathrm{~g} / 10 \mathrm{~min}$ & ASTM D1238 \\
\hline OIT & $>20$ & 16,6 & $\min$ & ASTM D3895 \\
\hline Teor NF & 2 a 3 & 2 & $\%$ & ASTM E1131 \\
\hline Dispersão & - & Insatisfatória & - & - \\
\hline PHI & $>1000$ & - & $\mathrm{h}$ & - \\
\hline
\end{tabular}

Fonte: Flores, V., \& Pierozam, R. (2009, p.20).

Onde:

IF = Índice de Fluidez;

OIT = Oxidation Index Time;

NF = Negro de Fumo;

PHI = Presão Hidrostática Interna. 
A seguir temos fotografia de uma das amostras retiradas na pesquisa, que mostra como a tubulação de 20 anos de operação ainda apresenta aspecto visual de um tubo novo, sem incrustações ou ranhuras.
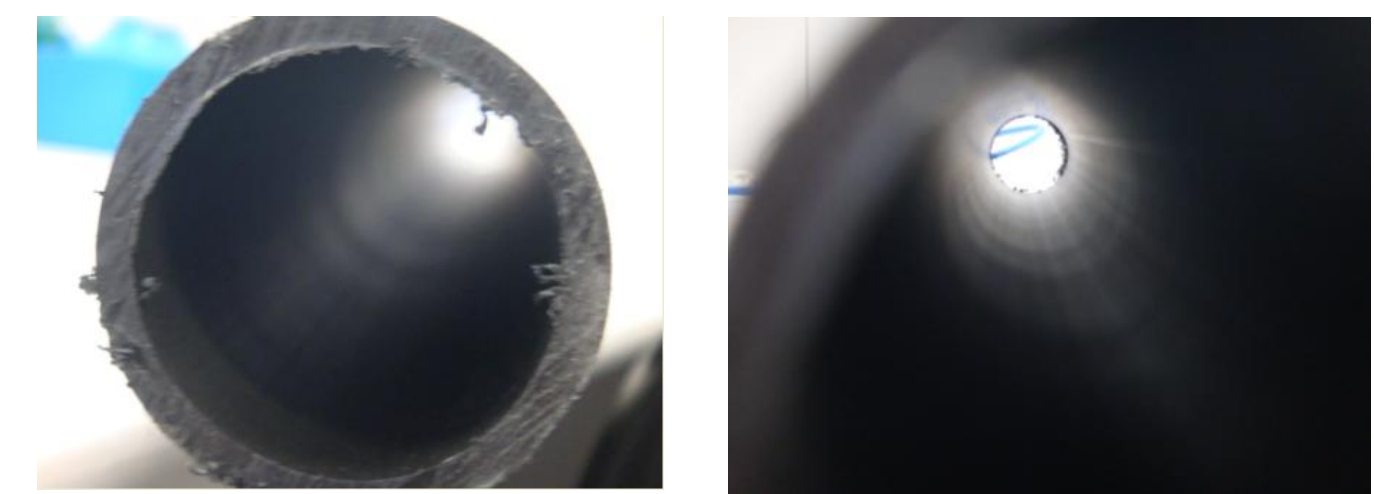

Figura 27 - Extensões de Redes de PEAD e Perdas no Sistema de Abastecimento de Água de Porto Alegre.

FONTE: DMAE-POA (2010)

As tubulações do grupo 2 foram instaladas e colocadas em operação no ano de 1998, já em conformidade com a norma ISO 4427 (Tubos de Polietileno para Distribuição de Água - Especificação), ainda em vigor. A resina utilizada foi o PE 80 e os tubos eram de diâmetro de $110 \mathrm{~mm}$, PN 10, SDR 13,6, de cor preta e produzidos em barras de 12 metros. Seu fabricante foi a Brastubo S/A e a empreiteira responsável pela execução das obras foi a Ribas Construções, na região próxima a estrada de Ponta Grossa, sul de Porto Alegre. A área era ocupada por uma população de médialbaixa renda, sem coleta de esgoto, com pressões médias na rede de distribuição de aproximadamente 25 mca de dia e 48 mca a noite.

Assim como o grupo 1, as tubulações deste grupo foram analisadas ainda instaladas, para posteriormente serem avaliadas visualmente e suas dimensões conferidas. Foram obtidos os seguintes resultados: 
Tabela 9 - Dados da Análise Dimensional e Visual das Tubulações com 10 Anos de Operação

\begin{tabular}{c|c}
\hline Indicador Analisado & Resultados \\
\hline Cor & Preto \\
\hline Diâmetro Externo Nominal & DE $110 \mathrm{~mm}$ \\
\hline SDR & 13,6 \\
\hline Deformação Diametral & Imperceptível \\
\hline Fissuras/Trincas & Imperceptível \\
\hline Deposição/Incrustações & Não \\
\hline & Fonte: Flores, V., \& Pierozam, R. (2009, p.22).
\end{tabular}

Tabela 10 - Análise Laboratorial das Tubulações com 10 anos de Operação

\begin{tabular}{|c|c|c|c|c|c|}
\hline $\begin{array}{l}\text { Indicador } \\
\text { Analisado }\end{array}$ & $\begin{array}{l}\text { Requisitos } \\
\text { NBR }\end{array}$ & $\begin{array}{c}\text { GM } 5010 \text { T2 } \\
\text { Padrão }\end{array}$ & Result. & Unid. & Norma \\
\hline IF $190^{\circ} \mathrm{C} / 5 \mathrm{~kg}$ & $<1,3$ & $0,35-0,55$ & 0,41 & $\begin{array}{l}\mathrm{g} / 10 \\
\mathrm{~min}\end{array}$ & $\begin{array}{l}\text { ASTM } \\
\text { D1238 }\end{array}$ \\
\hline Densidade & $>0,938$ & 0,955 & 0,9559 & $\mathrm{~g} / \mathrm{cm}^{3}$ & $\begin{array}{l}\text { ASTM } \\
\text { D1505 }\end{array}$ \\
\hline $\begin{array}{c}\text { Tensão de } \\
\text { escoamento }\end{array}$ & $>25$ & 22 & 23,1 & Mpa & ASTM D638 \\
\hline Alongamento Ruptura & $>350$ & 800 & 785 & $\%$ & ASTM D638 \\
\hline \multirow{3}{*}{ OIT } & \multirow{3}{*}{$>20$} & \multirow{3}{*}{$>60$} & $\begin{array}{l}\text { (externo) } \\
102\end{array}$ & $\min$ & $\begin{array}{l}\text { ASTM } \\
\text { D3895 }\end{array}$ \\
\hline & & & $\begin{array}{c}\text { (central) } \\
101\end{array}$ & $\min$ & $\begin{array}{l}\text { ASTM } \\
\text { D3895 }\end{array}$ \\
\hline & & & (interno) 75 & $\min$ & $\begin{array}{l}\text { ASTM } \\
\text { D3895 }\end{array}$ \\
\hline Teor NF & 2 a 3 & 2 a 3 & 3 & $\%$ & $\begin{array}{l}\text { ASTM } \\
\text { E1131 }\end{array}$ \\
\hline
\end{tabular}

Fonte: Flores, V., \& Pierozam, R. (2009, p.22).

Onde:

IF = Índice de Fluidez;

OIT = Oxidation Index Time;

$\mathbf{N F}=$ Negro de Fumo.

Tabela 11 - Teste Hidrostático das Tubulações com 10 anos de Operação

\begin{tabular}{c|c|c|c}
\hline $\mathbf{T}\left({ }^{\circ} \mathbf{C}\right)$ & Mpa & Requisito (tempo para ruptura) & Tempo de Ruptura \\
\hline 20 & 10 & 100 horas & $>400$ horas - Interrompido \\
\hline 80 & 4,6 & 165 horas & $>400$ horas \\
\hline 80 & 4 & 1.000 horas & $>400$ horas \\
\hline
\end{tabular}


Os resultados das análises das tubulações do grupo 1, de PE 63, instaladas e postas em operação no ano de 1988, apontaram deficiência relativas a OIT e dispersão de pigmentos, indicativos que a vida útil dos tubos estaria no seu fim. Apesar disso, durante os vinte anos de operação contínua, as tubulações não apresentaram ocorrências de vazamentos e a amostra recolhida suportou o teste hidrostático de 1.000 horas.

Já no grupo 2, das tubulações de PE 80 em operação há 10 anos, apresentaram melhores resultados, com todos os parâmetros sendo atendidos seguramente. Os resultados indicam que a vida útil estimada de 50 anos será atendida ou até superada por estas tubulações.

Esta estimativa de maior vida útil das tubulações de PEAD é outro fator que contribui para o crescimento de sua utilização. A taxa de substituição de redes aplicada atualmente pela Sabesp na RMSP varia entre 0,1 e 0,2\% do total de rede, contudo, considerando uma vida útil média de 50 anos para as tubulações hoje em operação, esta taxa deveria estar por volta de $2 \%$ ao ano, conforme estabelecido pela International Water Association (IWA) (SARZEDAS, 2009, pag. 79, apud SAEGROV, 2005). Se utilizando o PEAD, que fabricantes e pesquisadores prometem uma vida útil de 80, 100, ou até 200 anos (muito acima da norma NBR 15.651 de 50 anos), esta taxa poderia cair para 1,3 ou até 0,5 nas previsões mais otimistas, gerando significativa economia nos custos de manutenção do sistema e confiabilidade ao sistema.

\subsection{Ganhos em Perdas Físicas}

Visando avaliar se realmente o uso de tubulações de PEAD auxiliam no combate às perdas reais, se procurou em cada empresa prestadora de serviço de abastecimento de água correlacionar a melhora no índice de perdas com a evolução das extensões de redes de polietileno no sistema de abastecimento.

Claro que as tubulações de PEAD são mais um instrumento de combate às perdas totais, sendo também adotadas nos últimos anos medidas como controle de pressão na rede com otimização de zonas e instalação de VRP's, pesquisa de vazamentos em áreas críticas e agilidade/qualidade nos reparos de vazamentos e arrebentamentos. Também é válido lembrar as evoluções tecnológicas dos últimos 
anos, tanto na questão da qualidade dos materiais, válvulas, dispositivo e critérios de projetos, quanto no uso de softwares de modelagem, cadastro e gerenciamento de redes, aumentando a velocidade de informação e comunicação dentro das prestadoras de serviço.

\subsubsection{DMAE - Porto Alegre}

Entre os anos de 1990 e 2013, período em que o DMAE-POA começou a adotar os tubos de PEAD em seu sistema de distribuição de água, o índice de perdas totais passou de $46 \%$ para $26 \%$, o que corresponde a cerca de $30 \%$ de economia de recursos nos investimentos anuais (Flores, 2009). Vale lembrar que este considerável ganho em perdas também se deve à modernização da operação e equipamentos (ventosas, medidores, registros, etc), aperfeiçoamento dos cadastros de redes, otimização das técnicas de intervenção e ampliação do monitoramento das tubulações. Contudo, da mesma maneira é um indicador que as tubulações de polietileno são de fato uma ferramenta a ser utilizada no combate às perdas reais de água em sistemas de distribuição.

A seguir é apresentado o gráfico da evolução das perdas e da extensão de PEAD entre os anos de 1990 e 2013.

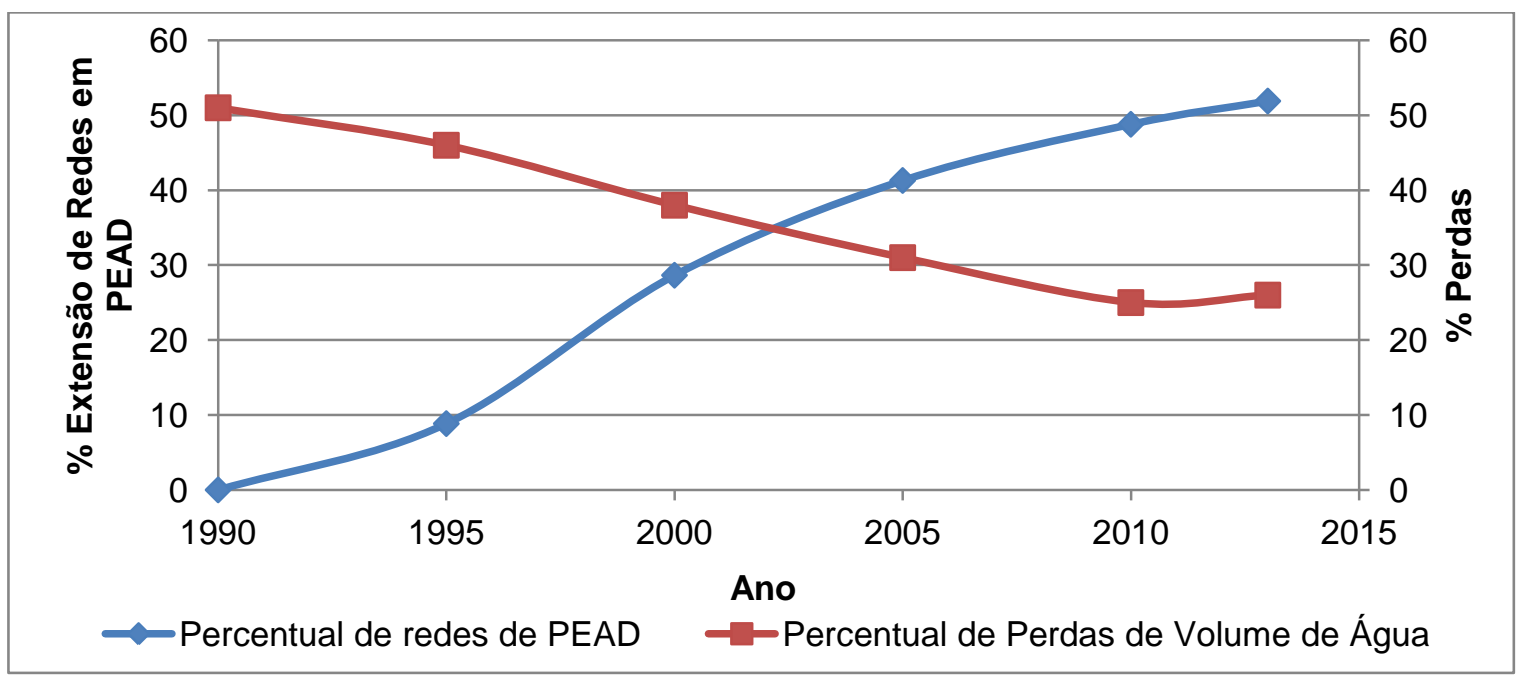

Figura 28 - Extensões de Redes de PEAD e Perdas no Sistema de Abastecimento de Água de Porto Alegre

Fonte: Apresentação DMAE - Porto Alegre - 2014

É possível também identificar uma relação inversamente proporcional entre a quantidade de água produzida por habitante e a porcentagem das extensões de 
redes em PEAD do sistema de abastecimento. Esta correlação é observada claramente na Figura 29, em que temos a evolução entre os anos de 1989 e 2009 dos dois fatores, com o aumento constante da porcentagem de tubulações de PEAD na rede e a diminuição constante da quantidade de água produzida por habitantes.

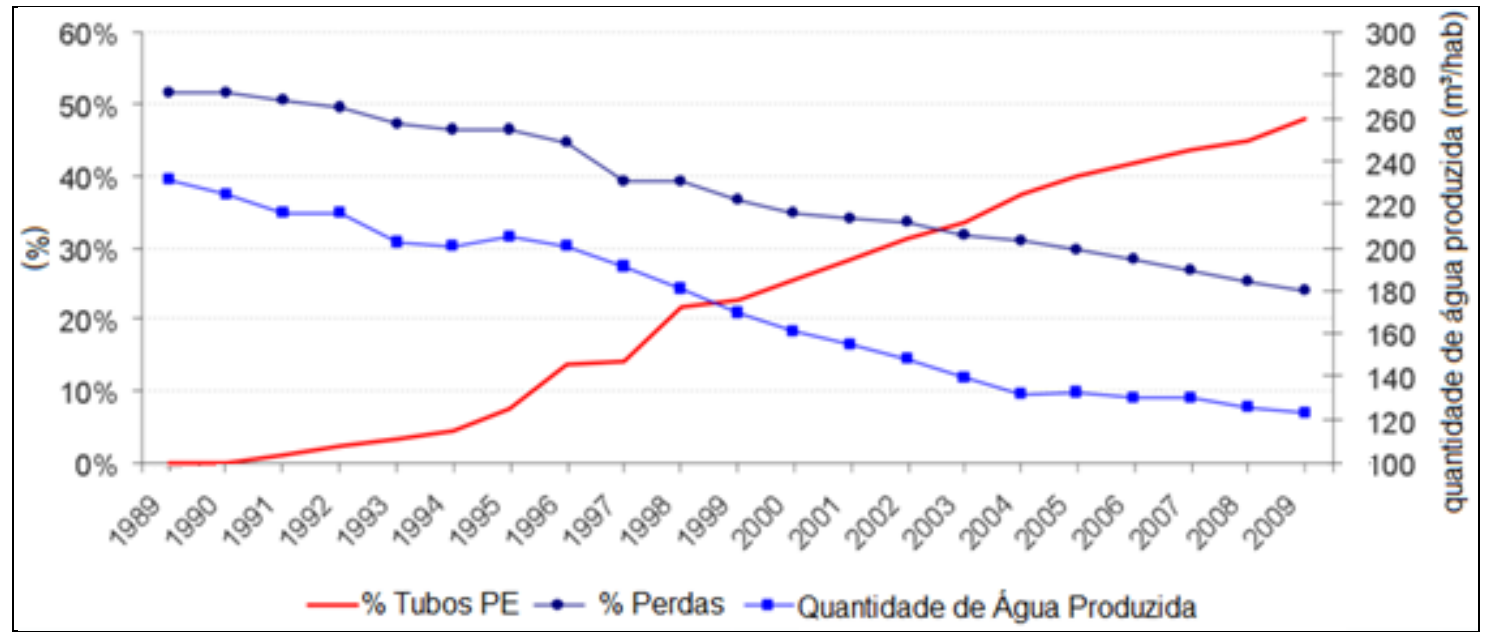

Figura 29 - Extensões de Redes de PEAD e Quantidade de Água Produzida em Porto Alegre Fonte: Apresentação DMAE - Porto Alegre - 2014

\subsection{2. $\underline{\text { SABESP }-M C}$}

Como já mencionado anteriormente no item 4.4.2, entre os anos de 2013 e 2107 a Sabesp está implementando o Programa Corporativo de Redução de Perdas de Água, financiado pela Japan International Cooperation Agency (JICA), com um total de investimento de 3,1 bilhões de reais nesta etapa. Sua meta é chegar ao ano 2020 com o Índice de Perdas Totais Médio (IPM) de 25,7\%. Em 2013, o índice foi de 31,2 \%, como pode ser observado o gráfico a seguir. Na figura 20 também podemos observar a evolução do Índice de Perdas por Ligação (IPDt) e os valores de recursos aplicados em cada ano pela Sabesp. 


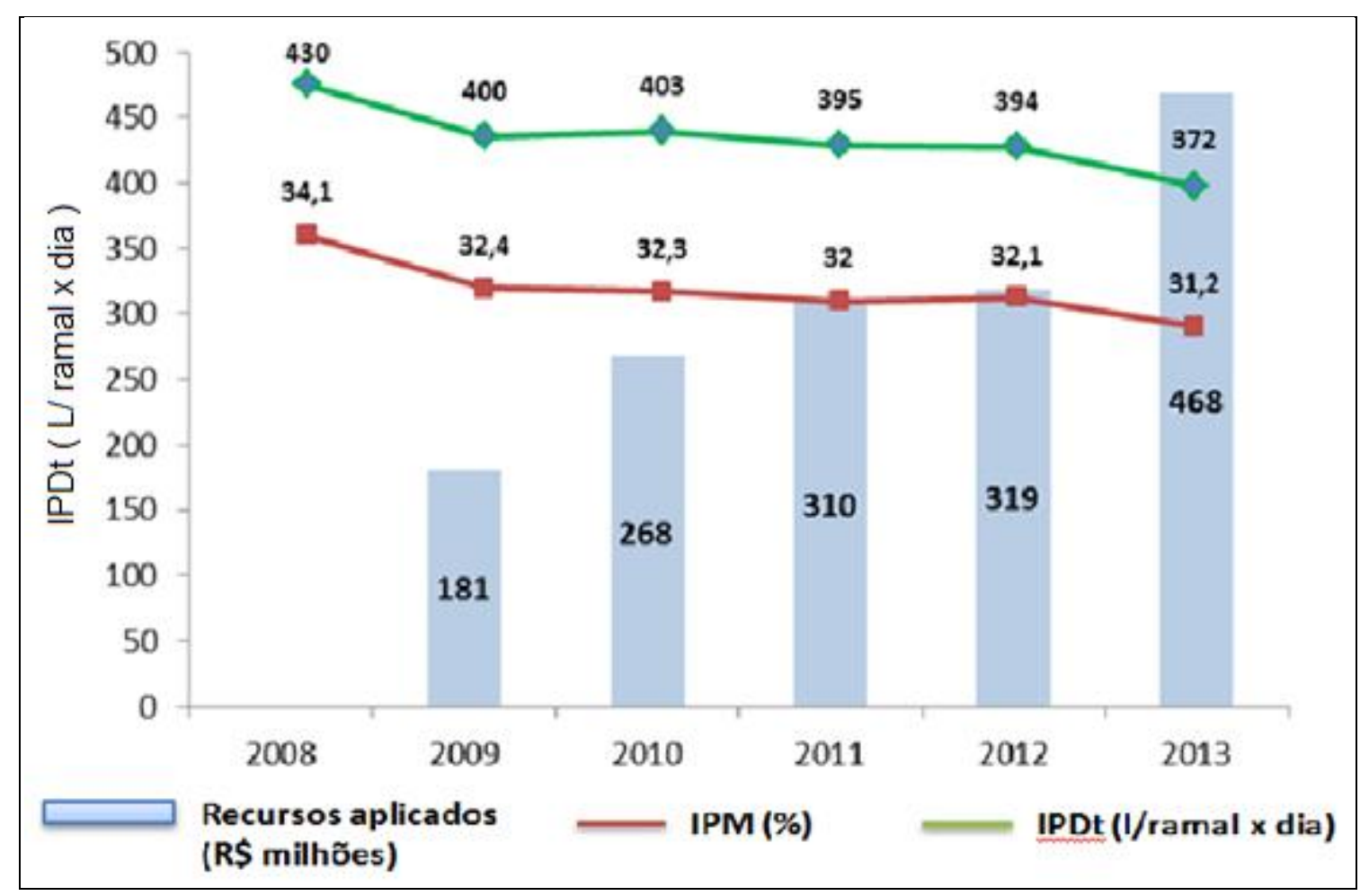

Figura 30 - Índices de Perdas Totais e Recursos Aplicados - Sabesp

Fonte: Apresentação APECS - Sabesp - 2014

Para alcançar esta meta a Sabesp prevê as seguintes obras e serviços a serem executados durante este período:

- Substituição de 910 mil ramais;

- Substituição de 670 km de redes;

- 120 mil reparos de redes;

- Substituição de 1,5 milhão de hidrômetros;

- 775 mil inspeções de ligações inativas e irregulares;

- 70 obras de setorização;

- Implantação de 150 válvulas redutoras de pressão (VRP's);

- Implantação de 400 distritos de medição e controle (DMC's);

- Implantação de 15 boosters;

- Instalação de adequação de 220 macro medidores.

Visando estudar o ganho em relação a perdas reais com o uso do PEAD na cidade de São Paulo, foi selecionada a área a seguir de aproximadamente 14 quadras, localizada entre as ruas Norma Pierutinni Gianotti, Dr. Abrahão Ribeiro, Av. Rudge e Eduardo Viana, no bairro Barra Funda, onde houve grande troca de tubulações de 
Ferro Dúctil por PEAD no ano de 2012. As tubulações destacadas em vermelho são as que foram substituídas por tubulações de polietileno no final de 2012 , de forma a permitir avaliação comparativa:

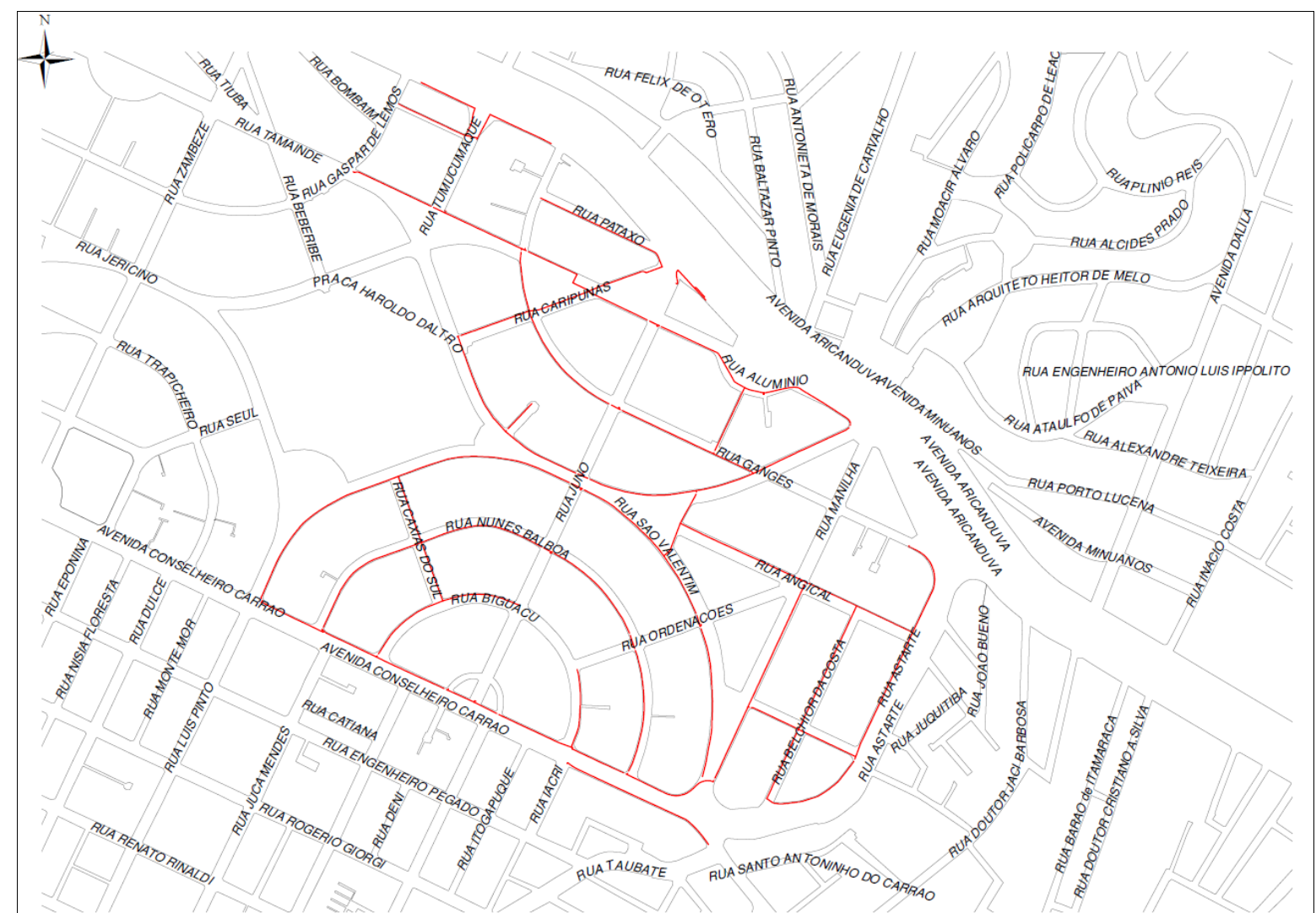

Figura 31 - Substituição de Tubulações de Ferro Fundido por PEAD na Área de Interesse

Fonte: SIGNOS, 2014

Nesta mesma área foi levantado mapas temáticos das ocorrências de vazamento entre os anos de 2007 e 2014, com o objetivos de analisar o ganho com a substituição de redes antigas de ferro por redes de PEAD. Nas Figuras 32 a 39 a seguir, as linhas vermelhas representam tubulações de ferro fundido que serão trocadas ao final de 2012 por tubulações de PEAD. As quadras são coloridas de acordo com o número de ocorrência de vazamentos e arrebentamentos que aconteceram no ano na quadra em questão, como demonstra a legenda de cada figura.

A comparação das figuras visa identificar se houve ganho em questão de ocorrências de vazamentos e arrebentamentos com a substituição de redes antigas por redes de PEAD. 


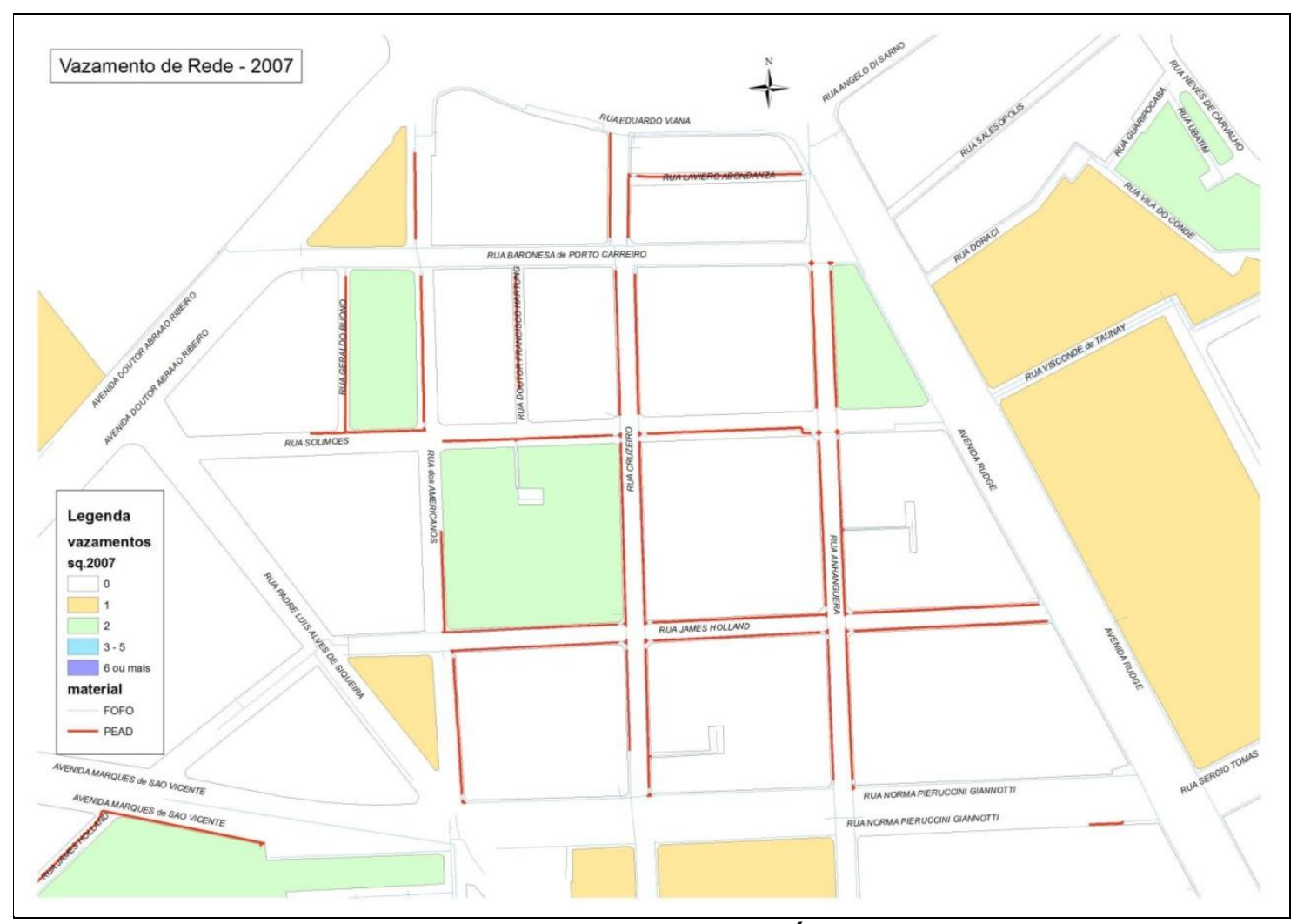

Figura 32 - Ocorrências de Vazamentos na Área de Interesse - 2007

Fonte: SIGNOS, 2014

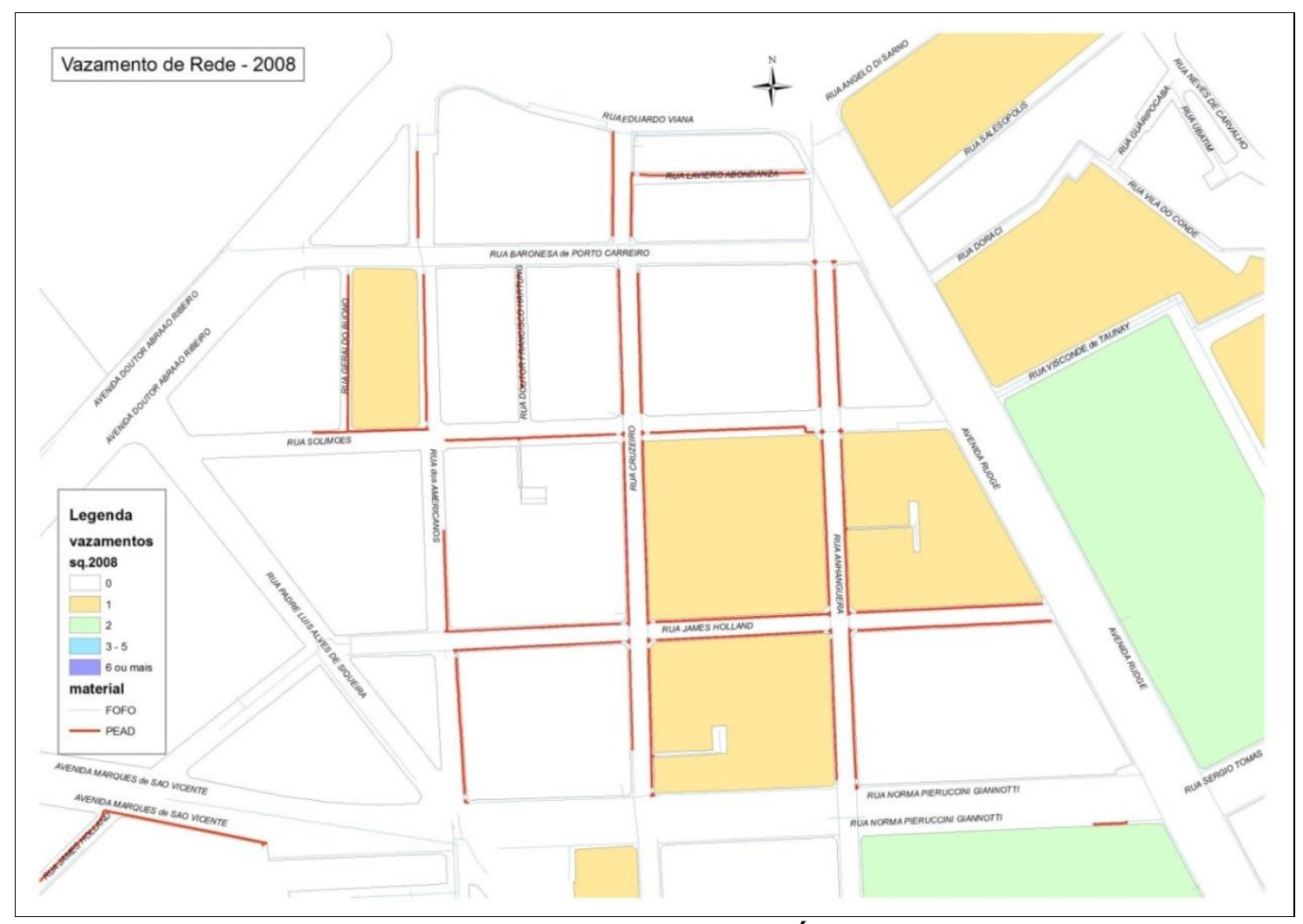

Figura 33 - Ocorrências de Vazamentos na Área de Interesse - 2008

Fonte: SIGNOS, 2014 


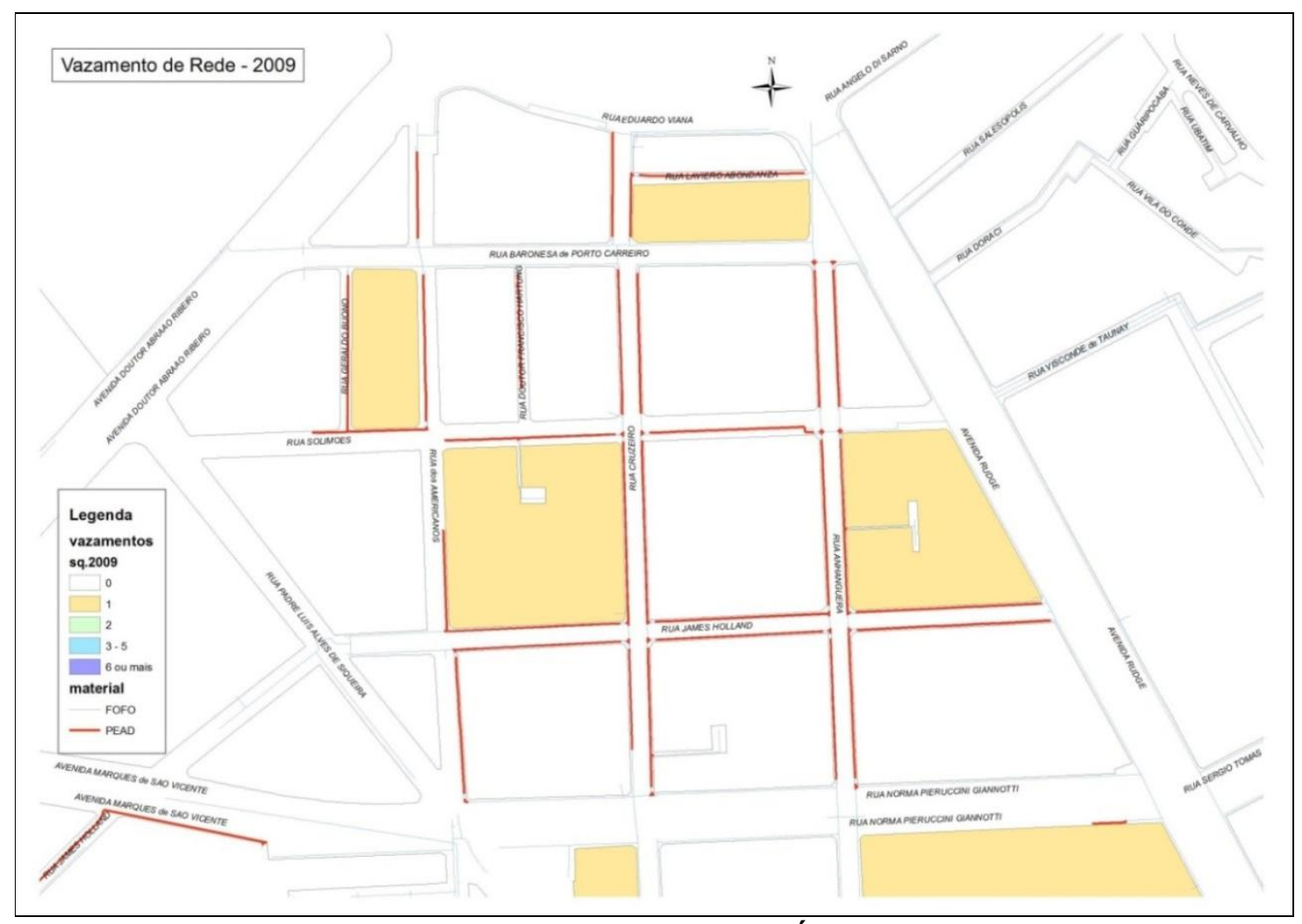

Figura 34 - Ocorrências de Vazamentos na Área de Interesse - 2009

Fonte: SIGNOS, 2014

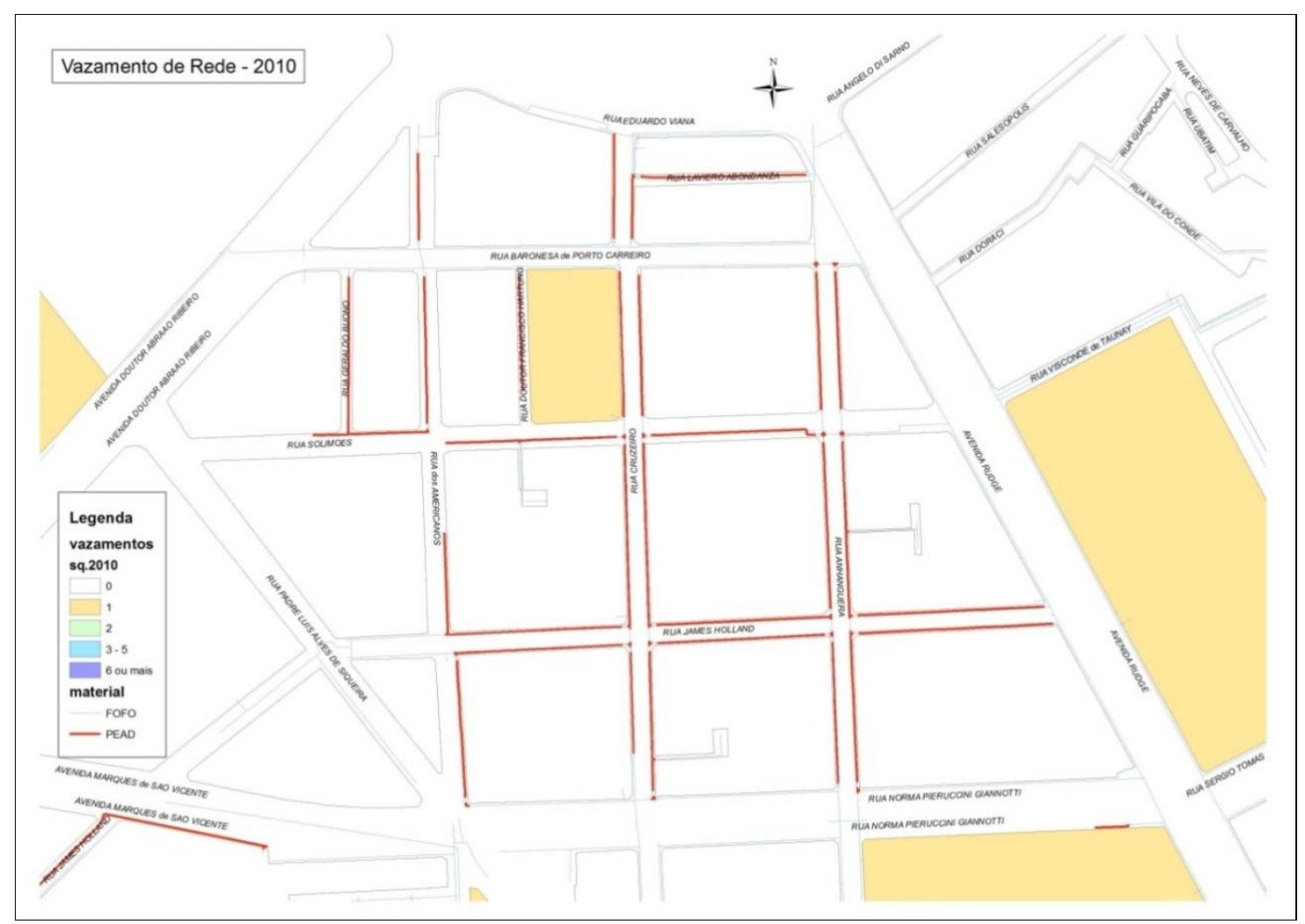

Figura 35 - Ocorrências de Vazamentos na Área de Interesse - 2010

Fonte: SIGNOS, 2014 


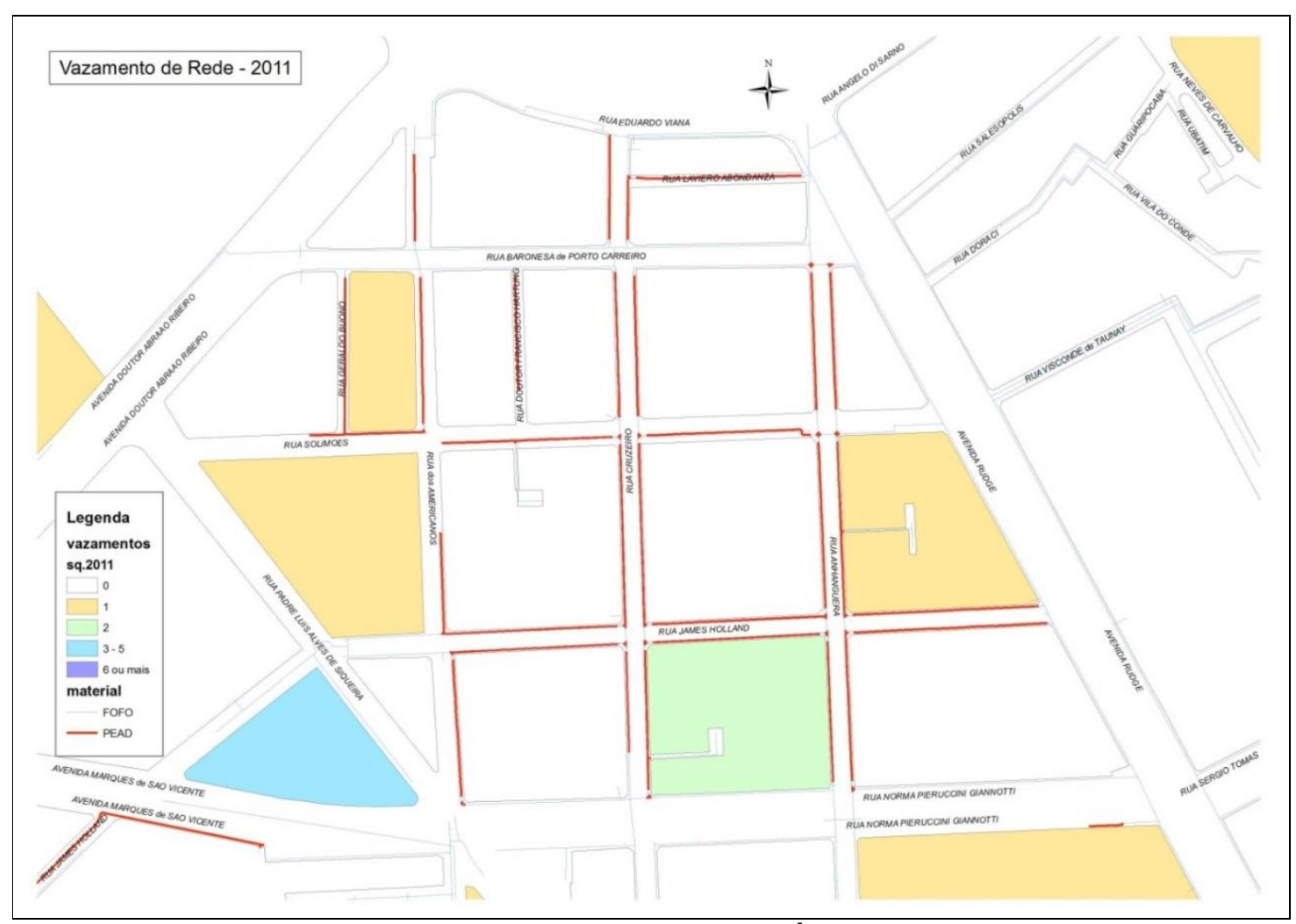

Figura 36 - Ocorrências de Vazamentos na Área de Interesse - 2011

Fonte: SIGNOS, 2014

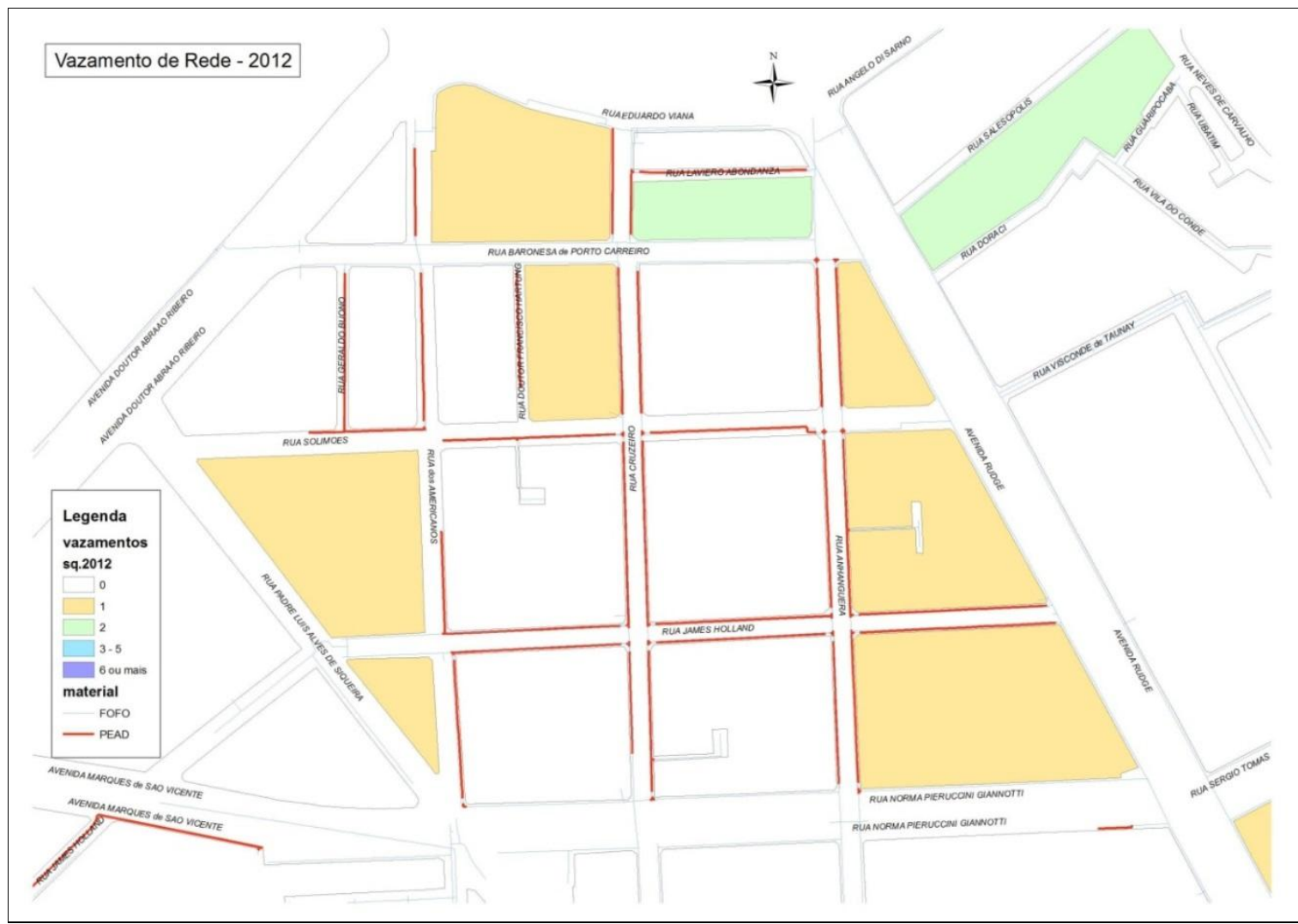

Figura 37 - Ocorrências de Vazamentos na Área de Interesse - 2012

Fonte: SIGNOS, 2014 


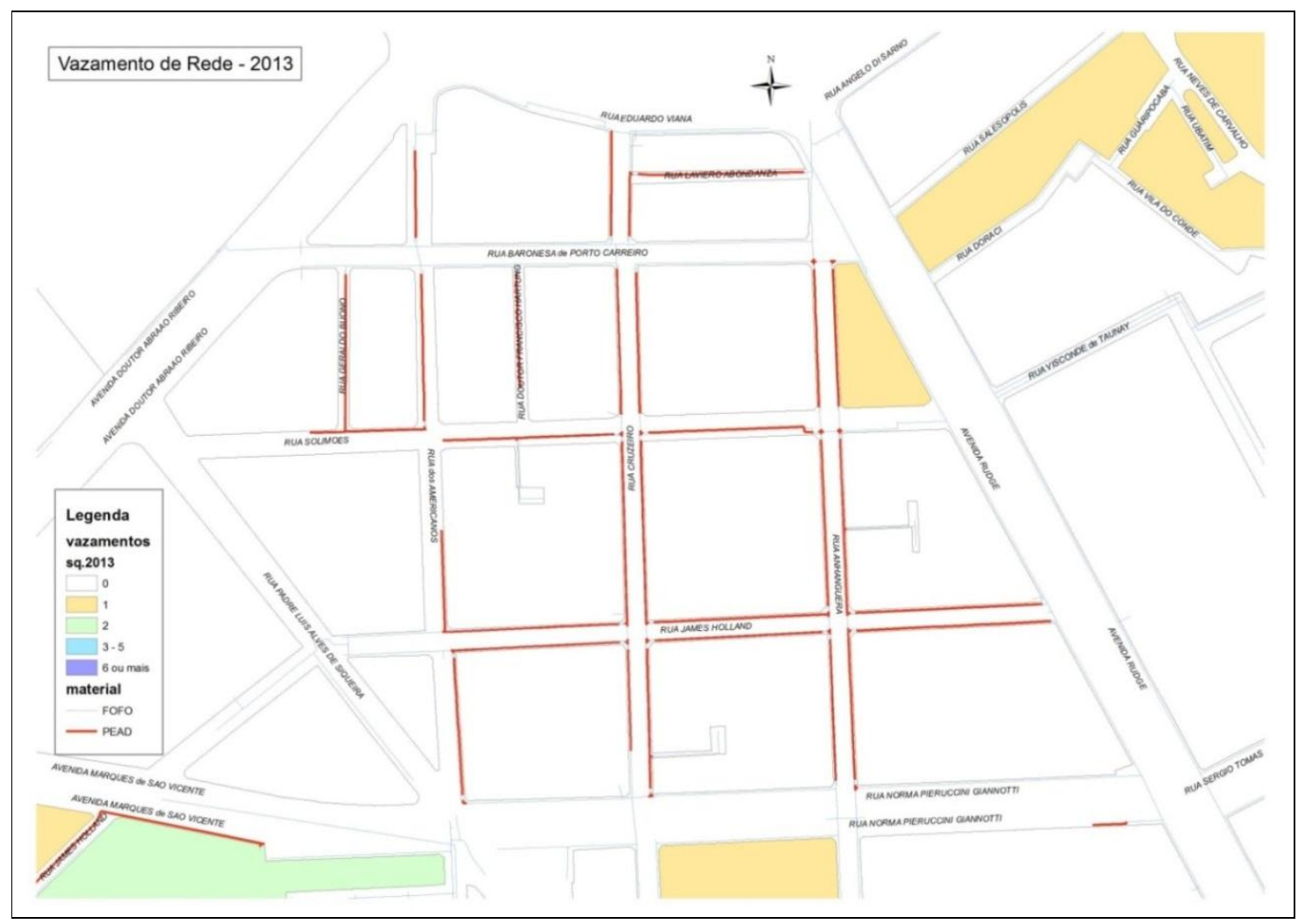

Figura 38 - Ocorrências de Vazamentos na Área de Interesse - 2013

Fonte: SIGNOS, 2014

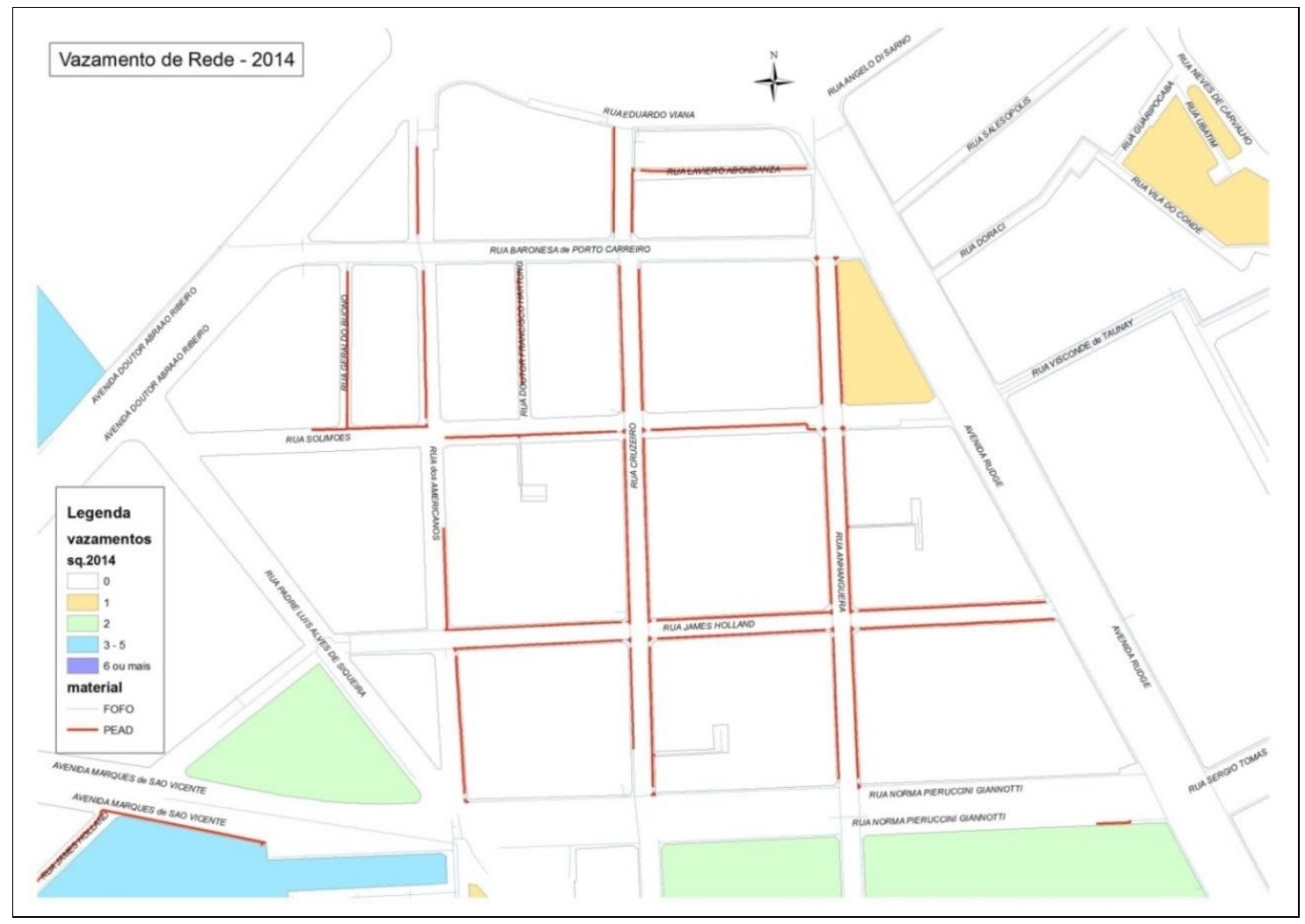

Figura 39 - Ocorrências de Vazamentos na Área de Interesse - 2014

Fonte: SIGNOS, 2014 
A partir destes dados coletados, é possível elaborar um gráfico do número de ocorrências de vazamentos na área estudada, e comparar os valores antes de depois de 2012, ano em que ocorreu a instalação de redes de PEAD.

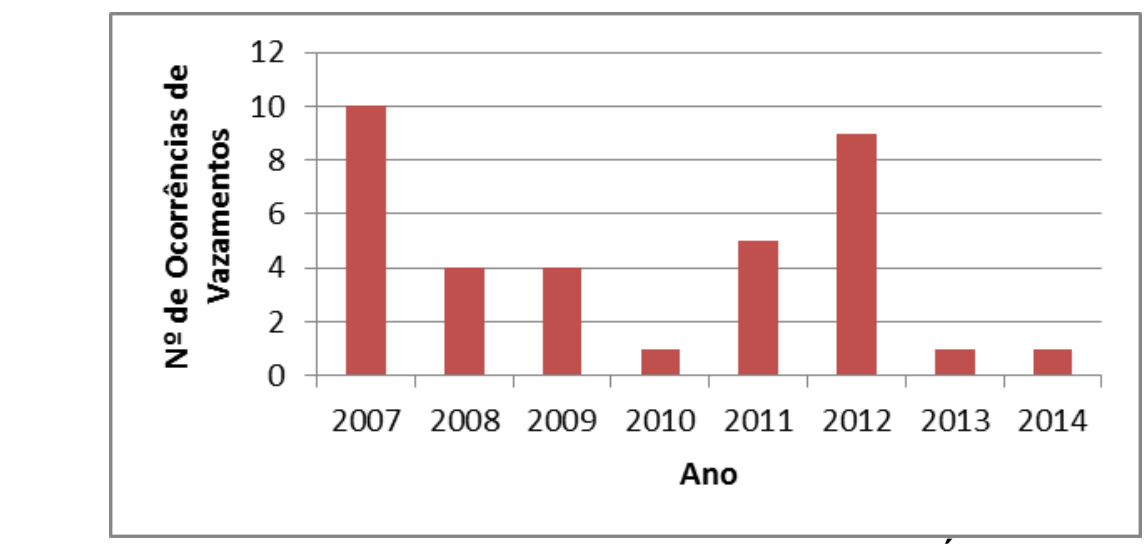

Figura 40 - Número de Ocorrências de Vazamentos na Área de Interesse

Fonte: SIGNOS, 2014

É possível verificar que nos anos 2013 e 2014 que se seguiram após as trocas de tubulações de Ferro Fundido por PEAD, houve considerável diminuição nas ocorrências de vazamentos de rede na região. Vale destacar que nestes anos a única ocorrência de vazamento foi na quadra que apresenta maior extensão de redes de ferro fundido que de PEAD, havendo uma maior possibilidade que esta ocorrência seja decorrente de falha nas redes antigas de ferro fundido. Portanto, podemos considerar essa análise como um indício dos ganhos em perdas reais com o uso de tubulações de PEAD.

Importante salientar que a melhor análise a ser feita para se estabelecer os ganhos de se utilizar tubulações de PEAD seria comparar as tubulações novas implantadas de PEAD com tubulações também novas de Ferro Fundido. Contudo, pela escassez de dados, pois somente a partir de 2011 que foi possível encontrar áreas significativas e, São Paulo com redes de polietileno, não é possível realizar este estudo ainda, porém com mais alguns anos de operação no sistema, será um comparativo a ser feito.

\subsubsection{Limeira}

Desde no ano de 1996, quando começou a se utilizar as tubulações de PEAD em todas as novas ligações prediais e execuções de rede na cidade, podemos perceber 
uma queda considerável no índice de perdas totais do sistema de Abastecimento de Água da cidade, conforme Figura 41 a seguir:

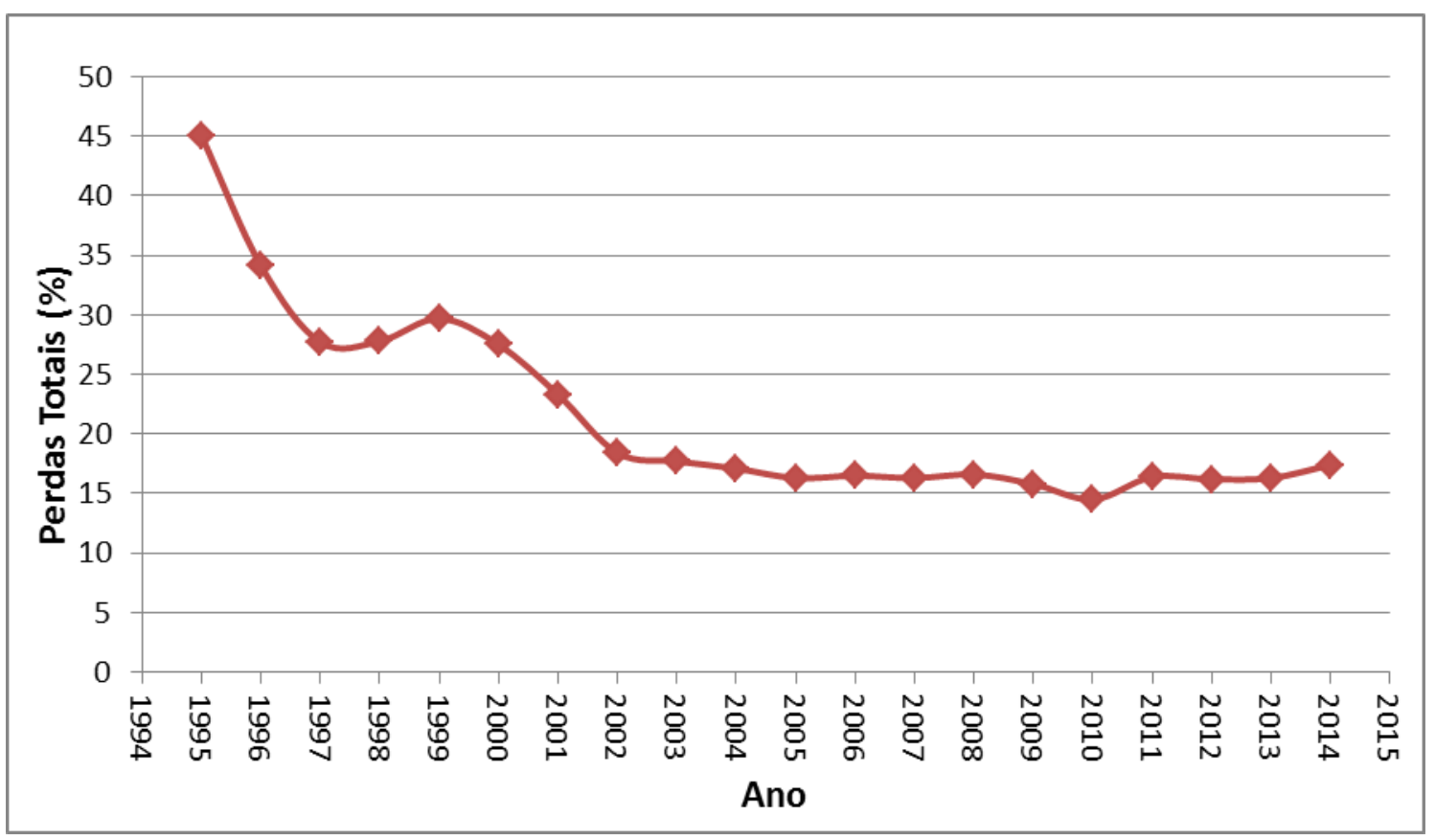

Figura 41 - Evolução do Índice de Perdas Totais do Sistema de Abastecimento da Água de Limeira

De acordo com a equipe de operação da Odebrecht Ambiental de Limeira, contribuiu para este ganho em perdas reais característica das tubulações de PEAD, como: fácil manuseio pela leveza e flexibilidade, menos pontos de vazamentos devido a menor utilização de conexões, rapidez na execução, estocagem e custos.

Visando enfrentar as dificuldades da implantação do novo material de tubulações como homologação de fornecedores e qualidade dos materiais adquiridos, a Odebrecht Ambiental implantou um programa seleção de fornecedores, com referências, visitas e testes, além de um acompanhamento de desempenho através do Índice de Desempenho do Fornecedor e avaliações semestrais.

Foram realizados também programas de treinamento das equipes, ensinando a realizar a soldagem de topo adequadamente e fazer a compactação das valas. Também que foram adotadas medidas como cadastramento de redes, instalçaão de válvulas e registros, campanhas de deteccão de vazamentos e controle de pressão através de setorização e instalação de VRP's e zonas de pressão. Todas essas medidas juntamente a adoção das tubulações de polietileno contribuíram para a diminuição das Perdas Totais da cidade de Limeira. 


\subsection{Custos de Instalação e Manutenção}

\subsubsection{DMAE - Porto Alegre}

Nos anos que se sucederam após a instalação das primeiras tubulações de polietileno, o DMAE-POA enfrentou muitos problemas devido à falta de experiência dos técnicos e empresas com o material, tais como juntas com soldas imperfeitas, danificação da tubulação no assentamento e utilização de peças e acessórios inadequados (Flores, 2009). Aliado ao fato da resina de então, a PE 63, não possuía a qualificação e regulamentação das resinas atuais (PE 80 e PE 100), o início do uso do polietileno acarretou em elevado número de vazamento e arrebentamentos em redes e ramais no Sistema de Abastecimento de Água de Porto Alegre.

Com o passar do tempo, os técnicos e empresas foram se tornando mais capacitados e o polietileno ganhou normas e padrões para serem seguidos, melhorando significantemente seus índices de vazamentos e manutenção.

A utilização do PEAD nas redes de abastecimento de água, aliada com o avanço nas tecnologias e técnicas de operação e manutenção, fizeram com que os gastos com manutenção caíssem consideravelmente em Porto Alegre.

Também foi realizado um trabalho pela DMAE-POA a respeito do tempo de gasto para reparo de redes de polietileno e comparação com as demais, resultando no quadro a seguir:

\begin{tabular}{c|c|c} 
Tabela 12 - Tempo de Reparo por Tamanho de Tubulação \\
\hline \multirow{2}{*}{ Diâmetro (mm) } & \multicolumn{2}{|c|}{ Tempo de Manutenção (min) } \\
\cline { 2 - 3 } & $\begin{array}{c}\text { Tubos não } \\
\text { plásticos }\end{array}$ & $\begin{array}{c}\text { Tubos de } \\
\text { Polietileno }\end{array}$ \\
\hline DE 110 & 210 & 105 \\
\hline DE 20 & 170 & 70 \\
\hline
\end{tabular}

Por ser mais leve e flexível, a tubulação de PEAD se torna mais fácil de ser manuseada, o que diminui o tempo médio de manutenção de uma vazamento ou arrebentamento. Assim, o DMAE-POA também conseguiu diminuir os custos de mão de obra na manutenção através da otimização das equipes. Em 1986, o sistema de abastecimento de Porto Alegre contava 30 equipes para atender $2.100 \mathrm{~km}$ de redes, 
enquanto que em 2013 somente cinco equipes atendiam os $2.100 \mathrm{~km}$ de redes de polietileno, enquanto que outras 20 equipes atendiam a extensão de $2.400 \mathrm{~km}$ de tubulações de outros materiais, como pode ser observado no quadro abaixo:

Tabela 13 - Quantidade de Equipes de Manutenção

\begin{tabular}{|c|c|c|c|c|}
\hline \multirow{2}{*}{ ANO } & \multicolumn{2}{|c|}{ TUBOS DE POLIETILENO } & \multicolumn{2}{c|}{ TUBOS DE OUTROS MATERIAIS } \\
\cline { 2 - 5 } & Extensão (km) & No de Equipes & Extensão (km) & No de Equipes \\
\hline 1986 & - & - & 2100 & 30 \\
\hline 2013 & 2100 & 5 & 2400 & 20 \\
\hline
\end{tabular}

Fonte: DMAE-POA (2007).

Tabela 14 - Custos de Execução de Redes - DMAE-POA (R\$/metro) (2006)

\begin{tabular}{|c|c|c|c|c|c|c|c|c|}
\hline \multirow{2}{*}{ Discriminação } & \multicolumn{4}{|c|}{ Ferro Fundido } & \multicolumn{4}{|c|}{ PEAD } \\
\hline & DN-100 & DN-200 & DN-300 & DN-400 & DE-110 & DE-225 & DE-315 & DE-400 \\
\hline \multicolumn{9}{|l|}{ Serviços } \\
\hline $\begin{array}{c}\text { 1. Escavação } \\
\text { Mecanizada de Terra }\end{array}$ & 4,01 & 4,81 & 6,31 & 9,72 & 2,62 & 2,62 & 4,74 & 4,74 \\
\hline 2. Reaterro c/ Areia & 20,38 & 25,78 & 31,52 & 43,9 & 16,48 & 16,48 & 22,64 & 22,64 \\
\hline $\begin{array}{l}\text { 3. Escoramento } \\
\text { Descontínuo }\end{array}$ & 23 & 23 & 23 & 23 & - & - & - & - \\
\hline $\begin{array}{l}\text { 4. Montagem/ } \\
\text { Assentamento }\end{array}$ & 6,43 & 9,82 & 13,25 & 17,65 & 4,56 & 5,89 & 6,9 & 7,19 \\
\hline $\begin{array}{l}\text { 5. Pavimentação } \\
\text { Basáltica Irregular }\end{array}$ & 21,76 & 21,76 & - & - & 15,23 & 15,23 & - & - \\
\hline $\begin{array}{l}\text { 6. Pavimentação } \\
\text { Asfáltica }\end{array}$ & - & - & 177,52 & 177,52 & - & - & 124,26 & 124,26 \\
\hline 7. Entroncamento & 0,4 & 0,48 & 0,53 & 0,62 & 0,45 & 0,45 & 0,58 & 0,58 \\
\hline $\begin{array}{l}\quad 8 . \\
\text { Lavagem/Desinfecção }\end{array}$ & 0,6 & 0,75 & 0,93 & 0,97 & 0,42 & 0,47 & 0,49 & 0,51 \\
\hline Sub Total & 76,58 & 86,25 & 253,06 & 273,38 & 39,76 & 41,14 & 159,61 & 159,92 \\
\hline \multicolumn{9}{|l|}{ Materiais } \\
\hline 1. Tubos & 101,15 & 157,28 & 214,52 & 287,9 & 30,82 & 127,27 & 250,35 & 403,08 \\
\hline 2. Conexões & 18,09 & 27,72 & 37,86 & 50,8 & 5,43 & 22,53 & 44,18 & 71,13 \\
\hline 3. Ligação Predial (20) & 19,63 & 26,48 & - & - & 23,8 & 27,5 & - & - \\
\hline Sub Total & 138,87 & 211,48 & 252,38 & 338,7 & 60,05 & 177,3 & 294,53 & 474,21 \\
\hline Total Geral & 215,45 & 297,73 & 505,44 & 612,08 & 99,81 & 218,44 & 454,14 & 634,13 \\
\hline
\end{tabular}




\subsubsection{Sabesp - MC}

Segundo Peres (2005), em 1998, 73,3\% dos ramais prediais da Região Metropolitana de São Paulo - RMSP eram de PEAD, 26\% de aço galvanizado e $0,7 \%$ de PVC.

Um estudo desenvolvido para a SABESP pela LYSA - Lyonnaise Des Eaux Services Associés em 1992 apontou, após análise de 808 casos de perdas, que 95\% das ocorrências ocorriam em ramais prediais, $80 \%$ destas eram em ramais de PEAD, $49 \%$ das falhas ocorriam no tubo de PEAD e $46 \%$ nas curvas, juntas e registros (PERES apud BARRETO, 2001).

Segundo PERES (2005), 90\% dos consertos de vazamentos executados pela SABESP na Região Metropolitana de São Paulo (cerca de 36.000 ocorrências mensais) eram realizados no ramal predial, sendo que $60 \%$ ocorriam no tubo de PEAD. Nos estudos de campo realizados pelo Instituto de Pesquisas Tecnológicas (IPT) na primeira fase do "Projeto - PEAD" (2000-2001) foram identificados 5 tipos de falhas mais significativas em ramais prediais com tubos de PEAD, os quais representavam cerca de $80 \%$ dos casos estudados: microfissuras, furos e trincas no tubo, trinca no adaptador, vazamento em junta mecânica, vazamento em junta rosqueada e trinca em registro.

O trabalho apontou como principais causas e origens das falhas: má fabricação do tubo e dos acessórios, má formulação e/ou má preparação do composto de polietileno e de outros compostos plásticos empregados nos acessórios, erros de projeto de componentes, controle de qualidade ausente (ou ineficaz), instalação inadequada do ramal e respectivos componentes, falta de treinamento dos instaladores e utilização de ferramentas impróprias.

ROCHA (1999), realizou um trabalho de aprimoramento dos ramais prediais, que além de constatar, registrar e classificar os problemas de vazamentos nos ramais, elaborou um plano de atividade para o combate destas perdas, que consistem:

- Elaboração do desenho de um novo projeto para o ramal predial;

- Aprimoramento das especificações técnicas elaboradas pela empresa e utilizadas como referência técnica na aquisição dos produtos utilizados no sistema ramal predial; 
- Recomendações para o reparo dos atuais ramais de polietileno tendo em vista o conjunto de falhas que foram identificadas nesse trabalho;

- Formulação dos requisitos técnicos mínimos a serem utilizados na implantação de programas para qualificação de fornecedores;

- Implantação de um sistema de registro de falhas para o ramal predial de polietileno (trabalho que já foi aqui apresentado);

- Concepção de um programa de garantia da qualidade a ser desenvolvido e implantado para o sistema ramal.

Em 1998 uma nova configuração de ramal predial foi implementada, substituindo os colares de tomada em PVC por Tês de serviço autotravados em Polipropilenos.

Em 2006 a Sabesp realizou uma nova pesquisa na incidência de reparos realizados em suas redes, ramais e cavaletes. O resultado foi que a maior incidência são os vazamentos no cavalete (46\%) - contribui para isso o fato de serem visíveis e, portanto mais facilmente percebíveis - seguidos dos ramais $(31 \%)$, como pode ser verificados na figura a seguir.

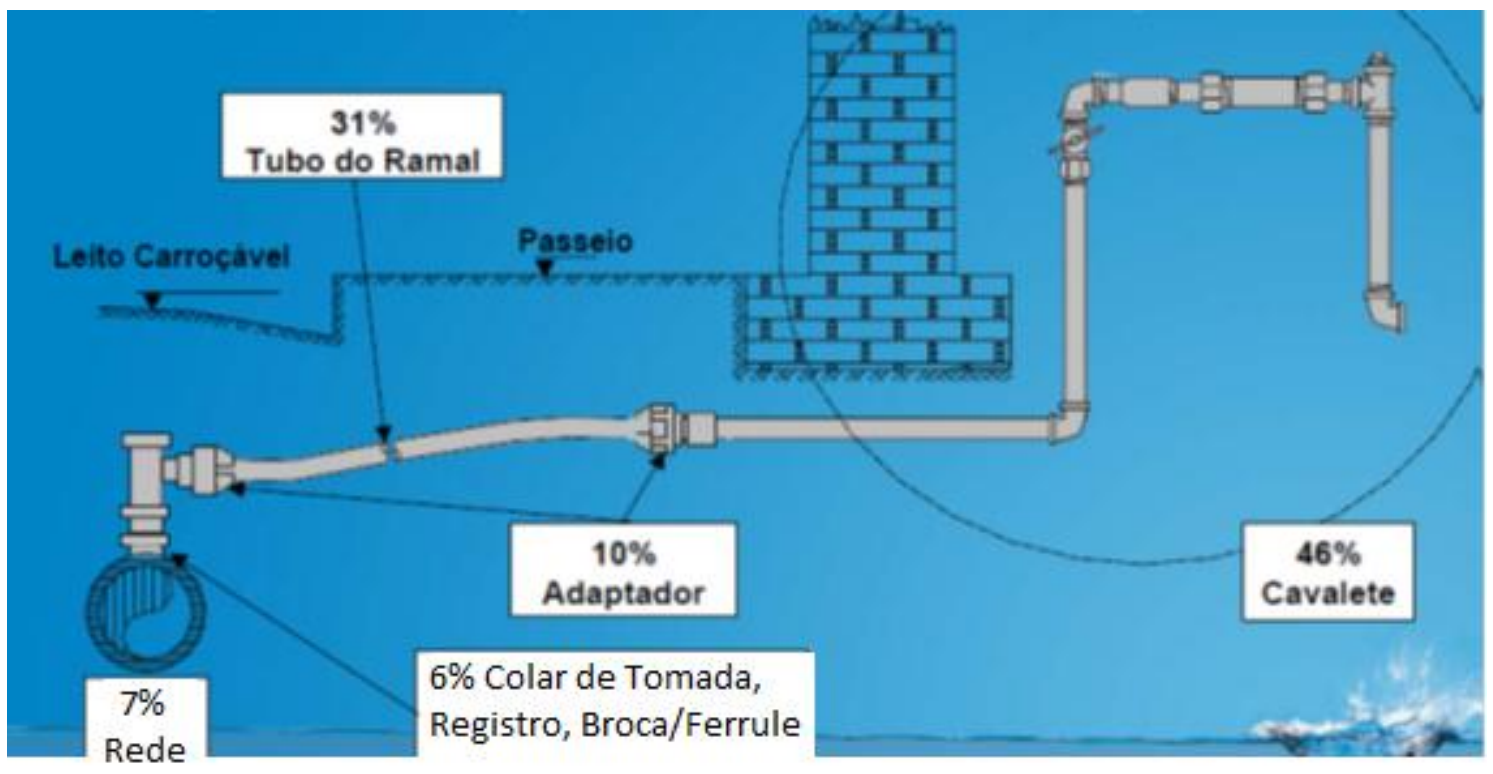

Figura 42 - Ocorrências de Vazamentos na Área de Interesse - 2014

Fonte: Sabesp, 2006

Durante todo o ano de 2011, a Sabesp realizou 336.914 reparos, sendo 63.206 $(18,8 \%)$ em redes e $273.208(81,2 \%)$ em ramais. Vale lembrar que os vazamentos em redes, por serem mais profundos são mais difíceis de serem percebidos e que 
normalmente por terem uma capacidade maior, resultam em uma vazão de perda maior.

A seguir temos os custos envolvidos na execução de redes em vala a céu aberto, a primeira tabela com tubulações de Ferro Fundido e a segunda envolvendo tubos de PEAD. Esses valores foram utilizados pela Sabesp na elaboração dos projetos do Programa Corporativo de Redução de Perdas de Água, etapa JICA, já mencionados anteriormente no item 4.4.2. São valores de referência, ainda passariam por revisão antes de usados nas licitações de obras pela Sabesp. 
Tabela 15 - Custos de Execução de Redes FoFo - Sabesp M (R\$/Metro)

\begin{tabular}{|c|c|c|c|c|}
\hline \multirow{2}{*}{ DISCRIMINAÇÃO } & \multicolumn{4}{|c|}{ FERRO FUNDIDO } \\
\hline & DN-100 & DN-200 & DN-300 & DN-400 \\
\hline \multicolumn{5}{|l|}{ LOCAÇÃO E CADASTRO } \\
\hline $\begin{array}{c}\text { LOCAÇÃO E ACOMPANHAMENTO TOPOGRÁFICO DE } \\
\text { OBRAS ESPECIAIS }\end{array}$ & 8,59 & 8,59 & 8,59 & 8,59 \\
\hline CADASTRO DE OBRAS LOCALIZADAS & 61,08 & 61,08 & 61,08 & 61,08 \\
\hline \multicolumn{5}{|l|}{ PESQUISA E DETECÇÃO } \\
\hline PESQUISA DE INTERFERÊNCIA & 4,05 & 4,86 & 6,07 & 6,07 \\
\hline \multicolumn{5}{|l|}{ SERVIÇOS PRELIMINARES } \\
\hline SINALIZAÇÃO DE TRÁFEGO & 1,84 & 1,84 & 1,84 & 1,84 \\
\hline TAPUME CONTÍNUO EM CHAPAS DE MADEIRA & 10,90 & 10,90 & 10,90 & 10,90 \\
\hline PASSADIÇOS DE MADEIRA PARA PEDESTRES & 1,49 & 1,49 & 1,49 & 1,49 \\
\hline PASSADIÇOS DE CHAPA METÁLICA PARA VEÍCULOS & 4,49 & 4,49 & 4,49 & 4,49 \\
\hline \multicolumn{5}{|l|}{ LEVANTAMENTO DE PAVIMENTAÇÃO } \\
\hline LEVANTAMENTO DE PAVIMENTAÇÃO ASFÁLTICA (A) & 9,04 & 10,84 & 13,55 & 13,55 \\
\hline \multicolumn{5}{|l|}{ MOVIMENTO DE TERRA } \\
\hline $\begin{array}{l}\text { ESCAVAÇÃO MECANIZADA DE VALAS, EM SOLO NÃO } \\
\text { ROCHOSO, COM PROFUNDIDADE ATÉ 2,00 M (A) }\end{array}$ & 2,78 & 3,34 & 4,18 & 4,18 \\
\hline $\begin{array}{l}\text { ESCAVAÇÃO MANUAL DE VALAS, POÇOS E CAVAS EM } \\
\text { SOLO NÃO ROCHOSO, COM PROFUNDIDADE ATÉ 1,25 M }\end{array}$ & 2,64 & 3,17 & 3,96 & 3,96 \\
\hline $\begin{array}{c}\text { ATERRO DE VALAS, POÇOS E CAVAS COMPACTADO } \\
\text { MECANICAMENTE, COM CONTROLE DO G.C. }>=95 \% \text { DO } \\
\text { ENSAIO NORMAL DE COMPACTAÇÃO (A) }\end{array}$ & 7,31 & 8,77 & 11,62 & 11,62 \\
\hline CARGA E DESCARGA - SOLO (A) & 0,59 & 0,73 & 0,77 & 0,77 \\
\hline ESCAVAÇÃO EM JAZIDA DE SOLO & 0,68 & 0,86 & 1,11 & 1,11 \\
\hline AQUISIÇÃO DE MATERIAL DE JAZIDA DE SOLO & 2,56 & 3,20 & 4,16 & 4,16 \\
\hline $\begin{array}{l}\text { TAXA DE BOTA-FORA EM ATERRO COM LICENÇA } \\
\text { AMBIENTAL (VIAGEM CAMINHÃO } 17 \mathrm{t}=17 \mathrm{~m} 3 \text { ) }\end{array}$ & 1,37 & 1,68 & 1,79 & 1,79 \\
\hline TRANSPORTE DE MATERIAL ESCAVADO - SOLO (A) & 16,54 & 20,45 & 23,50 & 23,50 \\
\hline \multicolumn{5}{|l|}{ ASSENTAMENTO } \\
\hline $\begin{array}{l}\text { INSUMOS - MO, VEÍCULO PARA REALIZAÇÃO DE } \\
\text { TRANSPORTE DE TUBO DE FOFO }\end{array}$ & 0,86 & 4,46 & 5,95 & 5,95 \\
\hline $\begin{array}{c}\text { INSUMOS - MO, VEÍCULOS, EQUIPAMENTOS - PARA } \\
\text { REALIZAÇÃO DA INSTALAÇAO DE TUBOS DE FOFO DN } 80 \\
\text { A 150MM }\end{array}$ & 10,16 & 96,29 & 117,68 & 117,68 \\
\hline \multicolumn{5}{|l|}{ PAVIMENTAÇÃO } \\
\hline LEVANTAMENTO DE PAVIMENTAÇÃO ASFÁLTICA (A) & 6,14 & 6,51 & 7,05 & 7,05 \\
\hline CONCRETO PARA FECHAMENTO DE VALAS (A) & 21,43 & 25,71 & 32,14 & 32,14 \\
\hline IMPRIMAÇÃO LIGANTE (A) & 4,38 & 5,01 & 5,95 & 5,95 \\
\hline CAPA DE CONCRETO ASFÁLTICO (A) & 29,22 & 33,39 & 39,65 & 39,65 \\
\hline LIMPEZA DA OBRA & 4,58 & 5,50 & 6,87 & 6,87 \\
\hline \multicolumn{5}{|l|}{ FORNECIMENTO DE MATERIAIS } \\
\hline TUBULAÇÃO & 1.178 & 1.486 & 1.817 & 2.204 \\
\hline TOTAL & $1.390,72$ & $1.809,16$ & $2.191,39$ & $2.578,39$ \\
\hline
\end{tabular}

Fonte: SABESP-M (2015). 
Tabela 16 - Custos de Execução de Redes PEAD (R\$/Metro)

\begin{tabular}{|c|c|c|c|c|}
\hline \multirow{2}{*}{ DISCRIMINAÇÃO } & \multicolumn{4}{|c|}{ PEAD } \\
\hline & DE-110 & DE-225 & DE-315 & DE-400 \\
\hline \multicolumn{5}{|l|}{ LOCAÇÃO E CADASTRO } \\
\hline $\begin{array}{l}\text { LOCAÇÃO E ACOMPANHAMENTO TOPOGRÁFICO DE } \\
\text { OBRAS ESPECIAIS }\end{array}$ & 8,59 & 8,59 & 8,59 & 8,59 \\
\hline CADASTRO DE OBRAS LOCALIZADAS & 61,08 & 61,08 & 61,08 & 61,08 \\
\hline \multicolumn{5}{|l|}{ PESQUISA E DETECÇÃO } \\
\hline PESQUISA DE INTERFERÊNCIA & 4,05 & 4,86 & 6,07 & 6,07 \\
\hline \multicolumn{5}{|l|}{ SERVIÇOS PRELIMINARES } \\
\hline SINALIZAÇÃO DE TRÁFEGO & 2,09 & 2,09 & 2,09 & 2,09 \\
\hline TAPUME CONTÍNUO EM CHAPAS DE MADEIRA & 12,10 & 12,10 & 12,10 & 12,10 \\
\hline PASSADIÇOS DE MADEIRA PARA PEDESTRES & 1,61 & 1,61 & 1,61 & 1,61 \\
\hline PASSADIÇOS DE CHAPA METÁLICA PARA VEÍCULOS & 4,95 & 4,95 & 4,95 & 4,95 \\
\hline \multicolumn{5}{|l|}{ MOVIMENTO DE TERRA } \\
\hline $\begin{array}{l}\text { ESCAVAÇÃO MECANIZADA DE VALAS, EM SOLO NÃO } \\
\text { ROCHOSO, COM PROFUNDIDADE ATÉ 2,00 M (A) }\end{array}$ & 6,89 & 6,89 & 7,17 & 10,40 \\
\hline $\begin{array}{l}\text { ESCAVAÇÃO MANUAL DE VALAS, POÇOS E CAVAS EM } \\
\text { SOLO NÃO ROCHOSO, COM PROFUNDIDADE ATÉ } 1,25 \mathrm{M}\end{array}$ & 1,50 & 1,50 & 1,50 & 1,70 \\
\hline $\begin{array}{c}\text { ATERRO DE VALAS, POÇOS E CAVAS COM ENVOLTÓRIA } \\
\text { DE AREIA (A) }\end{array}$ & 31,79 & 31,79 & 34,52 & 47,03 \\
\hline $\begin{array}{l}\text { ATERRO DE VALAS, POÇOS E CAVAS COMPACTADO } \\
\text { MECANICAMENTE, COM CONTROLE DO G.C. >= 95\% DO } \\
\text { ENSAIO NORMAL DE COMPACTAÇÃO (A) }\end{array}$ & 10,34 & 10,34 & 10,34 & 14,95 \\
\hline CARGA E DESCARGA - SOLO (A) & 2,29 & 2,29 & 2,46 & 3,52 \\
\hline ESCAVAÇÃO EM JAZIDA DE SOLO & 1,03 & 1,03 & 1,03 & 1,49 \\
\hline $\begin{array}{l}\text { TAXA DE BOTA-FORA EM ATERRO COM LICENÇA } \\
\text { AMBIENTAL (VIAGEM CAMINHÃO } 17 \mathrm{t}=17 \mathrm{~m} 3 \text { ) }\end{array}$ & 12,09 & 12,09 & 12,99 & 18,63 \\
\hline TRANSPORTE DE MATERIAL ESCAVADO - SOLO (A) & 49,35 & 49,35 & 52,36 & 75,27 \\
\hline \multicolumn{5}{|l|}{ ESCORAMENTO } \\
\hline ESCORAMENTO DESCONTÍNUO (A) & 35,47 & 35,47 & 35,47 & 35,47 \\
\hline \multicolumn{5}{|l|}{ ASSENTAMENTO } \\
\hline $\begin{array}{c}\text { INSUMOS - MO, VEÍCULO PARA REALIZACCÃO DE } \\
\text { TRANSPORTE DE TUBO DE PEAD }\end{array}$ & 3,74 & 3,74 & 3,74 & 3,74 \\
\hline $\begin{array}{c}\text { INSUMOS - MO, VEICCULOS, EQUIPAMENTOS - PARA } \\
\text { REALIZAÇÃO DA INSTALAÇAO DE TUBOS DE PEAD DN } \\
\text { 200MM }\end{array}$ & 96,29 & 96,29 & 96,29 & 96,29 \\
\hline \multicolumn{5}{|l|}{ PAVIMENTAÇÃO } \\
\hline LEVANTAMENTO DE PAVIMENTAÇÃO ASFÁLTICA (A) & 22,73 & 22,73 & 22,73 & 25,12 \\
\hline SUB - BASE EM BRITA OU MACADAME HIDRÁULICO (A) & 17,76 & 17,76 & 17,76 & 20,13 \\
\hline IMPRIMAÇÃO LIGANTE (A) & 6,66 & 6,66 & 6,66 & 7,36 \\
\hline CAPA DE CONCRETO ASFÁLTICO (A) & 18,27 & 18,27 & 18,27 & 20,71 \\
\hline \multicolumn{5}{|l|}{ SOLDA DA TUBULAÇÃO DE PEAD } \\
\hline SOLDA DA TUBULAÇÃO DE PEAD DE 200MM & 14,07 & 14,07 & 14,07 & 19,77 \\
\hline \multicolumn{5}{|l|}{ SERVIÇOS COMPLEMENTARES } \\
\hline LIMPEZA DA OBRA & 7,77 & 7,77 & 7,77 & 8,81 \\
\hline \multicolumn{5}{|l|}{ FORNECIMENTO DE MATERIAIS } \\
\hline TUBULAÇÕES & 103 & 245 & 262 & 507 \\
\hline TOTAL & 535,51 & 678,32 & 703,62 & 1013,88 \\
\hline
\end{tabular}


Podemos perceber pelas tabelas de custos que os preços de execução de redes do PEAD são ligeiramente mais elevados que as redes em Ferro Fundido, contudo a grande diferença está no fornecimento do material, no qual as tubulações e peças de ferro fundido são consideravelmente mais caras que as de PEAD, gerando um custo total maior para todos os diâmetros de ferro fundido.

\subsubsection{Limeira}

Desde 1996, quando começou a utilização de tubulações de PEAD no Sistema de Abastecimento de Água de Limeira, a Odebrecht Ambiental também passou a adotar o índice chamado TIA - Tempo de Intervenção das Equipes de Rede de Água, que representa o tempo médio em um ano de consertos de vazamentos e arrebentamentos das redes de água. Na figura 42 a seguir, podemos ver uma evolução nesse índice ao longo dos anos com a adoção de tubulações de PEAD e outras medidas de monitoramento e operação como inspeções noturnas, campanhas de detecção, trocas de válvulas e adoção de outro índices de qualidade e controle.

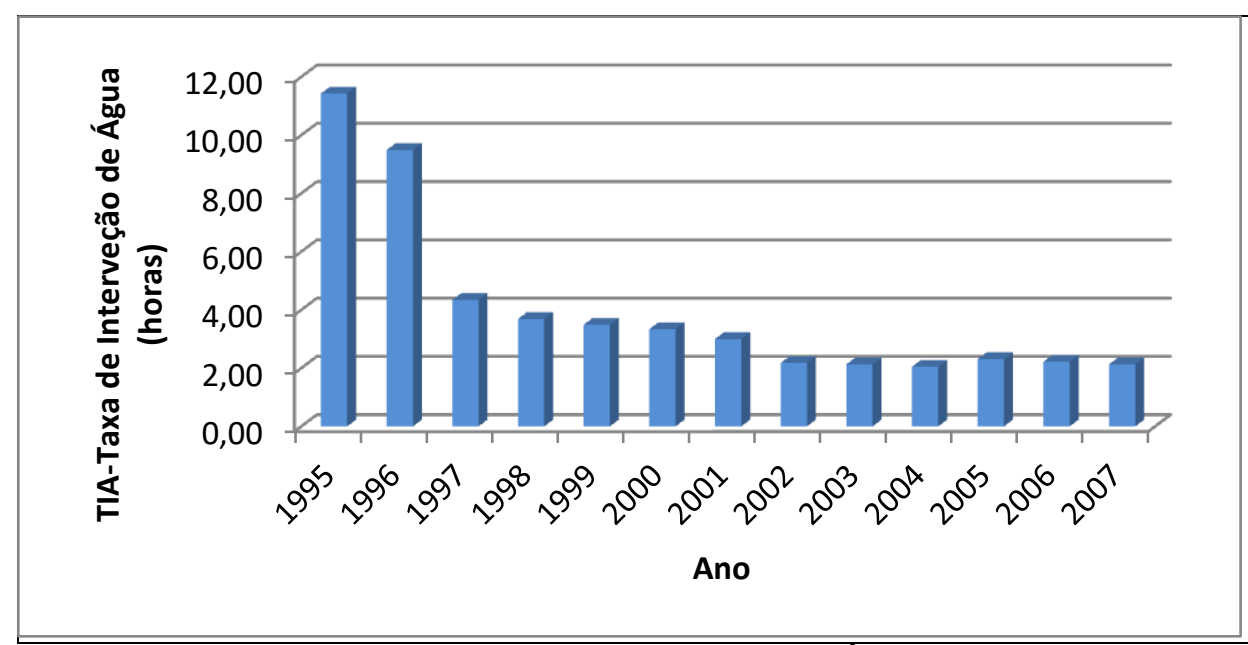

Figura 43 - TIA - Tempo de Intervenção de Água - Limeira/SP

Fonte: ODEBRECHT Ambiental (2014)

\subsection{Desempenho das Tubulações de Polietileno}

Em 1984, foi realizada uma grande pesquisa sobre o desempenho destas tubulações nas empresas prestadores de serviço que se utilizavam este material, combinando dados da American Water Works Association (AWWA) com entrevistas por telefone, visitas in loco e análises laboratoriais. Naquele ano, as tubulações 
analisadas tinham aproximadamente 20 anos de funcionamento. A média de satisfação com as tubulações de polietileno foi de $95 \%$, porém com um detalhe: foram excluídos da pesquisa os tubos de um dos fabricantes analisados.

A pesquisa realizada por Thompson and Jenkins "Review of Water Industry Plastic Pipe Practices", publicada em 1987 e patrocinada pela AWWA Research, encontrou resultados semelhantes, com o nível de satisfação entre 85 a 90\%. Uma pesquisa mais recente realizada no Reino Unido, onde $85 \%$ das novas tubulações são de PEAD, mostrou que os tubos de polietileno têm a menor taxa de falha dentre todos os materiais, como pode ser verificado na Figura 44 (Vibien; Chung; Fong; Oliphant, 2009).

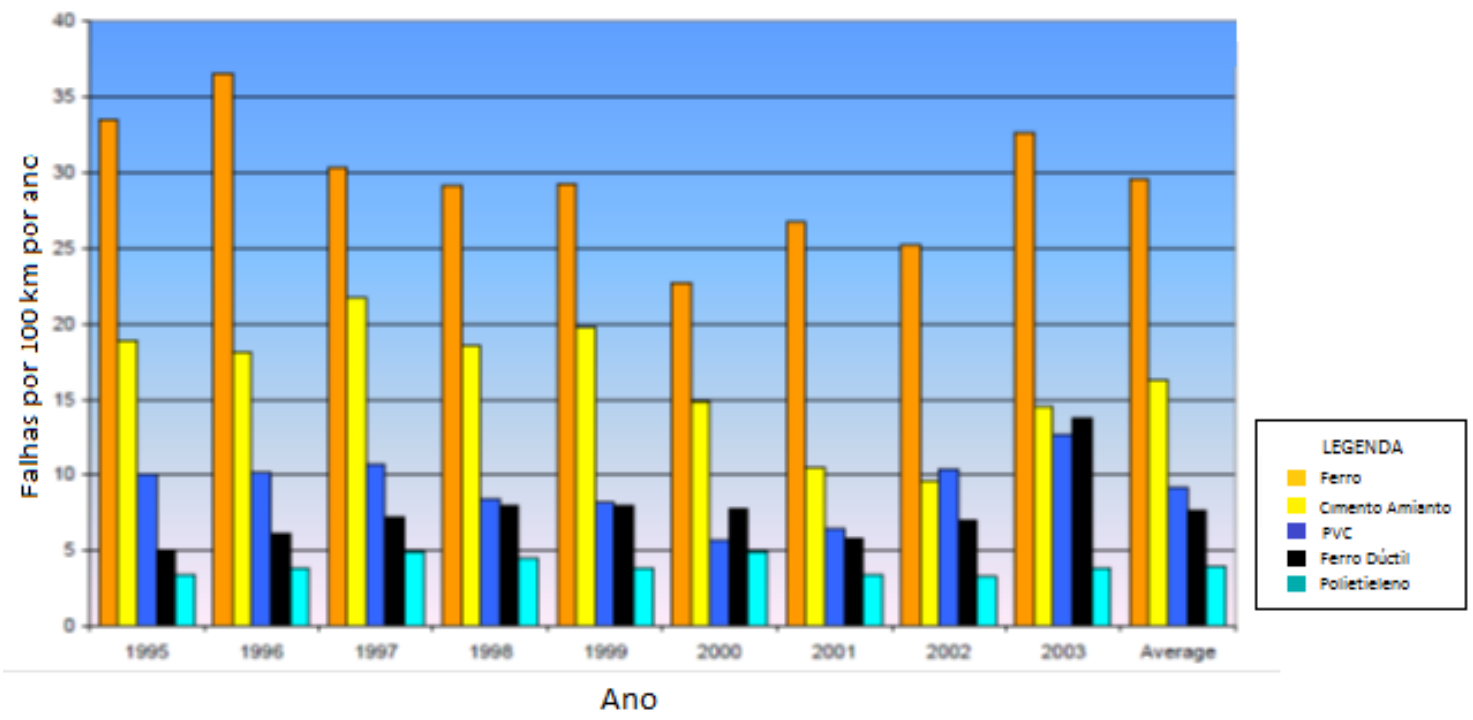

Figura 44 - Redes de Água do Reino Unido - Ocorrências de Falhas Fonte: Vibien; Chung; Fong; Oliphant, 2009.

Apesar dos níveis gerais elevados de satisfação, as pesquisas também identificaram problemas de desempenho das tubulações de dois fabricantes: Yardley e Orangeburg. Além disso, foi verificado que as falhas apareciam em maior frequência nas tubulações que transportavam água em temperaturas mais elevadas. As amostragens destes tubos indicaram depleção dos estabilizadores (aditivo) muito rápida.

Em 2010, foi realizada uma pesquisa sobre a experiência com as tubulações de polietileno no sistema de distribuição de água potável dos Estados Unidos da América. A pesquisa consistiu em entrevista por telefone de várias prestadoras de 
serviço de distribuição de água potável que utilizavam tubulações de PEAD em ramais e redes. Ao todo, as prestadoras de serviço atendiam 21 milhões de pessoas por todo território dos EUA. A seguir temos dois gráficos gerados a partir dos dados das pesquisas, o primeiro mostrando a distribuição das prestadoras de serviços de quando começaram a utilizar o PEAD nos ramais, da mesma forma o segundo gráfico para redes.

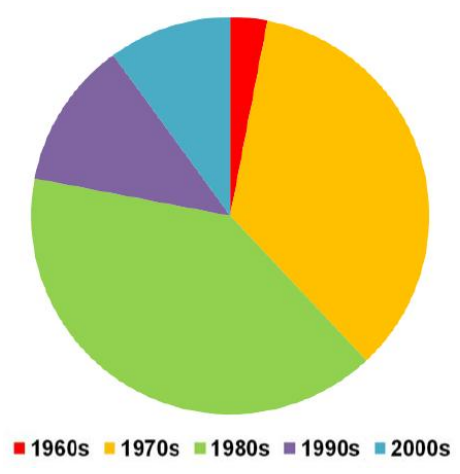

Figura 45 - Prestadoras de Serviço por

Data da Primeira Instalação de Tudo

PEAD - Ramal

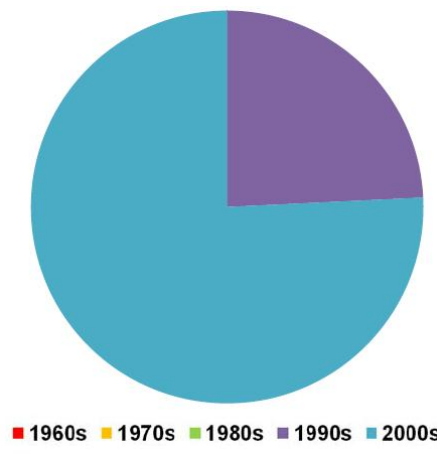

Figura 46 - Prestadoras de Serviço por

Data da Primeira Instalação de Tudo

PEAD - Rede

Fonte: Vibien; Chung; Fong; Oliphant, 2009.

Em uma das perguntas da pesquisa o entrevistador pedia uma nota de 1 a 5 para 0 nível de satisfação com a experiência com as tubulações de polietileno. Com os resultados, foi possível dividir nas três gerações de resinas, como pode ser observado na Figura 46.

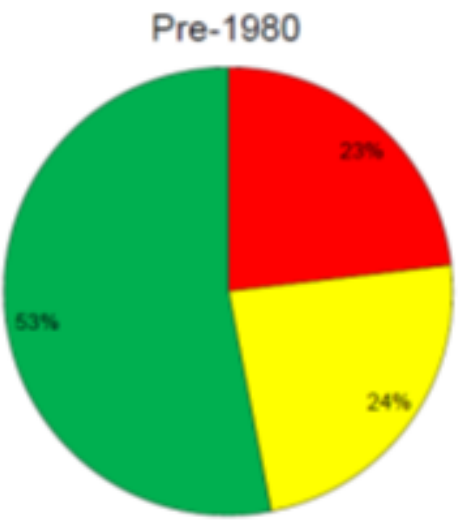

- Satisfeito (4 a 5)

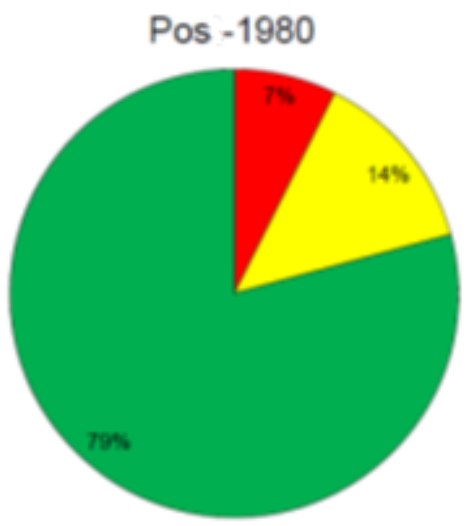

口 Pouco Satisfeito (3)

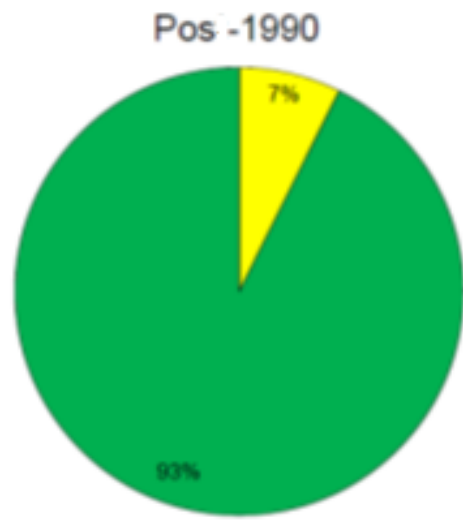

- Insatisfeito (1 a 2)

Figura 47 - Comparação da Satisfação com tubos de PE por Geração

Fonte: Vibien; Chung; Fong; Oliphant, 2009. 
Os gráficos mostram uma considerável evolução no desempenho das tubulações com o passar das gerações.

Além do âmbito econômico e ambiental é de suma importação a análise da satisfação dos clientes com o uso do material. Claro que a maioria dos clientes que passam a ser abastecidos pelas tubulações de polietileno não percebem a mudança, uma vez que a tubulação é enterrada e a aparência da água pouco muda. Ademais, no cenário nacional ainda não existem grandes pesquisas sobre satisfação dos usuários e prestadoras de serviços com as redes de PEAD, apenas pequenas pesquisas de satisfação das próprias concessionárias com seus clientes.

Contudo, é importante analisarmos a índice de satisfação geral das pessoas com a empresa prestadora de serviço de abastecimento de água com o inicio do uso de tubulações de polietileno na rede de distribuição, e observar se o material realmente colabora com a evolução do índice de satisfação.

\subsubsection{Sabesp}

Desde 2009, quando a Sabesp começou a utilizar com mais frequência as tubulações de PEAD em suas redes, podemos observar uma elevação no índice de satisfação geral dos clientes, mesmo que pequena. Essa evolução pode ser vista no gráfico a seguir, baseado em uma pesquisa realizada em 2013 pela Datamétrica Consultoria, Pesquisa e Telemarketing Ltda (5.850 entrevistas em toda a base operada com 1,3\% de margem de erro e intervalo de confiança de 95\%), publicada no Relatório de Administração da Sabesp de 2013. 


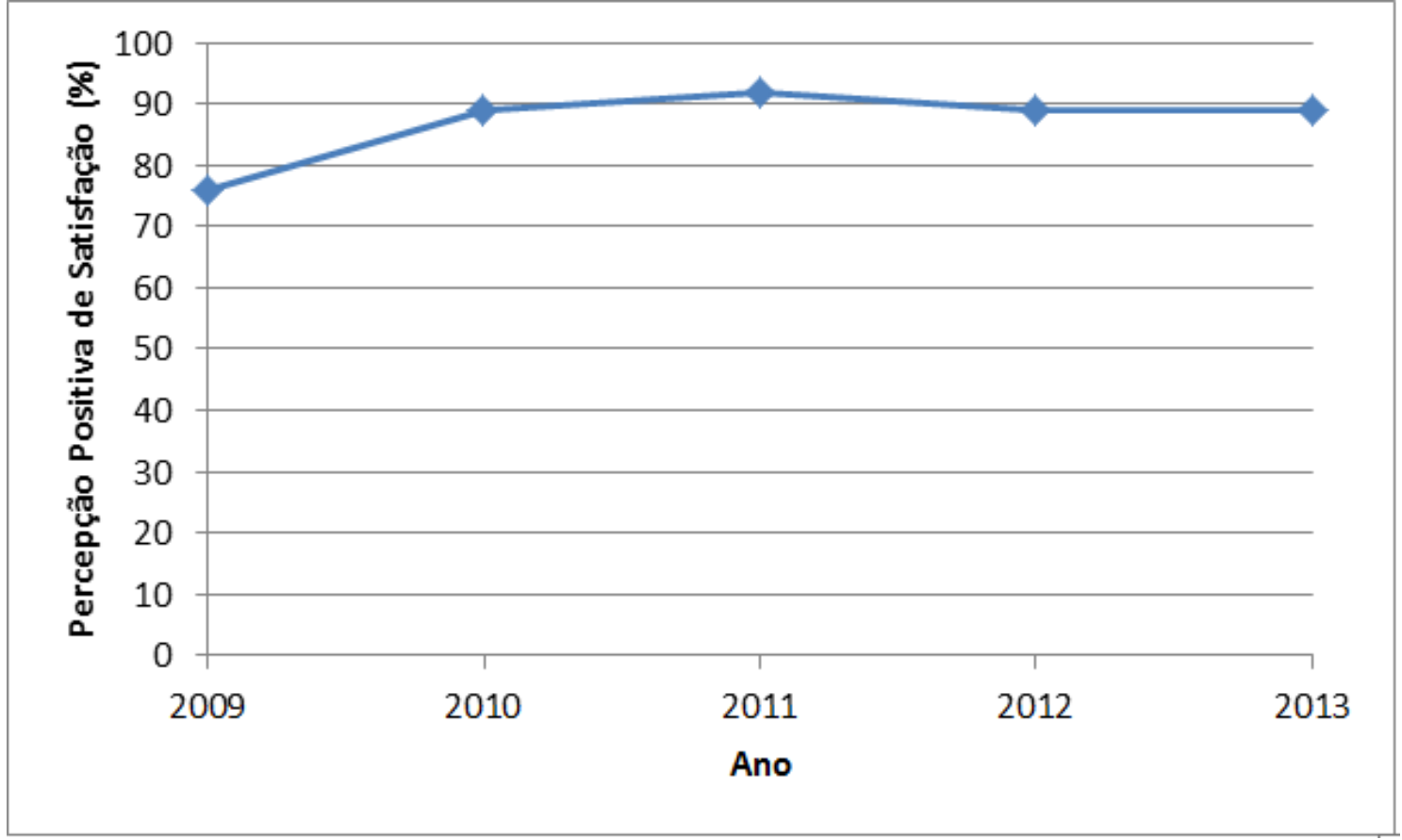

Figura 48 - Percepção Positiva de Satisfação do Cliente

\subsection{1. Águas de Limeira}

É possível verificar uma considerável diminuição das ocorrências de água turva e vermelha no sistema de distribuição de limeira desde o ano de 1996, quando se começo a utilizar o PEAD nas redes de abastecimento.

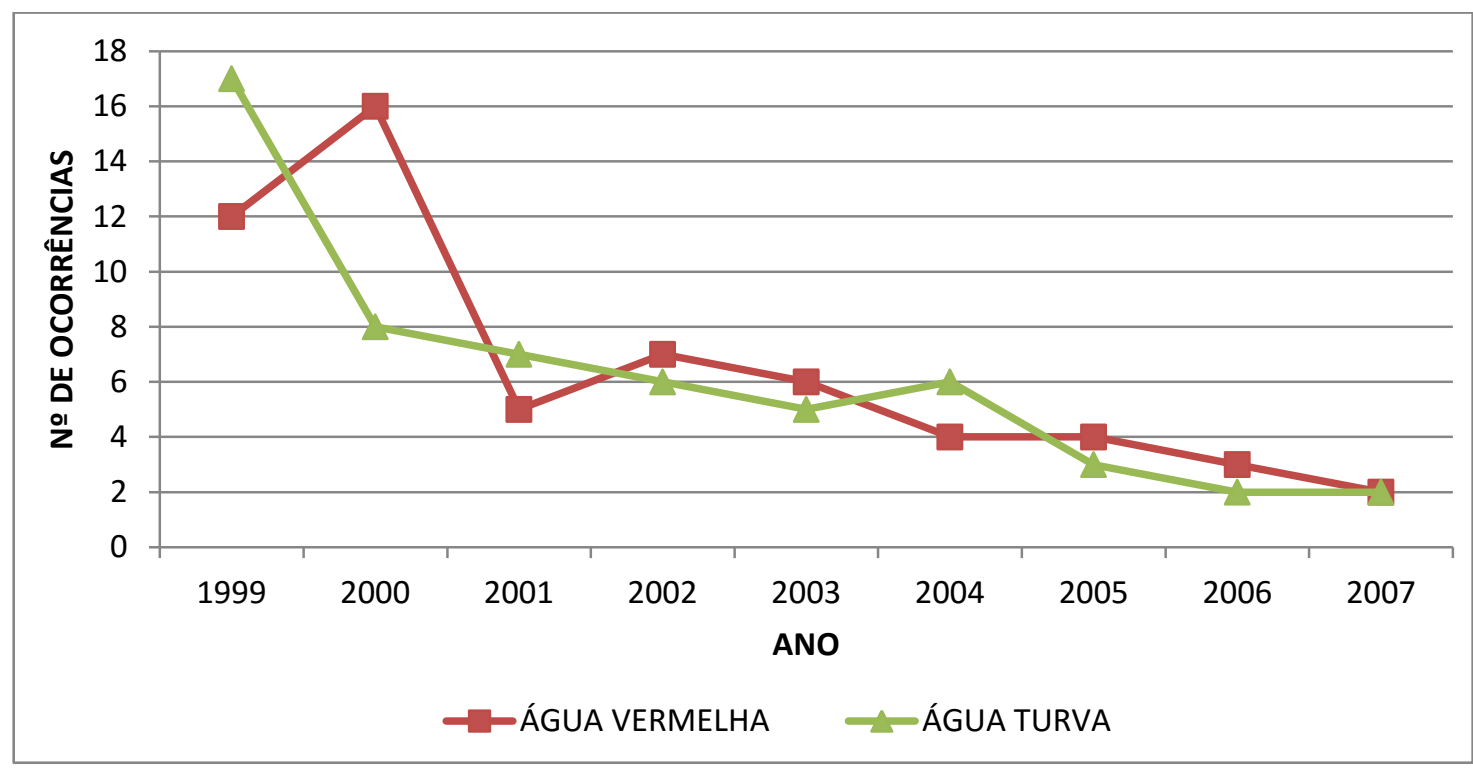

Figura 49 - Número de Ocorrências de Água Turva e Vermelha

FONTE: ÁGUAS DE LIMEIRA (2008) 
É possível constatar também na pesquisa de satisfação com clientes realizada em 2007, onze anos após o início da utilização de tubos de PEAD nas redes de Limeira, como todos os índices de satisfação estão elevados. Esta pesquisa se baseou em respostas únicas e estimuladas de cada serviço, com os usuários atribuindo uma nota de 1 a 10.

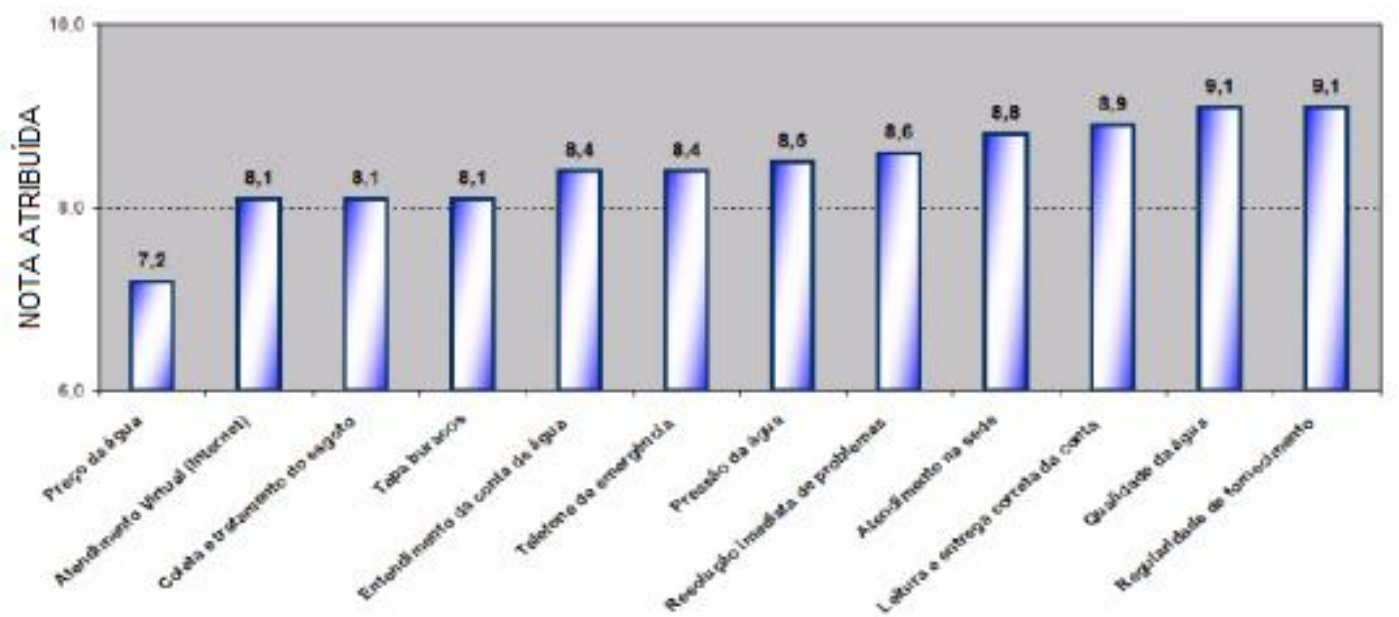

Figura 50 - Notas dos Clientes em Relação ao Serviço Prestado

FONTE: ÁGUAS DE LIMEIRA (2008)

\section{DISCUSSÃO}

Foram estudados três casos de grande relevância sobre o uso de tubulações de Polietileno nos sistemas de abastecimento de água potável do Brasil. Sempre que possível também foi realizado paralelo com estudos de fora do país, em regiões onde o mercado do polietileno já está mais consolidado e onde mais pesquisas foram desenvolvidas sobre eficiência e desempenho do material.

No primeiro caso, da empresa pública DMAE de Porto Alegre, foi possível constatar ganhos em relação à diminuição de perdas reais, além de ganhos na manutenção e análise da qualidade do material após anos de operação, o que demonstrou que apenas os tubos mais novos - desenvolvidos a menos de 15 anos - apresentaram características condizentes com sua vida útil projetada de 50 anos.

Vale lembrar que as tubulações mais novas instaladas hoje já são de outra geração, predominantemente PE 100, com propriedades mais avançadas do que as amostradas em operação há 15 anos. Foi possível também perceber a evolução das extensões de PEAD ao longo dos anos, com porcentagem insignificante no começo 
da década de 90 chegando á mais de $50 \%$ da extensão de rede total em 2013. Este crescimento foi acompanhando por todo tempo pelo decréscimo do índice de Perdas Totais e da quantidade de água produzida por habitante.

No segundo caso estudado, do sistema de distribuição de água de grande parte da região metropolitana de São Paulo (Sabesp-M), após estudo preliminar usando uma área de amostragem, apontou ganhos em relação à frequência de vazamentos de redes com o uso do PEAD, e consequente diminuição na Perda Real nas redes. Neste caso também foi possível perceber um vertiginoso crescimento das extensões de redes de PEAD desde 2009, acompanhado por uma sensível melhora da satisfação dos usuários do sistema.

Foi possível realizar um levantamento dos custos de implantação utilizados como referência pela Sabesp na elaboração de pacotes técnicos para licitação de obras de execuções de redes em vala a céu aberto, tanto para o PEAD quanto para o Ferro Fundido. O valor do serviço da execução para o material Fero Fundido é menor, contudo o custo de fornecimento de material para as tubulações de PEAD é consideravelmente menor, resultando em vantagem para as tubulações de PEAD no preço total da obra.

Foram relatados pelas equipes de operação da Sabesp-M problemas com a adaptação ao material, principalmente na questão da não vedação total de tubulações em reparo ou intervenção, que impossibilita a eletro/termofusão. Diante disso, foram adaptadas, pela própria equipe da Sabesp, conexões mecânicas para as tubulações de PEAD, capazes de unir tubulações mesmo não completamente estanques.

O terceiro e último caso estudado foi o sistema de abastecimento da cidade de Limeira, operado pela Odebrecht Ambiental. Neste caso também foi possível constatar a evolução das extensões de PEAD, passando de quase $13 \%$ para mais de $18 \%$ em extensão entre os anos de 2007 e 2014. Crescimento da utilização do PEAD acompanhado pela diminuição do índice de perdas reais e do número de reclamações de ocorrência de água turva e vermelha.

O trabalho também encontrou pesquisas realizadas fora do país relacionadas ao tema. Nos Estados Unidos e Reino Unido, foram realizadas entrevistas sobre 
satisfação com o uso de das tubulações de polietileno e os resultados corroboram com as pesquisas brasileiras, de uma maior satisfação com este tipo de material, excluindo alguns fabricantes deste cenário.

Como o uso das tubulações de PEAD em redes ainda é relativamente recente, e considerando que o material vem sofrendo mudanças constantes devido a evolução na resina e no processo de fabricação, é difícil estimar seu comportamento durante toda sua vida útil projetada baseando-se nas redes em operação. Contudo, o trabalho de Oliphant, Conrad, e Chung, (2011) realizou simulações de operação acelerada destas tubulações em laboratório, chegando à conclusão que a vida útil dos tubos nas novas gerações excederia 100 anos.

Comparando os valores de execução de obra de redes de PEAD adotados pelas empresas estudadas, se verifica algumas discrepâncias entre os custos utilizados como referência. Isto devido ao mercado dos tubos de polietileno ainda não estar completamente consolidado no país, com poucas empresas que realizam serviços de execução de rede e sem uma padronização completa de preços e serviços, o que tende a diminuir nos próximos anos. Como o trabalho em questão utilizou valores fornecidos somente como base de comparação com os valores das tubulações de ferro fundido, fornecidos pela mesma empresa, a análise se torna válida.

Seguindo as tendências de evolução das extensões das tubulações de PEAD levantadas para as três prestadoras de serviços, se espera um amadurecimento muito rápido do mercado, com o surgimento de novas fábricas e prestadoras de serviço de execução e projetos de rede deste material. 


\section{CONCLUSÕES}

Para o estudo do uso de tubulações de PEAD nos sistemas de distribuição de água do Brasil, foi apresentada primeiramente uma revisão bibliográfica com um breve histórico desde a descoberta do polietileno até os dias de hoje, com suas diversas aplicações e seu complexo mercado mundial. Sobre o uso em tubulações, foram apresentadas as gerações atuais, dimensionamento hidráulico, comportamento viscoelástico, dentre outras várias propriedades. Verificou-se uma vasta literatura deste tema, tanto estrangeira como nacional.

Foram levantados dados sobre os serviços de abastecimento de água brasileiro, com informações advindas principalmente do governo, através do relatório do SNIS e relatórios das empresas prestadoras de serviço. Os dados mostraram que muito trabalho ainda precisa ser feito, tanto no controle de perdas (o índice de perdas totais em 2013 foi de 37\%), como na expansão do atendimento de redes de abastecimento de água potável e tratamento de esgoto.

Elaborou-se levantamento da história das tubulações de PEAD no Brasil, no qual se encontrou quase nenhum material a respeito, sendo o trabalho feito baseado em entrevistas com pessoas do ramo que presenciaram e acompanharam a trajetória dos tubos de PEAD no país. Foram confrontadas várias versões e o resultado foi uma compilação de todas elas.

Foram estudadas três empresas prestadoras em serviços de distribuição de água: Departamento Municipal de Água e Esgoto (DMAE) de Porto Alegre RS, a Diretoria Metropolitana da Companhia de Saneamento Básico do Estado de São Paulo (Sabesp-M) e a Odebrecht Ambiental operadora da cidade de Limeira SP. Através dos dados fornecidos, análises e entrevistas, aliados com estudos, pesquisas e ensaios realizados no exterior, foi possível chegar a algumas conclusões a respeito da utilização dos tubos de PEAD:

- Segundo inspeções in loco e análises laboratoriais de amostras, a vida útil das tubulações de PEAD das últimas gerações tende a cumprir sua vida útil projetada de 50 anos e até superá-la, com a expectativa de que as tubulações mais novas irão superar 100 anos de operação. Contudo, tubulações mais antigas instaladas na década de 80 e início da década de 90, com tecnologia 
inferior, apresentaram sinais de desgaste após 25 anos de operação, apesar de ainda operarem perfeitamente;

- As extensões das tubulações de polietileno nos sistemas de abastecimento de água vêm crescendo exponencialmente nos últimos anos, devido a popularização do material, menor custo de execução, ajuda no combate às perdas, possibilitar execução em métodos não destrutivos e facilidade no manuseio devido sua flexibilidade e leveza. Algumas empresas já utilizam o material PEAD de maneira preponderante ou exclusiva para todos os diâmetro menores (normalmente inferiores a $315 \mathrm{~mm}$ ) e para os maiores somente em aplicações especiais (travessias, Pipe-bursting, etc);

- O crescimento das extensões de redes em PEAD tem acompanhado 0 decréscimo dos índices de Perda Total e de Reclamações da qualidade da água, indicando que o material auxilia no controle de perdas e na qualidade da água;

- Através de dados fornecidos pelas diferentes prestadoras de serviços estudadas, e pelas fabricantes e empreiteiras de execução de redes de PEAD, nota-se uma discrepância entre os valores adotados como referência do custo da execução das tubulações de polietileno pelas empresas estudadas. Contudo estes valores tendem a convergir nos próximos anos com a evolução e consolidação do mercado. Como o trabalho em questão se utilizou dos valores fornecidos somente como base de comparação com os valores das tubulações de ferro fundido fornecidos pela mesma empresa, a análise se torna válida, concluindo-se que o custo de execução das tubulações de PEAD é menor que as tubulações de Ferro Fundido. Contudo, foi encontrada pouca informação e muita dificuldade em levantar os dados de custo;

- Verificou-se problemas com o material nas intervenções em redes em operação, nas quais os registros existentes não conseguem vedar completamente a passagem de água, tornando inviável a eletro/termofusão. A própria equipe de operação da Sabesp tem adaptado luvas mecânicas para este tipo de operação;

- Não foram encontrados muito dados e informações sobre os ganhos com o uso do PEAD nas redes de abastecimento, principalmente trabalhos 
brasileiros. Foram encontrados muitos trabalhos sobre 0 material do polietileno, de seu comportamento e propriedades físico-químicas como tubulação, porém nenhuma pesquisa mais específica, quantificando ganhos em sistema de abastecimento nas aplicações em tubulações no transporte de água, principalmente no meio acadêmico.

Infelizmente não foi possível responder grande parte das perguntadas levantadas na introdução deste trabalho de forma satisfatória, uma vez que faltam dados e o mercado de polietileno da alta densidade ainda se encontra em desenvolvimento. Contudo, foi possível avançar na discussão sobre elas, com oportunidade para trabalhos futuros, sobre horizontes maiores de informações sobre o tema.

Por fim, as tubulações de PEAD se mostraram uma grande aliada das prestadoras de serviço em busca de maior eficiência e no controle de perdas reais. Pelo seu uso mais recente ainda faltam dados sobre seu benefício e recomenda-se continuar acompanhando as tubulações em operação e comparar seu desempenho com as tradicionais tubulações de Ferro Fundido e de PVC. 


\section{REFERÊNCIAS BIBLIOGRÁFICAS}

AMERICAN WATER WORKS ASSOCIATION, Water Transmission and Distribution, 3를 Edição, EUA, 2003.

ASSOCIAÇÃO BRASILEIRA DAS EMPRESAS DE ENGENHARIA SANITARIA E AMBIENTAL ABES, Perdas em Sistemas de Abastecimento de Água: Diagnóstico, Potencial de Ganhos com sua Redução e Propostas de Medidas para o Efetivo Combate - São Paulo, 2013.

ASSOCIAÇÃO BRASILEIRA DE TUBOS POLIOLEFÍNICOS E SISTEMAS ABPE Apresentação. São Paulo, Jun/2014.

Arabplast \& Tekno Tube - Apresentação realizada em Dubai International Conventionand Exhibition Centre. Dubai, 2011.

ARRUDA, R. A., Entrevista Revista Tubo e Cia, 20 de Junho de 2013.

AMADO, J.M.P. \& MARQUES, J.A.S. - Modelação Hidráulica de Escoamentos Permanentes e Variáveis em Pressão, 7º Congresso da Água, Portugal, 2004.

BIOLCATTI, B. T., PALACIO MONTES, C., \& MEIRELES, M. H. Substituição de redes antigas de abastecimento de água em área de urbanização consolidada na RMSP, Projeto de Formatura, Escola Politécnica da Universidade de São Paulo, São Paulo, 2011.

BOROUGE PTE, PE Pipes for Gas \&Water Mains, PIPA Seminars - Apresentação. Austrália, 2007.

COMPANHIA DE SANEAMENTO BÁSICO DO ESTADO DE SÃO PAULO, Banco de Insumos - Mar/2015. São Paulo: SABESP, 2009.

COMPANHIA DE SANEAMENTO BÁSICO DO ESTADO DE SÃO PAULO, Programa Corporativo de Redução de Perdas - Apresentação - Jul/2014. São Paulo: SABESP, 2014.

COMPANHIA DE SANEAMENTO BÁSICO DO ESTADO DE SÃO PAULO, Programa Corporativo de Redução de Perdas na Região Metropolitana de São Paulo - Apresentação - Dez/2006. São Paulo: SABESP, 2007.

COMPANHIA DE SANEAMENTO BÁSICO DO ESTADO DE SÃO PAULO, Relatório da Administração 2013. São Paulo: SABESP, 2014.

COMPANHIA DE SANEAMENTO BÁSICO DO ESTADO DE SÃO PAULO, Relatório de Sustentabilidades 2014. São Paulo: SABESP, 2015.

COMPANHIA DE SANEAMENTO BÁSICO DO ESTADO DE SÃO PAULO, Sistema de Informações Geográficas no Saneamento SIGNOS . São Paulo: SABESP, 2015. 
DANIELETTO, J. R. B. Manual de Tubulações de Polietileno e Polipropileno Características, Dimensionamento e Instalação. 2ª Edição. São Paulo. 2011.

DANIELETTO, J. R. B. Manual de Tubulações de Polietileno e Polipropileno Características, Dimensionamento e Instalação. 3ª Edição. São Paulo. 2014.

DEPARTAMENTO MUNICIPAL DE ÁGUA E ESGOTO DE PORTO ALEGRE, Informações Sobre o Sistema de Abastecimento de Água, Disponível em: < http://www2.portoalegre.rs.gov.br/dmae/>. Acesso em: 13 de Dez. 2015.

ELBASHIR, M.A.M. \& AMOAH, S.O.K. - Hydraulic Transient in a Pipeline - Using Computer Model to Calculate and Simulate Transient. Master Thesis, Division of Water Resources, Lund University, Sweden, 2007.

FLORES, V. Polietileno, 20 anos, uma história de sucesso, pag. 13-24. Porto Alegre RS, 2009.

FLORES, V. Apresentação Plástico e Saneamento: A Experiência do DMAE. Porto Alegre RS, 2014.

FRANÇA, V.P.F. - Verificação da Adequação do Esquema Numérico de MacCormack na solução de Transientes Hidráulicos em Condutos Forçados. Dissertação de Mestrado, EPUSP, São Paulo, 2006.

FRANÇA, V.P.F. Transitório Hidráulico com Tensão de Cisalhamento na Parede do Conduto Forçado Modelada por Gradiente Harmônico de Pressão. Tese de Doutorado, EPUSP, São Paulo, 2012.

FURUSAWA, R. T. Contribuição ao dimensionamento de rede de distribuição de água por critério de custo global. Dissertação de Mestrado, EPUSP. São Paulo, 2011.

GABRIEL, H. L. History and Physical Chemistry of HDPE. In The Complete Corrugated Polyethylene Pipe Design Manual and Installation Guide. California, USA, 1998.

HISTORY OF SOLUTION METHODS - Bentley. Disponível em: <http://docs.bentley.com/en/HMHammer/HAMMER_V8i_Help-15-04.html>. Acesso em: 16 de Mai. 2013.

HORLACHER, H.B. - Transient Behavior of HDPE Pipes due to Pressure Fluctuations. Technical University of Dresden, Dresden, 1998.

IHS Inc., Polyethylene Global View, Apresentação, Ciudad de Mexico 2012.

JANSON, L., Investigarion of Long Term Creep Modulus for Buried Polyethylene Pipes Subjected to Constant Deflection, ASCE, Madison, W, 1985.

LIMA, F.M.L. - Termo de Atrito em Escoamento Transitório para Condutos Forçados. Tese de Doutorado, EPUSP, São Paulo, 2006. 
MEDEIROS, A.F. - Substituição de Metal por Polímeros de Alto Desempenho em Componentes de Sistemas Hidráulicos, FENASAN, São Paulo, 2011.

Melato, B. S. Discussão de uma metodologia para o diagnóstico e ações para redução de perdas de água: aplicação no sistema de abastecimento de água da região metropolitana de São Paulo, Dissertação de Mestrado, EPUSP, São Paulo, 2010.

MESQUITA, B. I. O. A. Modificação das propriedades do polietileno de alta densidade por diferentes condições de extrusão. Dissertação de Mestrado, EPUSP, São Paulo, 2010.

MANUAL TÉCNICO DO POLIETILENO - Grupo BRASTUBO. <http://www.fusaopead.com.br/resources/Inf.\%20sobre\%20tubos\%20de\%20polietileno.pdf>. Acesso em: 12 de Nov. 2015

MARTINS, J.R.S. \& SOUZA P.A. Transitórios Hidráulicos em Condutos Forçados. Notas de Aula Hidráulica 3, EPUSP, São Paulo, 2013.

NBR 15593, Sistemas enterrados para distribuição e adução de água e transporte de esgoto sob pressão - Requisitos para conexões soldáveis de polietileno de PE 80 e PE 100, 2008.

NBR 15802, Sistemas enterrados para distribuição e adução de água e transporte de esgoto sob pressão - Requisitos para projetos em tubulação de polietileno PE 80 e PE 100 de diâmetro externo nominal entre $63 \mathrm{~mm}$ e $1600 \mathrm{~mm}$, 2010.

NBR 15803, Sistemas enterrados para distribuição e adução de água e transporte de esgoto sob pressão - Requisitos para conexões de compressão para junta mecânica, tê de serviço e tê de ligação para tubulação de polietileno de diâmetro externo nominal entre 20 mm e 160 mm, 2012.

ODEBRECHT AMBIENTAL, Aplicação dos Tubos de PEAD em Saneamento Apresentação Dezembro 2014.

ODEBRECHT AMBIENTAL, Aplicação do Tubos de PEAD na cidade de Limeira Apresentação 2008.

OLIPHANT, K., Ph.D., M. Conrad, Ph.D., S. Chung, M. S. Polyethylene (PE) Pipe Performance in Potable Water Distribution Systems Past, Present and Future. JANA Reports. Aurora, Canadá, 2011.

PERES, F. M.. Desenvolvimento de métodos alternativos para a avaliação da resistência à fratura por fluência de resinas de polietileno utilizadas para a extrusão de tubos de água. Dissertação de Mestrado, EPUSP, São Paulo, 2005.

PLASTICS INDUSTRY PIPE ASSOCIATION OF AUSTRALIA SEMINARS Apresentação, Austrália 2007. 
PLASTIC ENGINEER PRODUCTS. - Thermoplastic Pressure Pipe Design and Selection. Disponível em: <http://www.plasticengineeredproducts.com/manufacturers/unibell/pubs/uni-tr-7.pdf>. Acesso em: 16 de Mai. 2013.

Poly Easy do Brasil, Catálogo de Produtos. São Paulo, 2015.

PPI - THE PLASTIC PIPE INSTITUTE. Engineering properties of polyethylene. Disponível em <http://www.plasticpipe.org >. Acesso em 18/11/2014.

PLASTICS PIPE INSTITUTE ® HANDBOOK OF POLYETHYLENE PIPE. (n.d.), (March 2009). Disponível em < http://plasticpipe.org/pdf/chapter01.pdf>. Acesso em 18/11/2014.

RELATÓRIO DE VISITA DE GRUPO TÉCNICO - ENFRENTAMENTO DA CRISE HíDRICA NA CALIFORNIA. São Paulo, Julho 2015 - Revisão Dezembro 2015.

ROCHA, A. L., Barreto, D., \& Neto, P. J. C. (1999). Aprimoramento dos ramais prediais de PEAD. 210 Congresso Brasileiro de Engenharia Sanitária e Ambiental. São Paulo, 1999.

RODRIGUES, J. C. S. O Monitoramento do Emissário Submarino como Ferramenta na Evolução do Padrão de Qualidade das Águas na Bacia de Santos. Dissertação de Mestrado, CEETEPS, São Paulo, 2012.

SECRETARIA NACIONAL DE SANEAMENTO AMBIENTAL. Sistema Nacional de Informações sobre Saneamento: diagnóstico dos serviços de água e esgotos 2008. Brasília: MCIDADES.SNSA, 2014. Disponível em: <http://www.snis.gov.br>. Acesso em 16 NOV. 2015

SARZEDAS, G. L. Planejamento para a substituição de tubulações em sistemas de abastecimento de água - Aplicação na rede de distribuição de água da Região Metropolitana de São Paulo. Dissertação de Mestrado, EPUSP, São Paulo, 2009.

SANTOS, R.M.N. \& CASTRO, M.A.H. - Modelagem Computacional de Transientes Hidráulicos em Sistemas e Recalque. Dissertação de Mestrado, UFC, Fortaleza, 2000.

SHIROMOTO, J., LEITÃO, J. C., TSUTIYA, M. T., Operação do Sistema Taquacetuba para a Transferência de Água do Reservatório Billings para a Represa Guarapiranga - Região Metropolitana de São Paulo. 23 Congresso de Engenharia Sanitária e Ambiental, Campo Grande-MS, Brasil, 2005.

SILVA, P.A. - Amortecimento da Celeridade de Onda em Condutos Forçados. Dissertação de Mestrado, EPUSP, São Paulo, 2006.

SOUZA, P. A.. Nova Formulação Explícita para o Cálculo do Fator de Atrito (f) de Escoamento Forçado. XII Congresso Latinoamericano de Hidráulica. São Paulo: DAEE/CTH, 1986. p. 75-85. 
SUZUKI, K. C. Investigação do uso do polietileno de ultra alto peso molecular como matriz em compositos reforçados com fibras de vidro. Trabalho de Conclusão de Curso para Escola de Engenharia da UFRGS. Porto Alegre RS, 2009.

THOMPSON C., JENKINS D., Review of Water Industry Plastic Pipe Practices, University of California, 1987.

TSUTIYA, M.T. Abastecimento de Água. Departamento de Engenharia Hidráulica e Sanitária da Escola Politécnica da Universidade de São Paulo. São Paulo, 2006.

WYLIE, E.B.; STREETER, V.L. Fluid Transients. New York, McGraw-Hill Book Company, 1978.

VIARO, V. L. ; LUVIZOTTO JR., E. ; ANDRADE, J. G. P. . Influencia do fator de atrito variável na avaliação do escoamento transitório em sistemas hidráulicos. XXVII Congresso Interamericano de Engenharia Sanitária e Ambiental. João Pessoa, 2001.

VIBIEN, P., M.Sc., P.Eng., Sarah Chung, M.A.Sc., P.Eng., Sheyla Fong, Ken Oliphant, Ph.D., P. E., \& Inc., J. L. Long-Term Performance of Polyethylene Piping Materials in Potable Water Applications. JANA Reports. Aurora, Canadá, 2009. 
ANEXO - MAPA DO MATERIAL DA REDE DE DISTRIBUIÇÃO DE ÁGUA DA ÁREA ESTUDADA DA REGIÃO METROPOLITANA DE SÃO PAULO 


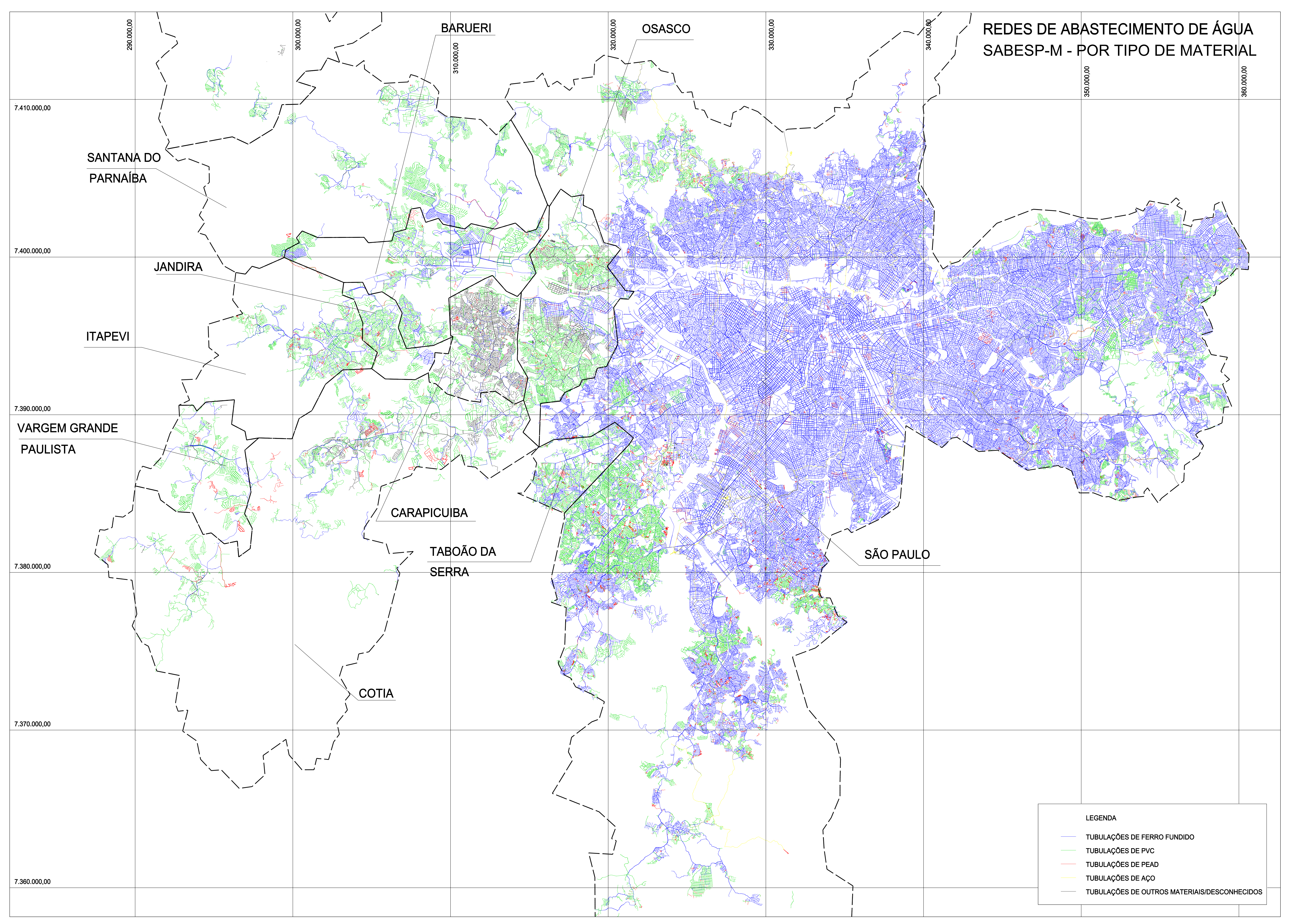

